\title{
WestVirginiaUniversity
}

THE RESEARCH REPOSITORY @ WVU

Graduate Theses, Dissertations, and Problem Reports

2014

\section{Peripheral challenge with a viral mimic elicits seizure hypersusceptibility}

\author{
Lindsay Tanis Michalovicz
}

Follow this and additional works at: https://researchrepository.wvu.edu/etd

\section{Recommended Citation}

Michalovicz, Lindsay Tanis, "Peripheral challenge with a viral mimic elicits seizure hypersusceptibility" (2014). Graduate Theses, Dissertations, and Problem Reports. 6228.

https://researchrepository.wvu.edu/etd/6228

This Dissertation is protected by copyright and/or related rights. It has been brought to you by the The Research Repository @ WVU with permission from the rights-holder(s). You are free to use this Dissertation in any way that is permitted by the copyright and related rights legislation that applies to your use. For other uses you must obtain permission from the rights-holder(s) directly, unless additional rights are indicated by a Creative Commons license in the record and/ or on the work itself. This Dissertation has been accepted for inclusion in WVU Graduate Theses, Dissertations, and Problem Reports collection by an authorized administrator of The Research Repository @ WVU.

For more information, please contact researchrepository@mail.wvu.edu. 
Peripheral challenge with a viral mimic elicits seizure hypersusceptibility

$$
\text { Lindsay Tanis Michalovicz }
$$

Dissertation submitted to the School of Medicine at West Virginia University in partial fulfillment of the requirements for the degree of

\author{
Doctor of Philosophy \\ in \\ Neuroscience
}

\author{
Gregory W. Konat, Ph.D., Chair \\ Ariel Agmon, Ph.D. \\ Rosana Schafer, Ph.D. \\ Han-Ting Zhang, M.D., Ph.D. \\ Eric S. Tucker, Ph.D. \\ Neuroscience Graduate Program \\ Morgantown, West Virginia \\ 2014
}

Keywords: seizure, inflammation, hippocampus, gene expression, protein expression 


\begin{abstract}
Peripheral challenge with a viral mimic elicits seizure hypersusceptibility
\end{abstract}

Lindsay Tanis Michalovicz

Seizure syndromes are common neuropathologies associated with epilepsy, metabolic disturbances, stroke, traumatic brain injury, heat stroke, fatigue, drug overdose and several other conditions. Peripheral inflammatory conditions have emerged as important comorbid factors in seizures. We found that peripherally restricted acute phase response (APR) elicited by intraperitoneal (i.p.) injection of a viral mimic, polyinosinic-polycytidylic acid (PIC), renders the brain hyperexcitable as seen from profoundly exacerbated kainic acid (KA)-induced seizures. This hypersusceptibility was protracted for up to $72 \mathrm{~h}$. Neither blood plasma transfer from PIC challenged mice nor injection of two highly expressed blood cytokines, IL-6 and IFN $\beta$, were able to recapitulate the effects of PIC. We also found the hypersusceptible phenotype to be cyclooxygenase (COX)-independent. These results indicate that peripheral APR-induced seizure hypersusceptibility is reliant on the diffusion of a number of blood-borne inflammatory factors in a concentration-dependent manner.

To understand how peripheral challenge with PIC can alter neural excitability and lead to hyperexcitability, we profiled hippocampal gene expression. qRT-PCR revealed rapid upregulation of 23 genes encoding cytokines, chemokine and chemokine receptors and 12 genes encoding proteins related to glutamatergic and GABAergic neurotransmission generally within $6 \mathrm{~h}$ after PIC challenge. Moreover, the expression of ten microRNAs (miRs) was rapidly affected by PIC challenge, but their levels generally exhibited oscillating profiles over the time course of seizure hypersusceptibility. Further exploration into this robust polygenic response by microarray analysis identified 625 differentially expressed genes (DEGs) across 6,24 , and $48 \mathrm{~h}$ post-PIC challenge. The complement pathway was found to be the most robustly activated. qRT-PCR quantification verified temporal upregulation of the mRNA encoding eight complement components, i.e., C1qa, C1qb, C1qc, CfB, C2, C3, C4, and C6. Collectively, these results indicate that peripheral PIC challenge triggers an extensive genetic reprograming in the hippocampus that may play a causative role in the remodeling of neural circuits resulting in the hyperexcitable phenotype. 


\section{Acknowledgements}

I wish to thank my mentor, Dr. Gregory Konat, for his support and confidence in me throughout my dissertation work. His mentorship has helped me grow as a scientist and I am grateful to have had his guidance.

I would also like to thank my committee members, Dr. Ariel (Aric) Agmon, Dr. Rosana Schafer, Dr. Han-ting Zhang and Dr. Eric Tucker for their insight, patience, and guidance.

Additionally, I wish to thank the current and past members of the Konat lab for their assistance and support throughout my work. In particular, I am exceedingly grateful to Dr. Elzbieta Borysiewicz who not only helped to train me upon my entrance into the lab, but also became one of my closest friends. Special thanks to Brent Lally for his assistance with immunohistochemistry.

Finally, I would like to thank my family for their constant love and support. They have always nurtured my ambitions and been there for me in the best and worst of times. Their confidence in me has helped me persevere through all things. 


\section{Table of Contents}

Abstract

Acknowledgements

iii

Table of Contents

iv-V

List of Figures and Tables

vi

Glossary of Abbreviations

vii-viii

Chapter 1: Introduction

Chapter 2: Peripheral challenge with PIC elicits seizure hypersusceptibility

2.1. Acute phase response to viral infection and sickness behavior

2.2. Peripheral APR enhances seizure susceptibility

2.3. The role of blood borne cytokines in PIC-induced seizure susceptibility

2.4. The role of COX in PIC-induced seizure susceptibility

2.5. Conclusions

2.6. Contributions

Chapter 3: Peripheral challenge with PIC alters hippocampal gene expression

3.1. Inflammatory genes

3.2. Neurotransmission-related genes

3.3. microRNAs

3.4. Genome-wide microarray

3.5. Conclusions

3.6. Contributions

Chapter 4: Peripheral challenge with PIC upregulates complement and activates microglia 
4.2. Activation of microglia ...................................................... 36

4.3. Conclusions $\quad$................................................................ 37

Chapter 5: Conclusions and Future Directions

Chapter 6: Materials and Methods

6.1. Animals

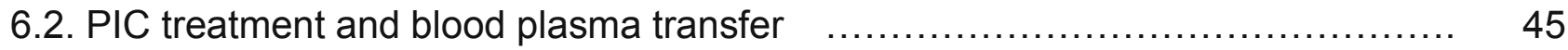

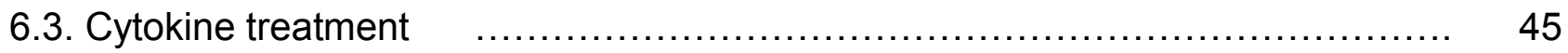

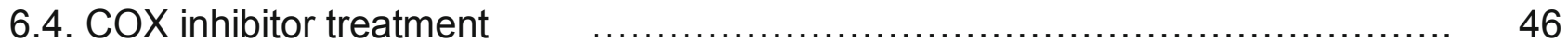

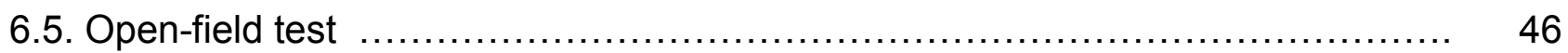

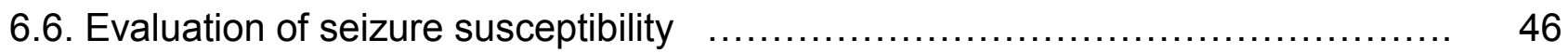

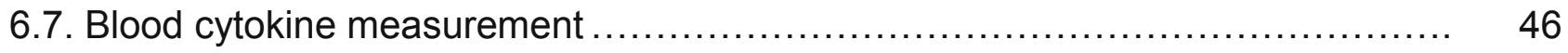

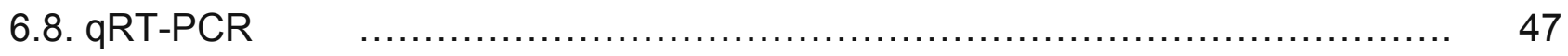

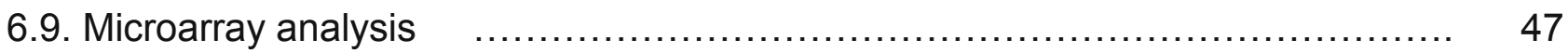

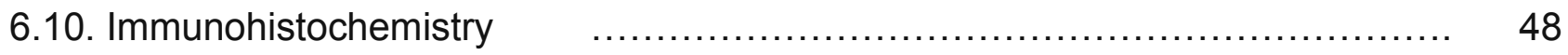

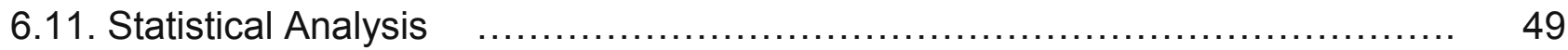

References

Peripheral immune challenge with dsRNA enhances kainic acid-induced status epilepticus (Kirschman et al. 2011)

Peripherally restricted acute phase response to a viral mimic alters hippocampal gene expression (Michalovicz and Konat 2014) 


\section{List of Figures and Tables}

Figure 1. The suppression of locomotor and rearing behavior by PIC challenge $\quad \ldots \ldots \ldots \ldots . . . \quad 8$

Figure 2. Kinetics of KA-induced status epilepticus $\quad$ ……....................................... 9

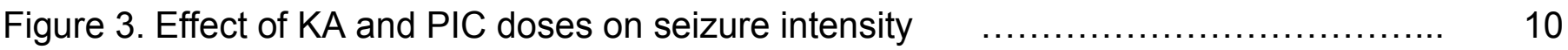

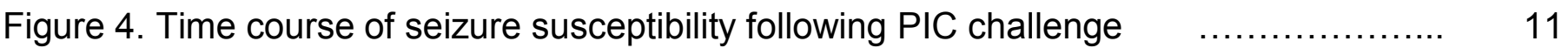

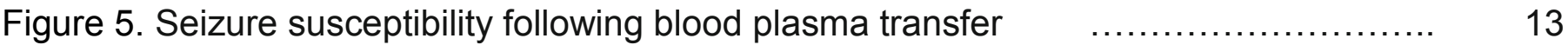

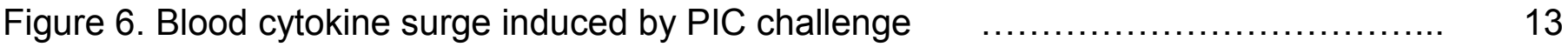

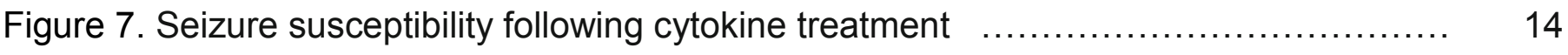

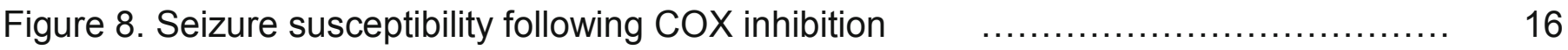

Figure 9. Cerebral inflammatory response following COX inhibition $\ldots \ldots \ldots \ldots \ldots \ldots \ldots \ldots \ldots \ldots \ldots \ldots \ldots \ldots$

Figure 10. The expression of cytokine genes in the hippocampus following PIC challenge $\quad 20$

Figure 11. The expression of chemokine genes in the hippocampus following PIC challenge 21

Figure 12. The expression of chemokine receptor genes following PIC challenge $\ldots \ldots \ldots \ldots . .22$

Table 1. Maximal upregulation of selected cytokine and chemokine genes in the forebrain vs. hippocampus in response to PIC challenge $\quad \ldots \ldots \ldots \ldots \ldots \ldots \ldots \ldots . \ldots . \ldots . \ldots 24$

Figure 13. The expression of neurotransmission-related genes following PIC challenge $\quad \ldots \quad 26$

Figure 14. The expression of hippocampal miRs following PIC challenge $\quad \ldots \ldots \ldots \ldots \ldots \ldots \ldots . . . . . .30$

Figure 15. Peripheral inflammation triggered by PIC challenge alters hippocampal gene

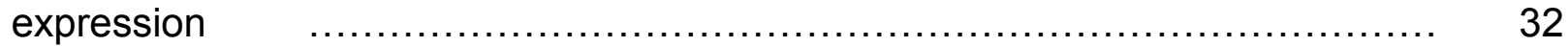

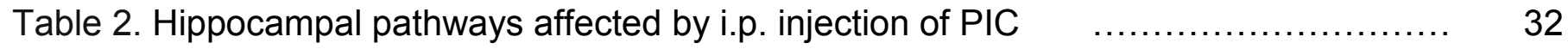

Figure 16. PIC challenge alters the expression of complement genes in the hippocampus 35

Figure 17. Expression of complement proteins in the hippocampus instigated by PIC challenge 35

Figure 18. Regional expression differences of complement genes following i.p. PIC challenge 36

Figure 19. Morphological changes and migration of microglial cells instigated by PIC challenge 37

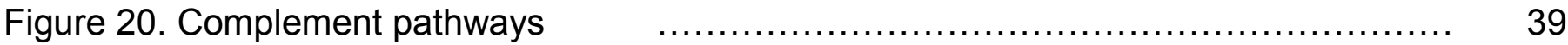

Figure 21. Mechanism of PIC-induced complement-mediated synaptic stripping $\quad \ldots \ldots \ldots \ldots . .39$

Figure 22. Proposed mechanism of peripheral APR-induced seizure hypersusceptibility $\ldots \quad 41$

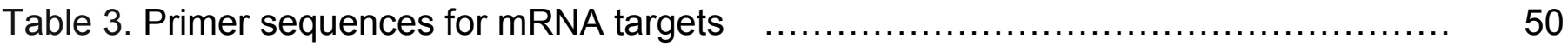

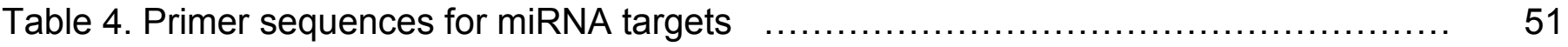




\section{Glossary of Abbreviations}

AMPA

ANOVA

APR

BBB

$\mathrm{C}(2,3 \ldots)$

CCL/R

cDNA

CFB

CON

COX

CSS

CVO

CXCL/R

DEG

DNA

dsRNA

ELISA

FBS

GABA

GABRE

GABRQ

GABRR

GAD

GLDH

GRIA4

GRIK3

GRM

IBU

ICV

IFN

IL
a-Amino-3-hydroxy-5-methyl-4-isoxazolepropionic acid

analysis of variance

acute phase response

blood brain barrier

complement component

C-C motif chemokine ligand/receptor

complementary DNA

complement factor $b$

control

cyclooxygenase

cumulative seizure score

circumventricular organs

C-X-C motif chemokine ligand/receptor

differentially expressed gene

deoxyribonucleic acid

double stranded RNA

enzyme-linked immunosorbent assay

fetal bovine serum

gamma-aminobutyric acid

$\mathrm{GABA}_{A}$ receptor subunit epsilon

$\mathrm{GABA}_{\mathrm{A}}$ receptor subunit theta

$\mathrm{GABA}_{A}$ receptor subunit rho

L-glutamic acid decarboxylase

glutamate dehydrogenase

glutamate receptor, ionotropic AMPA 4

glutamate receptor, ionotropic kainate 3

glutamate receptor, metabotropic

ibuprofen

intracerebroventricular

interferon

interleukin 
IP intraperitoneal

KA

kainic acid

KCNJ10

ATP-sensitive inward rectifier potassium channel 1, $\mathrm{K}_{\mathrm{ir}} 4.1$

LDHA

lactate dehydrogenase

LPS

lipopolysaccharide

MAC

membrane attack complex

$\mathrm{miR}$

micro RNA

mRNA

messenger RNA

NSAID

nonsteroidal anti-inflammatory drug

PAMPS

pathogen-associated molecular patterns

PBS

phosphate-buffered saline

PIC

polycytidilic-polyinosinic acid

PIROX

piroxicam

PRRs

pattern recognition receptors

qRT-PCR

quantitative real-time polymerase chain reaction

RNA

ribonucleic acid

SAL

saline

$\mathrm{SC}$

subcutaneous

SD

standard deviation

TLE

temporal lobe epilepsy

TNF

tumor necrosis factor

WHO

World Health Organization 


\section{Chapter 1: Introduction}

\section{Epilepsy}

Epilepsy is a severe neuropathology characterized by recurrent seizure that affects approximately $1 \%$ of the world population (WHO Fact sheet No999). Furthermore, approximately $8 \%$ of the population experience seizures within their lifetime (Hauser 1997). Seizures result from abnormally excessive and/or synchronous neuronal activity (hyperexcitability) in the brain (Fisher et al. 2005) and can range in severity from mild cognitive impairment to complete loss of consciousness and convulsions. In addition to serious personal safety hazards, seizures also facilitate excitotoxicitydriven neuronal cell death and, consequently, the development of diverse mental disorders (TellezZenteno et al., 2007).

\section{Hyperexcitability}

The brain can become hyperexcitable in many ways which involve changes in either neuronal or network excitability. For a single neuron, hyperexcitability refers to the increased likelihood of the cell firing an action potential, which can result from different alterations in the cell's normal physiology. One way in which neurons can become more excitable is by changes in in neurotransmitter receptor expression and activity (Casillas-Espinosa et al., 2012;Gonzalez 2013; Werner and Covenas, 2011). For example, if the cell expresses more receptors for the excitatory neurotransmitter glutamate, then the cell would require less glutamate to depolarize and lower the threshold for the firing of an action potential. Similarly, if there was a reduction in the number of inhibitory neurotransmitter receptors, then the cell would become less responsive to inhibitory inputs and facilitate the summation of excitatory inputs required for an action potential. Separate from their receptors, alterations in the synthesis and release of excitatory neurotransmitter, e.g. glutamate, and inhibitory neurotransmitters, e.g. GABA, can affect neuronal excitability. Thus, reductions in GABA levels and the activity of L- 
glutamic acid decarboxylase (GAD), the critical enzyme involved in GABA synthesis, have been observed in epileptic tissue (Badwy et al., 2009a).

In addition to neurotransmitter receptors, neurons express a veritable plethora of ion channels along the cell membrane that are crucial to normal function. The flow of ions into or out of a neuron through ion channels is involved in the membrane depolarization necessary for action potential generation and the release of neurotransmitters at the synapse, as well as the recovery of the resting state of the neuron after an action potential is fired. Therefore, it is not surprising that dysfunction in these channels, also referred to as channelopathies, is implicated in epileptic disorders (Badawy et al., 2009a; Heron et al., 2007). During membrane depolarization, the rapid influx of sodium through ion channels is crucial to the generation of an action potential; however, these sodium channels need to inactivate in order for the neuron to stop firing. Several mutations in the sodium channel have been identified in epilepsy (Badawy et al., 2009a; Caterwall 2014;Heron et al., 2007). Some mutation result in increased activity of the excitatory neurons due to slow inactivation of the channel. Other mutations result in a total loss of function of the channel in inhibitory neurons that also lead to hyperexcitability. Changes in potassium channels are also associated with epilepsy (Badawy et al., 2009a;Heron et al., 2007;Maljevic and Lerche 2013). In these cases, the efflux of potassium that is necessary for recovery after membrane depolarization is reduced. This results in an accumulation of positive ions inside the cell, maintaining depolarization and making the neuron hyperexcitable. Also, changes in the properties of calcium channels can greatly affect the excitability of a neuron (Badawy et al., 2009a; Heron et al., 2007; Siwek et al., 2012). At the synapse, transient calcium influx is involved in the release of neurotransmitter; mutations altering the inactivation of these channels can result in excessive or sustained release of neurotransmitter.

Hyperexcitability can also occur within neuronal networks, which include neurons and glia. The organization of these networks is crucial to the proper functioning of the brain. Many developmental disorders that result in improper migration of neurons result in epilepsy (Badawy et al., 2009b;Guerrini 
and Dobyns, 2014). This is due to either the neurons not making the required connections or making aberrant connections with other neurons. For example, if an inhibitory neuron does not make a proper connection with its target excitatory neuron, the activity of the excitatory neuron cannot be properly regulated. This is also true in the adult brain in situations that result in neuron loss, such as stroke or trauma. In these instances, the properly formed connections are lost and the network can lose the proper balance of excitation and inhibition. This can be further exacerbated by changes in morphology of surviving neurons. For example, a loss of neurons in the hilus of the hippocampus triggers axonal sprouting in the granule cells of the dentate gyrus which results in increased excitatory signaling to downstream neurons (Badawy et al., 2009b). Cell morphology also plays a role in the proper function of neuronal networks as evidenced by the increased excitability in networks of cells displaying hypertrophy and/or changes in dendritic structure (Badawy et al., 2009b). In addition to aberrant connections between neurons, dysfunctional associations between neurons and glia can result in hyperexcitability (reviewed in Seifert and Steinhauser, 2013). Excessive extracellular glutamate leads to neurotoxicity by increasing intracellular calcium concentrations. Glia, namely astrocytes, express glutamate transporters on the cell membrane to actively remove neurotransmitter from the synaptic cleft. Decreases in the function of these transporters facilitate hyperexcitability and, thusly, are associated with seizures and epilepsy (Seifert and Steinhauser, 2013). Finally, impaired removal of extracellular potassium by astrocytes via potassium channels results in hyperexcitability (Seifert and Steinhauser, 2013).

\section{Inflammation and seizures}

There are many factors that can affect the risk for developing epilepsy. Peripheral inflammation has been demonstrated to significantly lower seizure threshold (Tellez-Zenteno et al., 2005). This is a significant finding due to its implications for the enhancement of seizure frequency and severity in 
susceptible populations by concurrent peripheral inflammation resulting from infections, arthritis flareups, peptic ulcers, etc. The susceptible populations include not only epileptic patients and stroke or traumatic brain injury victims, but also individuals in situations constituting already high seizure risk, e.g., heat-stroke, dehydration or exhaustion. Such potentiation of seizure propensity poses serious health and safety risks. However, the underlying mechanisms have not been defined.

Inflammation is the body's response to a damaging insult such as infection, injury, or trauma and is defined by several symptoms: redness, swelling, heat, pain, and loss of function. The inflammatory response is carried out by the innate immune system comprised of cells that recognize pathogen-associated molecular patterns (PAMPs), e.g., viral and bacterial proteins, lipids, and nucleic acids. The binding of PAMPs to pattern recognition receptors (PRRs) on these cells instigates the release of inflammatory factors, such as cytokines, chemokines, reactive oxygen species, complement and other inflammatory mediators. This surge of inflammatory mediators is referred to as the acute phase response (APR). Due to its non-specific nature, the innate immune system responds very quickly to infection. In contrast, the adaptive immune system takes longer to activate, but mounts a pathogen-specific, antibody-based response. Although the primary role of inflammation is to combat infections, the cytokines released from the site of inflammation into the circulation have significant effects on the brain.

\section{Immune-to-brain communication}

It is well established that signals of peripheral inflammation are relayed to the brain via humoral and/or neural pathways and elicit behavioral changes, collectively referred to as "sickness behavior". These behaviors include malaise, cognitive dysfunction, anxiety, depression, anhedonia, anorexia, adipsia, lethargy and fatigue. Evolutionarily, these symptoms are believed to be protective by promoting conservation of energy. Cytokines produced in response to peripheral inflammagens can circulate in the blood and act on or through brain endothelium, initiating a signaling cascade in 
the brain that ultimately results in the up-regulation of cytokines in neurons and glial cells (Dantzer 2006). There are multiple pathways by which peripheral inflammatory signals can be communicated to the brain (Dantzer 2006;Quan and Banks, 2007). One path involves the diffusion of blood-borne inflammatory mediators across the blood brain barrier (BBB) or circumventricular organs (CVO) into the brain parenchyma. Another mechanism involves the transduction of the inflammatory signal across the BBB or CVO by the generation of secondary mediators. For example, blood-borne inflammatory mediators, like IL-1 $\beta$, activate endothelial cyclooxygenase (COX) 2 , stimulating the synthesis of prostaglandins. COX2 is known to have a role in neural function and "sickness behavior;" most notably in fever where COX inhibitors, or non-steroidal anti-inflammatory drugs (NSAIDs), prevent inflammation-induced changes in body temperature (reviewed in DuBois et al., 1998).

\section{Experimental model}

While increased seizure susceptibility produced by peripheral inflammation has been demonstrated in animal models of sepsis (Balter-Seri et al., 1999; Sayyah et al., 2003), colitis (Riazi et al., 2008;Riazi et al., 2004), arthritis and subcutaneous granuloma (Rao et al., 2008), the limitations of these models have prevented dissection of the mechanisms. Not only do these models require several days to develop, but also they involve the amalgamation of several different pathological processes to acquire the ultimate phenotype. Although the LPS model of sepsis (Sayyah et al., 2003) is the most commonly studied, it involves direct insult to the brain due to rapid entrance of the inflammagen into circulation (Lenczowski et al., 1997;Romanovsky et al., 2000). Our lab has developed a mouse model system that avoids these complications. In our model, APR is induced by intraperitoneal (i.p.) injection of double stranded (ds) RNA. The vast majority of viruses (of both the RNA and DNA types) generate dsRNA species during their replication (Jacobs and Langland, 1996; Weber et al., 2006). Mammalian cells have several receptors that detect the presence of extra- 
and intracellular dsRNA, i.e., Toll-like receptor 3 (TLR3), retinoic acid-inducible gene 1 (RIG-1), melanoma differentiation-associated protein 5 (MDA-5) and protein kinase R (PKR) (Berke et al., 2013). The ligation of these receptors leads to the production of type I interferons and other inflammatory cytokines with antiviral activity (Muller et al., 1994). In our model, we use synthetic dsRNA, polyinosinic:polycytidylic acid (PIC). Using this model, our lab has shown that the peripherally-generated inflammatory mediators are conveyed to the brain via circulation and induce a robust inflammatory response in the brain (Konat et al., 2009; Konat and Borysiewicz, 2009; Fil et al., 2011). Furthermore, i.p. injected PIC does not reach the blood (Fil et al., 2011). Therefore, in our system, the brain is exposed only to the inflammatory mediators and not to the inflammagen itself. Moreover, PIC is a short-lived molecule (Krasowska-Zoladek et al., 2007) allowing hour-by-hour kinetic analysis of APR and the brain responses.

\section{Objectives and hypothesis}

The objective of the body of work presented in this dissertation was to characterize the mechanisms by which peripheral inflammation increases seizure susceptibility using our model of peripherally-restricted inflammation. In the first set of studies, we evaluated the mechanisms by which blood-borne inflammatory mediators elicit seizure hypersusceptibility. In the second set of studies, we investigated the genetic mechanisms underlying PIC-induced seizure hypersusceptibility. Our central hypothesis was that peripheral inflammation instigates a surge of blood-borne cytokines that reach the brain and alter the expression of hippocampal genes leading to the increased seizure susceptibility. 


\section{Chapter 2: Peripheral challenge with PIC elicits seizure hypersusceptibility}

\subsection{Acute phase response to viral infection and sickness behavior}

Sickness behavior is thought to promote optimal recovery and survival by altering the priorities of the affected individual to conserve resources and to prevent the spread of infection within the population (Dantzer, 2006; Dantzer and Kelley, 2007; Quan and Banks, 2007). Thus, intraperitoneal injection of a synthetic dsRNA, PIC, in mice induces symptoms of "sickness behavior" (Muller et al., 1994;Guha-Thakurta and Majde, 1997;Cunningham et al., 2007) that are congruent with behavioral effects of peripheral viral infections in humans (Loftis et al., 2008;Huckans et al., 2009;Nelligan et al., 2008). The PIC-induced symptoms peak at $6 \mathrm{~h}$ after the injection and subside by $48 \mathrm{~h}$ (Cunningham et al., 2007). For example, PIC challenge strongly suppresses burrowing activity, a species-typical behavior (Cunningham et al., 2007; Konat et al, 2009), exemplifying the loss of motivation that is a typical component of sickness behavior. Although at nadir ( $6 \mathrm{~h}$ post-injection), the burrowing activity of PIC-challenged animals drops below $10 \%$ of the respective controls, the test is rather cumbersome and lengthy $(2 \mathrm{~h})$. Locomotor assessment is another behavioral test typically used to assess the hypoactivity associated with sickness behavior. Cunningham et al. (2007) also found suppression of locomotor activity using the open field test, albeit to a much lesser extent than the burrowing activity. In concordance with this study, we observed the locomotion of mice to be reduced by approximately $30 \%$ and $60 \%$ at $3 \mathrm{~h}$ and $6 \mathrm{~h}$ after PIC injection, respectively (Fig. 1). However, we found that the rearing activity, which assesses the number of times the animal stands on two legs, was suppressed equally to the burrowing activity, as it dropped by $70 \%$ and $96 \%$ at $3 \mathrm{~h}$ and $6 \mathrm{~h}$, respectively (Fig. 1.). Consequently, the rearing test, which lasts only $15 \mathrm{~min}$, provides a convenient, highly sensitive method to verify successful induction of sickness behavior. 


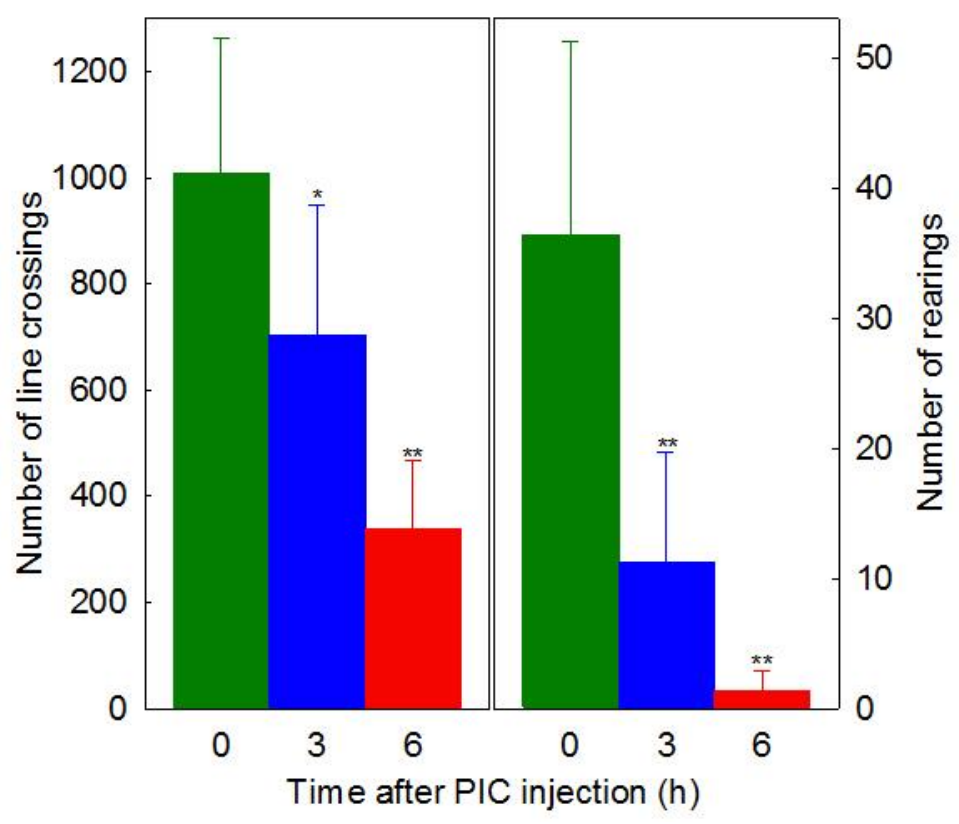

Figure 1. The suppression of locomotor and rearing behavior by PIC challenge. Mice were i.p. injected with $12 \mathrm{mg} / \mathrm{kg}$ of PIC and after $3 \mathrm{~h}$ (blue) or $6 \mathrm{~h}$ (red) the locomotor and rearing activities were evaluated (for details see Materials and Methods). Saline injected mice served as controls (green, 0 h). Bars represent means \pm S.D. from 6-10 animals. Values significantly different from controls are indicated by asterisks. ${ }^{*} p \leq 0.05 ;{ }^{* *} p \leq 0.01$.

\subsection{Peripheral APR enhances seizure susceptibility}

Considering the clinical and experimental research indicating peripheral inflammation as a comorbidity for seizures (Tellez-Zenteno et al. 2005), we investigated whether PIC challenge would enhance the ability for kainic acid (KA) to induce seizure. The most common form of epilepsy in humans, temporal lobe epilepsy (TLE), is modeled by systemic KA administration (Ben-Ari and Cossart, 2000). KA is a glutamate analog binding to the kainate receptor subclass of ionotropic glutamate receptors. In the KA model, seizures originate from the hippocampus (Ben-Ari and Cossart, 2000), but the increased activity quickly spreads through the brain. The hyperactivity of hippocampal neurons often leads to their death and, ultimately, to hippocampal sclerosis that can be revealed by postmortem examination or MRI (Das et al., 2010). The KA model closely mimics hippocampal neuron loss and neuroinflammation in TLE (Ben-Ari and Cossart, 2000;Das et al., 2010).

Previous studies have shown that peripheral APR induced by PIC challenge results in a robust inflammatory response in the brain that substantially subsides by $24 \mathrm{~h}$ (Cunningham et al., 2007; Konat and Borysiewicz, 2009;Konat et al., 2009;Fil et al., 2011). Since it is well-established that seizures are enhanced concurrently with brain inflammation (Choi and Koh, 2008; Vezzani and 
Granata, 2005), we initially evaluated seizure activity after the behavioral and brain inflammatory responses to PIC had subsided (48 h post-injection).

Peripheral PIC challenge profoundly increased the intensity of seizures in comparison to saline treated animals (Fig 2). PIC challenge also altered the kinetics of status epilepticus (Fig. 2). Thus, seizure intensity peaked at approximately $35 \mathrm{~min}$ in the saline group, and at approximately $80 \mathrm{~min}$ in the PIC group. Whereas the seizures ceased in the saline group at approximately 110 min after KA injection, the PIC pretreated animals were still in a full-blown status epilepticus at that time point. Cumulative seizure scores (CSS) calculated by summation of the incremental scores over the 2-h observation period revealed a 5.2-fold enhancement by PIC over the saline group (Fig. 3a).

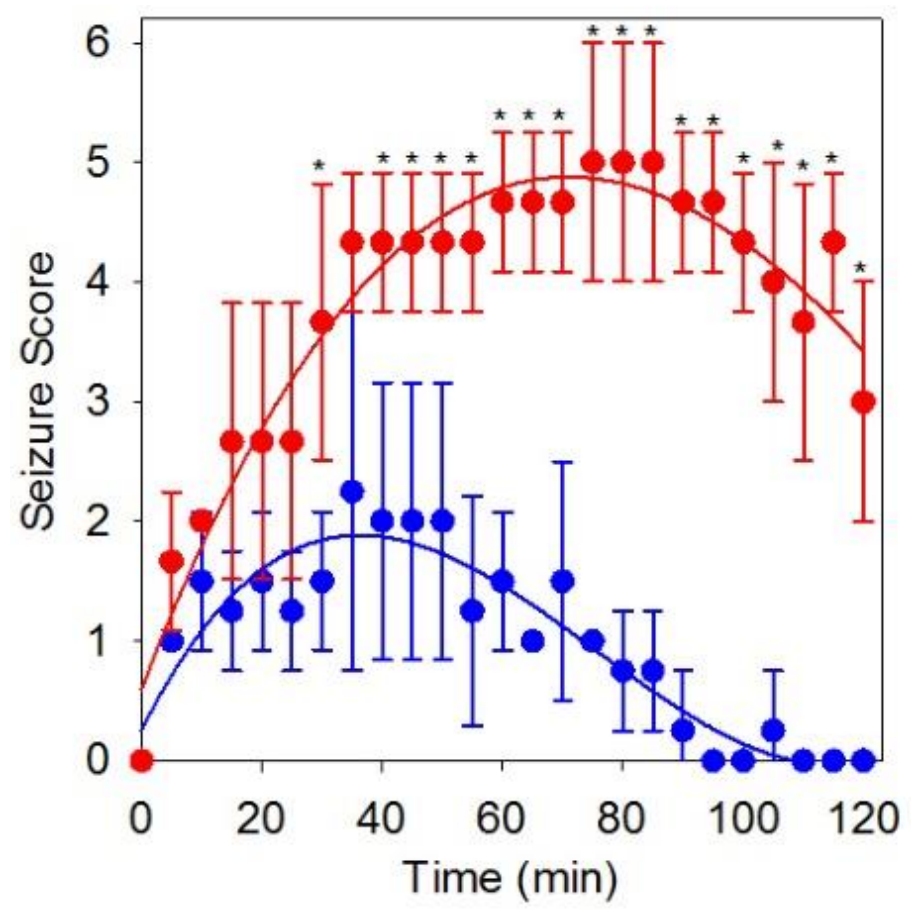

Figure 2. Kinetics of KA-induced status epilepticus. Mice were pretreated daily with PIC (red) or saline (blue) for three consecutive days. After $48 \mathrm{~h}$, seizures were induced by the administration of $15 \mathrm{mg} / \mathrm{kg}$ of $K A$, and their intensity was scored over a period of $2 h$. For details see "Chapter 5: Materials and methods". Points represent averages \pm S.D. from 3-4 animals. Values significantly different from controls are indicated by asterisks $(p \leq 0.05)$.

We also found that seizure intensity was directly related to doses of the excitotoxin (Fig. 3a). In saline treated mice, CSS were 11,25 and 46 at 10,15 and $20 \mathrm{mg} / \mathrm{kg}$ of $\mathrm{KA}$, respectively. PIC challenge increased seizure intensities by approximately $6.9,3.8$ and 2.7-fold over the saline groups at $\mathrm{KA}$ doses of 10,15 , and $20 \mathrm{mg} / \mathrm{kg}$, respectively. Although no mortality was observed at 10 or 15 $\mathrm{mg} / \mathrm{kg}$ doses, intense seizures induced by $20 \mathrm{mg} / \mathrm{kg}$ of KA in triply injected mice occasionally resulted in death. Finally, as shown in Fig. 3b, even a single peripheral challenge with PIC profoundly 
enhanced seizure intensity. CSS of this group did not differ significantly from CSS of the corresponding triple injection group (Fig. 3a) indicating that a single dose of PIC provides a saturating effect.

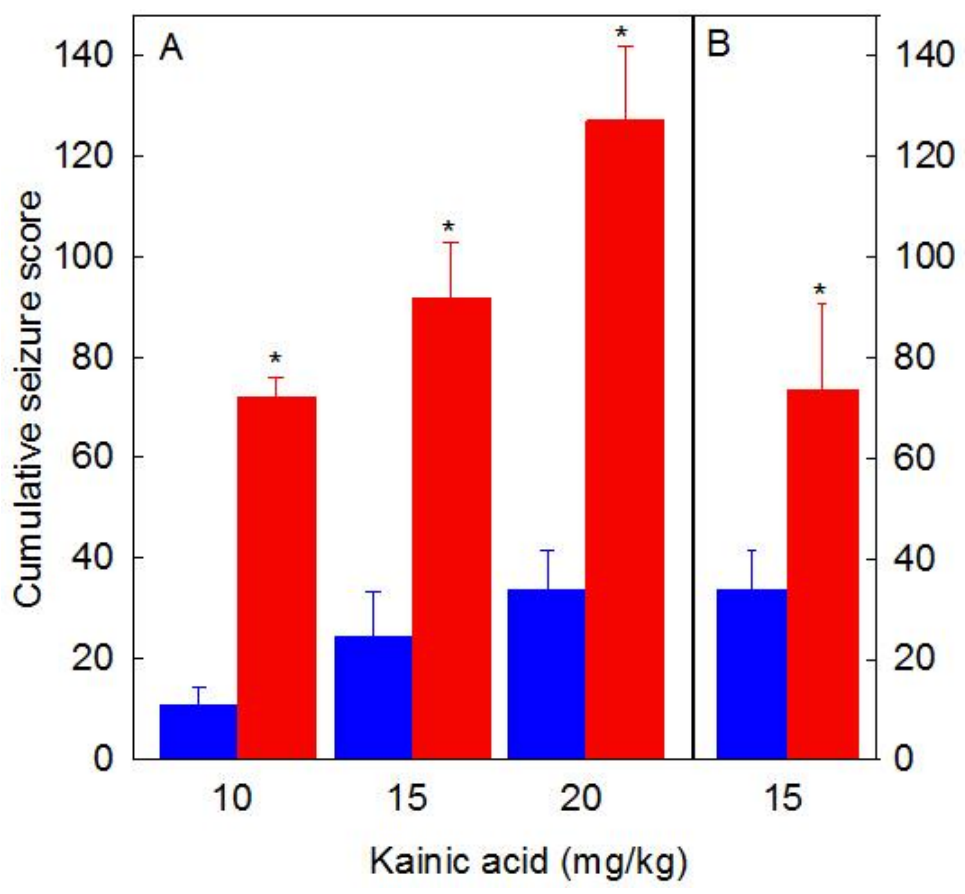

Figure 3. Effect of KA and PIC doses on seizure intensity. A) mice were pretreated daily with PIC (red) or saline (blue) for three consecutive days. After $48 \mathrm{~h}$, seizures were induced by the administration of different doses of KA. B) mice were pretreated with a single dose of PIC, and after $48 \mathrm{~h}$, seizures were induced by the administration of 15 $\mathrm{mg} / \mathrm{kg}$ of $K A$. The results are expressed as CSS. Bars represent averages \pm S.D. from 3-4 animals. Values significantly different from controls are indicated by asterisks $(p \leq 0.05)$.

Having demonstrated that PIC challenge strongly enhances the susceptibility of mice to KAinduced seizures at $48 \mathrm{~h}$ after PIC injection (Fig. 2 \& 3), we determined the duration of this hypersusceptible phenotype. As seen from Fig. 4, the seizure response was highest one day postPIC, reaching nearly 3-fold over saline injected controls. Although the hypersusceptibility gradually decreased, it was still significant at 2 and 3 days post-PIC. By days 4 and 7 , the response of the PIC challenged animals was indistinguishable from that of controls. 


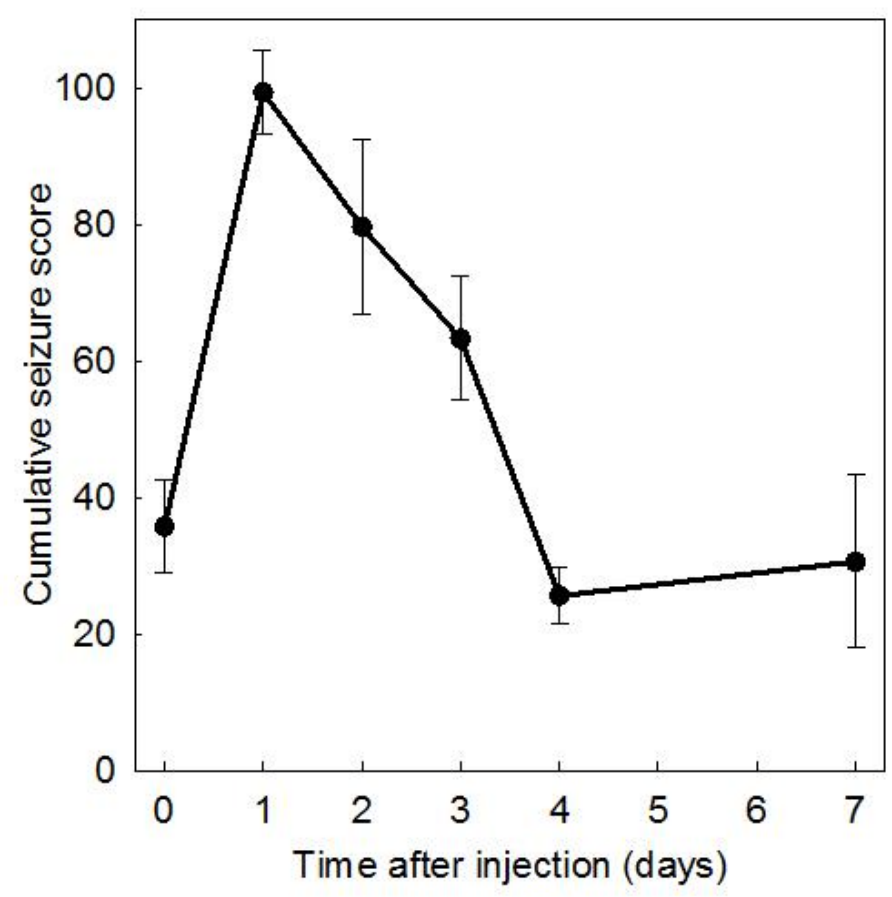

Figure 4. Time course of seizure susceptibility following PIC challenge. Mice were i.p. injected with $12 \mathrm{mg} / \mathrm{kg}$ of PIC or saline (day 0). At different time points after PIC challenge, the animals were s.c. injected with $20 \mathrm{mg} / \mathrm{kg}$ of $K A$ to induce seizures. The results are expressed as CSS. Bars represent means \pm S.D. from 3-7 animals. Values significantly different from controls are indicated by asterisks $(p \leq 0.05)$.

\section{Discussion}

These data indicate an enhancing effect of prior peripheral challenge with PIC on cerebral vulnerability to KA-induced status epilepticus. Thus, our results complement previous reports showing enhanced seizure susceptibility following bacterially-induced peripheral inflammation (Riazi et al. 2010), and support a causative link between peripheral infections and seizures (Tellez-Zenteno et al. 2005). Moreover, because PIC effects are restricted to the peritoneal cavity (Fil et al. 2011), our results prove that the cerebral effects are mediated by immune-to-brain signaling. In contrast, the bacterial models featured a highly possible direct interaction of the inflammagen with the brain. Consequently, the PIC paradigm provides a unique model to study mechanisms by which bloodborne inflammatory mediators generated in the periphery alter neural function within the brain rendering it more vulnerable to excitotoxic insult.

Our lab has previously shown that the cerebral inflammatory response to PIC challenge features a robust but transient upregulation of a plethora of cytokine and chemokine genes (Konat et al. 2009; Fil et al. 2011). Interestingly, we found that the response to KA is enhanced from one to three days following PIC-induced peripheral APR, when the cerebral inflammatory response has 
largely subsided. Therefore, the cerebral inflammatory response must have induced protracted alterations of brain function that manifested as KA hypersusceptibility.

\subsection{The role of blood borne cytokines in PIC-induced seizure susceptibility}

As mentioned previously, peripheral inflammatory signals are relayed to the brain through the blood and/or neural pathways to produce "sickness behavior" (Dantzer 2006;McCusker and Kelley 2013). However, transection of the vagus nerve, a component of the neural pathway, does not prevent the upregulation of IL-1 $\beta$ in the brain following peripheral inflammation (Van Dam et al., 2000). Furthermore, a past study from our lab demonstrated that i.p. injection of blood plasma from a PIC-treated mouse to a naïve mouse mimics PIC's upregulation of chemokines in the brain (Fil et al., 2011). These studies suggest the involvement of blood-borne cytokines in the immune-to-brain communication of inflammatory signals. To test the involvement of these blood-borne factors in seizure hypersusceptibility, we investigated whether blood plasma transfer could mimic the effects of PIC on KA-induced seizures.

Although plasma transfer was able to recapitulate the brain inflammatory response (Fil et al., 2011), we did not find increased seizure susceptibility in these mice (Fig. 5). This result is most likely due to the limitation on the amount of plasma that can be i.p. injected into the mouse, $300 \mu \mathrm{L}$. This represents a fraction of the total blood volume of our mice (approximately $1 / 5^{\text {th }}$ ), effectively cutting the concentration of blood-borne inflammatory factors by $80 \%$, not accounting for potential proteolysis in the peritoneal cavity. This notion is further supported by previous data from our lab that demonstrated a 10-fold lesser upregulation of chemokines by plasma transfer in comparison to PIC treatment (Fil et al., 2011). 


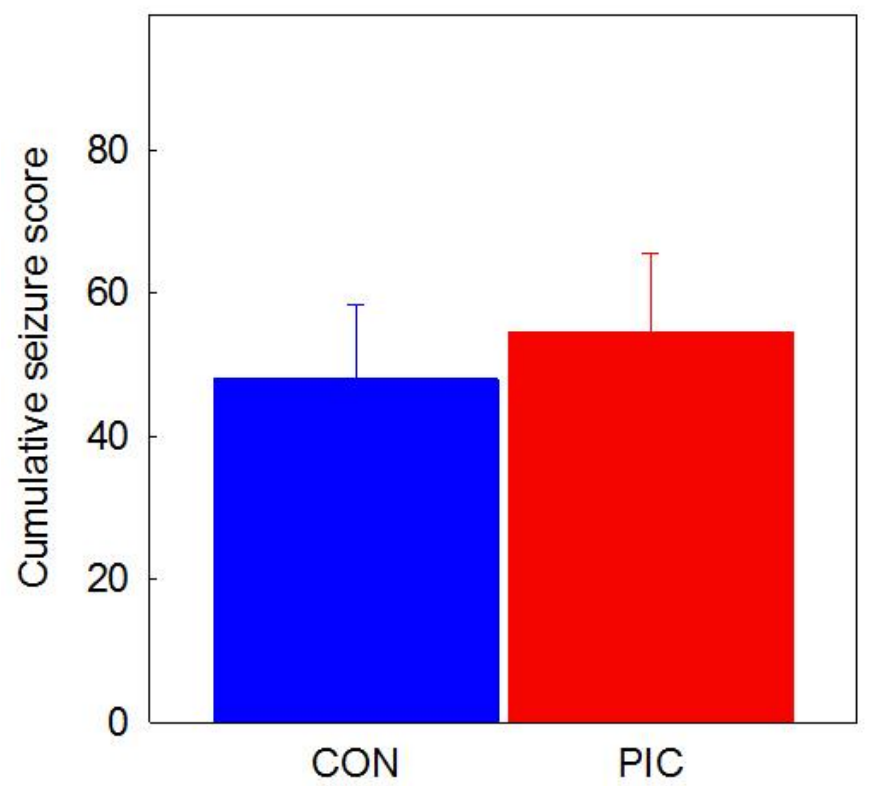

Figure 5. Seizure susceptibility following blood plasma transfer. Naïve mice were i.p. injected with $300 \mu \mathrm{L}$ of citrated blood plasma collected from PIC-(red) or salinetreated (blue) $2 \mathrm{~h}$ post-injection. After $24 \mathrm{~h}$, seizures were induced by the administration of $15 \mathrm{mg} / \mathrm{kg}$ of $K A$. The results are expressed as CSS. Bars represent means \pm S.D. from 3 animals.

To overcome the volumetric limitations posed by the plasma transfer experiment, we tested whether i.p. injection of inflammatory cytokines could enhance KA-induced seizures. Intraperitoneal PIC injection induces the synthesis of IFN $\beta, I L-6, I L-1 \beta$ and TNF $\alpha$ that rapidly reach the circulation as seen from the surge of these inflammatory cytokines in the blood (Cunningham et al., 2007). Their levels peak sharply at $3 \mathrm{~h}$ post-injection and then quickly decline. We confirmed these results for IFN $\beta$ and IL-6 as shown in Fig. 6 . Thus, both cytokines reached the highest levels $3 \mathrm{~h}$ after PIC challenge, and decreased rapidly thereafter, reaching baseline levels at $12 \mathrm{~h}$ post-injection. The maximal blood concentrations of IFN $\beta$ and IL-6 were 33.5 and $21.5 \mathrm{ng} / \mathrm{ml}$, respectively, which is in concordance with the values observed by Cunningham et al (2007).

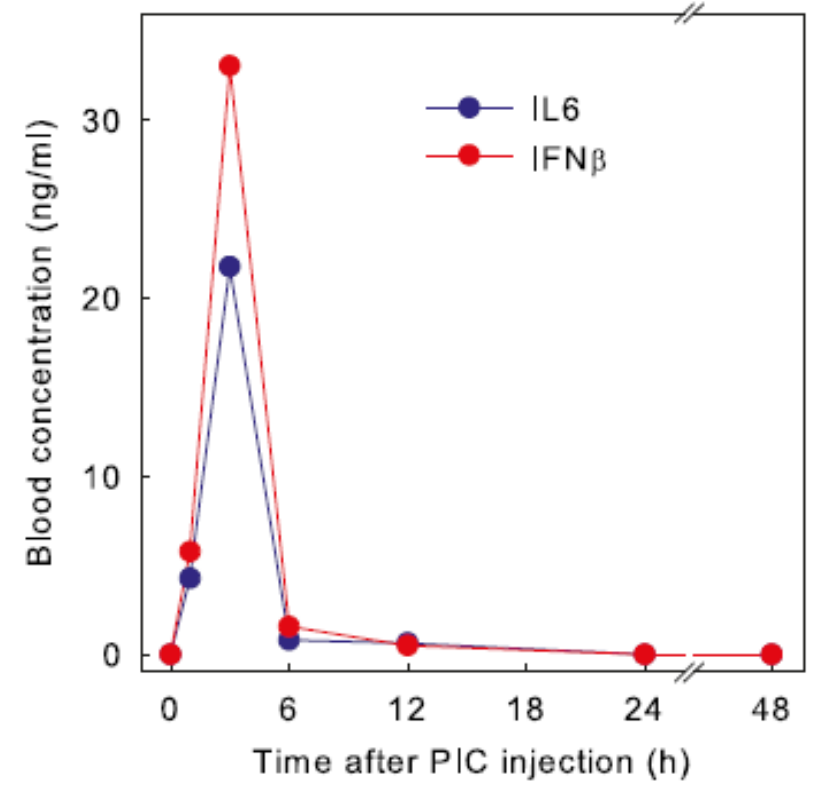

Figure 6. Blood cytokine surge induced by PIC challenge. Mice were i.p. injected with $12 \mathrm{mg} / \mathrm{kg}$ of PIC and the levels of IFN $\beta$ and IL-6 in the blood plasma were determined at various time points as indicated. Data represent averages from 2 animals. 
After determining the peak blood concentrations of IL-6 and IFN $\beta$ (Fig. 6), we tested whether i.p. injection of the cytokines at these concentrations could recapitulate the hypersusceptible phenotype induced by PIC treatment (Fig. 7). Similarly to plasma transfer, the injection of IL-6 (26.1 ng) and IFN $\beta$ (39.7 ng) was insufficient to recapitulate PIC-induced seizure hypersusceptibility. To account for potential breakdown of the cytokines in the peritoneal cavity, a second set of mice were i.p. injected with a mixture of $1 \mu \mathrm{g}$ each of IL-6 and IFN $\beta$. However, even these higher concentrations were insufficient to recapitulate the phenotype seen with PIC treatment. Furthermore, we found that IL-6 and IFN $\beta$ were insufficient to upregulate $C x c / 10$ mRNA (data not shown), one of the chemokines most profoundly affected by peripheral PIC challenge (Fil et al., 2011). These data suggest that the most highly upregulated blood cytokines, i.e. IFN $\beta$ and IL-6, are not responsible for the development of seizure hypersusceptibility or the upregulation of CXCL10 following PIC-induced peripheral inflammation.

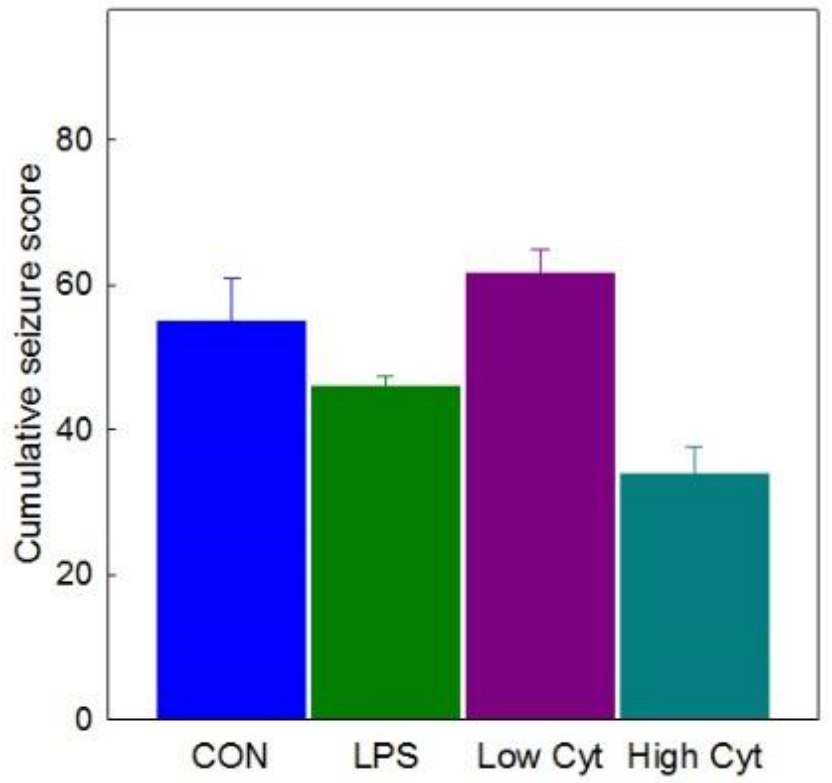

Figure 7. Seizure susceptibility following cytokine treatment. Mice were i.p. injected with: a mixture of $30 \mathrm{ng}$ of IL6 and 40 ng of IFN $\beta$ (purple), a mixture of $1 \mu \mathrm{g}$ each of IL-6 and IFN $\beta$ (teal), $200 \mathrm{pg}$ of LPS (green; to account for trace levels of endotoxin potentially present with the recombinant proteins), or saline (blue). After $24 \mathrm{~h}$, seizures were induced by the administration of $15 \mathrm{mg} / \mathrm{kg}$ of $K A$. The results are expressed as CSS. Bars represent means \pm S.D. from 2-3 animals.

\section{Discussion}

It is possible that other inflammatory mediators are responsible for transmitting this signal to the brain. For example, the cytokines IL-1 $\beta$ and TNF $\alpha$, which exhibit much lower levels in the blood following PIC challenge than IL-6 or IFN $\beta$ (Cunningham et al., 2007), have been demonstrated to 
mimic "sickness behavior" (McCusker and Kelley, 2013). However, many studies use either intracerebroventricular (i.c.v.) injection of the cytokines into the brain or very large doses. For example, using 2500x the plasma concentration measured for TNF $\alpha$ (Anisman et al., 2008) or over 10,000x for IL-1 $\beta$ (Bluthé et al., 1994;Bluthé et al., 2006) found by Cunningham et al (2007), making the results difficult to interpret. Furthermore, studies using IL-1 receptor knockout mice showed that treatment with LPS or i.c.v. TNF $\alpha$ could circumvent the knockout-induced reduction in "sickness behavior" (reviewed in McCusker and Kelley, 2013). In contrast, IL-6 and type-I IFNs are believed to enhance the effects of TNF $\alpha$ and IL-1 $\beta$ in sickness behavior while being insufficient to induce sickness behavior on their own (McCusker and Kelley, 2013). Taken together, these studies support the hypothesis that a number of inflammatory mediators, not individual cytokines, are required for the induction of sickness behavior. The same seems to be true for PIC-induced seizure hypersusceptibility.

\subsection{The role of COX in PIC-induced seizure susceptibility}

Our lab has found that peripheral PIC challenge results in the transient upregulation of Cox2 mRNA in the forebrain (Borysiewicz and Konat, unpublished data). This is in agreement with a similar study that identified the upregulation of COX2 protein in hippocampal endothelium (Cunningham et al., 2007); indicating that COX2 may be involved in the transduction of inflammatory signals from the periphery to the brain. Since the necessary components of the humoral signal for the induction of seizure hypersusceptibility remain unclear, we investigated whether COX signaling is required for the enhancement of KA-induced seizures by PIC. Pretreatment with two non-specific COX inhibitors, ibuprofen (IBU) and piroxicam (PIROX) at concentrations demonstrated to inhibit COX activity (Teeling et al., 2010) had no effect on PIC-induced seizure hypersusceptibility (Fig. 8). Furthermore, the NSAIDs failed to attenuate the cerebral inflammatory response, even resulting in an increase in 
the gene expression of the inflammatory chemokine, CXCL11 (Fig. 9). The administration of COX inhibitors alone had no effect on KA-induced seizures or on the cerebral inflammatory gene expression (data not shown).

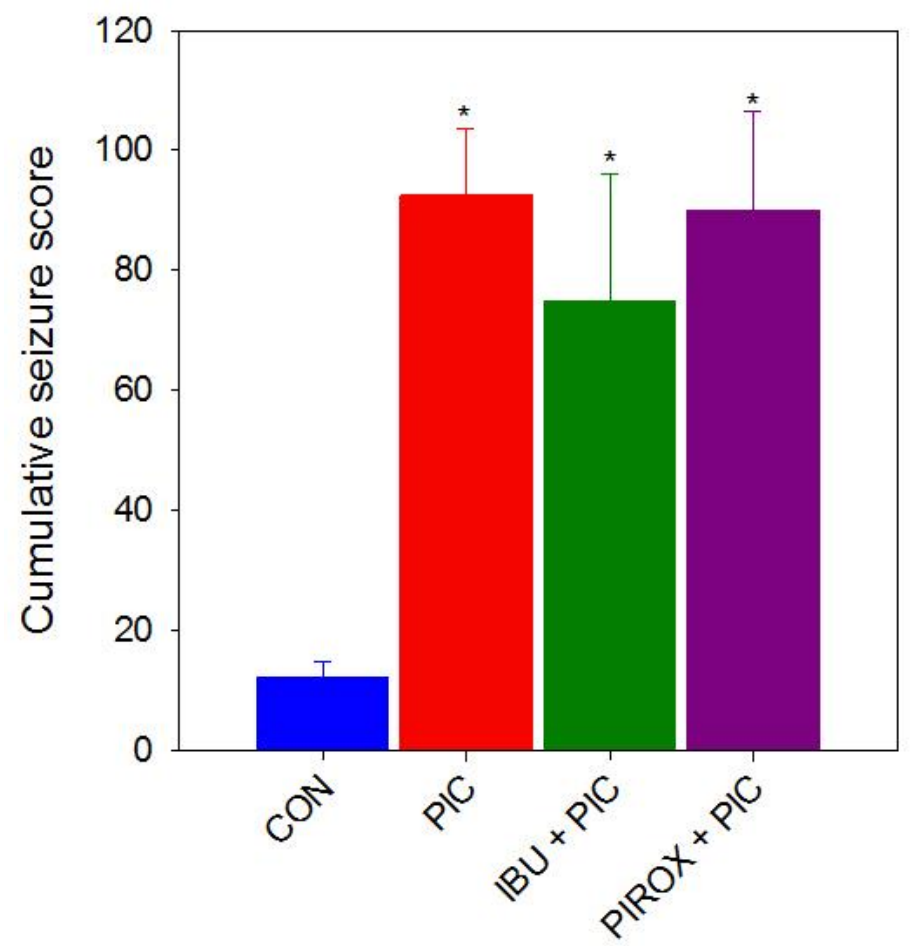

Figure 8. Seizure following COX inhibition. Mice were i.p. injected with $30 \mathrm{mg} / \mathrm{kg}$ of IBU (IBU + PIC) or 10 $\mathrm{mg} / \mathrm{kg}$ of PIROX (PIROX + PIC) $1 \mathrm{~h}$ prior to receiving an i.p. injection of $12 \mathrm{mg} / \mathrm{kg}$ of PIC. Controls were injected only with saline (blue). After $24 \mathrm{~h}$, mice received a s.c. injection of $15 \mathrm{mg} / \mathrm{kg}$ of $K A$ to induce seizures. The results are expressed as CSS. Bars represent means \pm S.D. from 3-5 animals. Values significantly different from controls are indicated by asterisks $(p \leq 0.05)$.

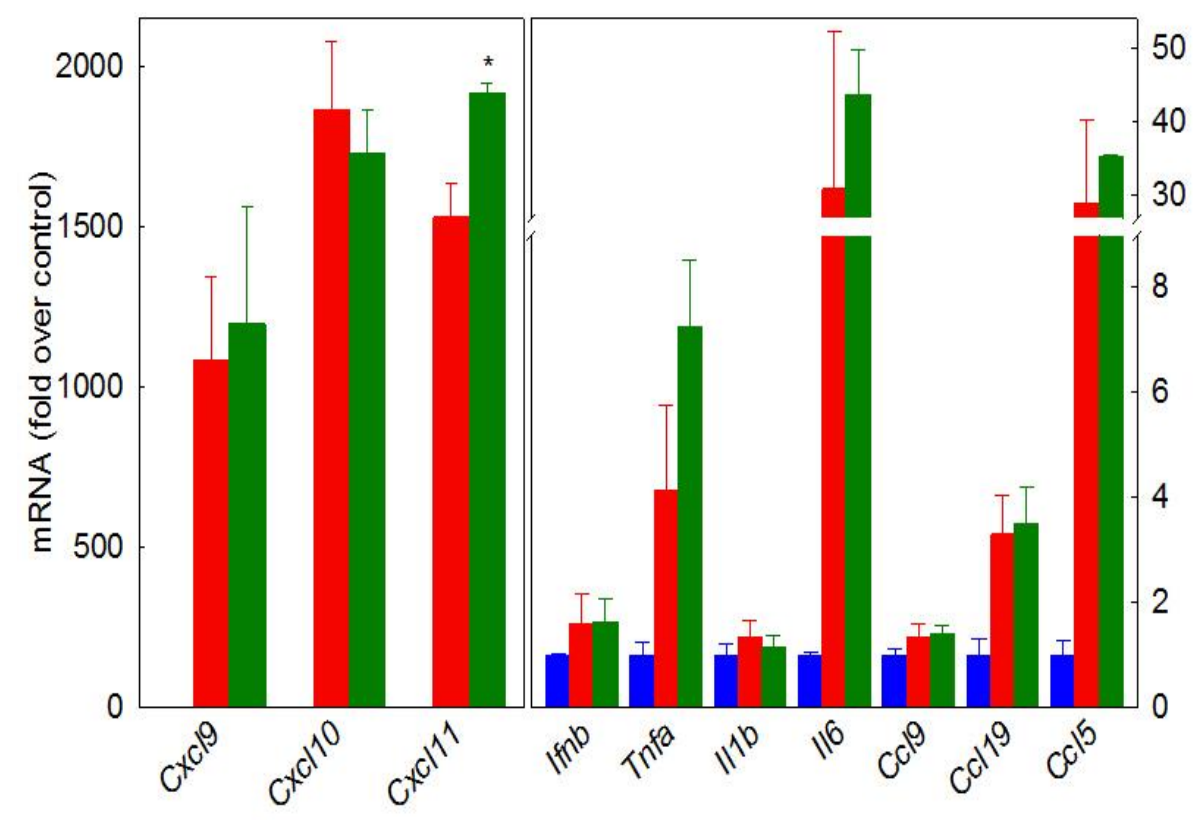

Figure 9. Cerebral inflammatory response following COX inhibition. Mice were i.p. injected with $30 \mathrm{mg} / \mathrm{kg}$ of IBU (green) $1 \mathrm{~h}$ prior to receiving an i.p. injection of $12 \mathrm{mg} / \mathrm{kg}$ of PIC (PIC alone; red). Controls were injected only with saline (blue). After $24 \mathrm{~h}$, mice were sacrificed and the hippocampal RNA was isolated. Expression of several inflammatory genes was evaluated by qRT-PCR. Bars represent means \pm S.D. from 2-3 animals. Values significantly different from controls are indicated by asterisks $(p \leq 0.05)$.

\section{Discussion}

The inability of non-selective COX inhibitors to block or significantly reduce PIC-induced seizure susceptibility suggests that cyclooxygenases (COX1 and COX2) are not necessary for the 
transduction of the inflammatory signals responsible for the development of seizure hypersusceptibility. In support of this notion, Teeling et. al. (2010) found that i.p. injection of ibuprofen and piroxicam did not reduce the levels of circulating or brain expressed IL-6, IL-1 $\beta$, or TNF $\alpha$ following LPS treatment, emphasizing the potential role for blood-borne inflammatory cytokines in immune-to-brain communication. Interestingly, both ibuprofen and piroxicam were able to reverse LPS-induced suppression of locomotion and burrowing behaviors (Teeling et. al., 2010), suggesting that the pathways involved in these behaviors and seizure susceptibility may diverge.

\subsection{Conclusions}

The preceding studies add further evidence to the developing link between peripheral inflammation and seizures by illustrating that PIC challenge increases the susceptibility to KA-induced seizures (Fig. 2). Interestingly, a single dose of PIC is sufficient to cause a dramatic increase in the seizure severity (Fig. 3). This observation further supports the validity of the PIC model to study viral APR and "sickness behavior" due to its rapid and potent effects on the brain. Furthermore, we have demonstrated that the window of increased susceptibility lasts up to three days after PIC challenge (Fig. 4). This is in contrast to a previous report on hypersusceptibility induced by i.p. injection of LPS (Sayyah et al., 2003). In that model of bacterial infection/sepsis, seizure hypersusceptibility was limited to the initial $24 \mathrm{~h}$. Several factors may contribute to the observed differences in the duration of the hypersusceptible phenotype induced by PIC vs. LPS. For example, LPS rapidly enters the circulation (Lenczowski et al., 1997;Romanovsky et al., 2000) and thus, the brain is exposed simultaneously to peripherally-generated inflammatory factors and the LPS itself. On the contrary, PIC does not reach the circulation (Fil et al., 2011) and therefore, elicits the cerebral response solely through blood-borne inflammatory mediators. Moreover, the composition of the blood-borne mediators induced by PIC vs. LPS challenge may differ. For example, IFNy is produced in response to LPS (Gibb et al., 2008; Finney et al., 2012) but not in response to PIC (Gandhi et al., 2007). 
The mechanisms by which blood-borne inflammatory mediators induce seizure hypersusceptibility remain unclear. The inability for i.p. IL-6 and IFN $\beta$ to replicate PIC-induced seizure susceptibility (Fig. 7) corroborates previous data that has suggested these cytokines are insufficient to mimic sickness behavior (McCusker and Kelley, 2013). Thus, a multitude of blood-borne factors may be required to instigate seizure susceptibility. The blood plasma isolated from a PIC challenged mouse should contain the majority of these factors; however, the limitations of the plasma transfer study (Fig. 5) illustrate that the concentration of those factors is crucially important. Furthermore, our results demonstrate that the peripheral inflammatory signals produced by viral APR are not transduced across endothelium by COX (Fig. $8 \& 9$ ). This is not to say that there is no involvement of COX signaling in sickness behavior; on the contrary, NSAIDs are highly efficient at reducing fever in response to infection (Taniguchi et al., 1997). However, COX signaling is not required for PICinduced seizure hypersusceptibility nor does it seem to be involved in propagating the cerebral inflammatory response.

Regardless of the mechanisms, our findings have important clinical implications because they indicates that viral infections may increase the risk of ictal attacks even several days after the active phase of infection has subsided. This should be particularly relevant to populations of vulnerable individuals, e.g., epileptics and post-stroke victims, or individuals exposed to seizure-inducing conditions such as heat stroke or exhaustion.

\subsection{Contributions}

Portions of this chapter were taken from previously published manuscripts (Kirschman et al., 2011; Michalovicz and Konat, 2014); see Appendix I. 


\section{Chapter 3: Peripheral challenge with PIC alters hippocampal gene expression}

\subsection{Inflammatory genes}

The induction of sickness behavior is concomitant with transient upregulation of genes encoding IL-1 $\beta$, IL-6, TNF $\alpha$ and IFN $\beta$ in the hippocampus and hypothalamus (Cunningham et al., 2007). Our lab has confirmed the expression of these genes in the brain and shown that their upregulation is global rather than regional, as it is featured in all parts of the brain, i.e., the forebrain, cerebellum and brain stem (Konat et al., 2009). Furthermore, the brain also features upregulation of a plethora of chemokines and their receptors (Fil et al., 2011). Generally, the upregulation of respective mRNAs peaks between 3-6 $\mathrm{h}$ following the PIC challenge and reaches from several- to several thousand-fold over control. After $24 \mathrm{~h}$, the expression of most of the genes returns to the baseline levels. We have found that this robust, albeit generally transient, genomic response to PIC-induced APR renders the brain hypersusceptible to excitotoxic insult (Chapter 2). The PIC pretreatment profoundly increased both the intensity and duration of KA-induced seizures as compared to naïve animals challenged with KA alone. Since KA administration models hippocampal-generated seizures (Ben-Ari and Cossart, 2000), we focused on this structure throughout our molecular studies.

Based on previous studies from our lab (Konat et al 2009; Fil et al, 2011), we selected 23 inflammation-related genes comprising cytokines, chemokines and chemokine receptors, and profiled their expression in the hippocampus following PIC challenge. The blood cytokine surge (Chapter 2, Fig. 6) was associated with a rapid upregulation of cytokine (Fig. 10) and chemokine (Fig. 11) genes, buttressing the cause-effect relationship between the circulating cytokines and the gene expression response of the hippocampal cells. However, differences in the expression pattern of the genes were evident. The expression of the I/6, Ifnb, Cxc/17, Cc/4,Cxc/1, Cxcl2, Cxc/9, Cxc/10 and Cxc/11 genes peaked between 3 and $6 \mathrm{~h}$ after PIC injection and dwindled rapidly thereafter. The Tnfa, $/ 11 \mathrm{~b}, \mathrm{Ccl}$, 
Ccl12 and Ccl2 genes featured an extended time frame of upregulation with high levels of their mRNA remaining at $24 \mathrm{~h}$. The expression of the $C c / 19, C x c / 13$ and $C c / 5$ genes actually peaked at 24 h. Most of the genes, except the Ifnb, I/1b,Cxc/17, Cxcl1, and Cxcl2 genes, were significantly upregulated even at $72 \mathrm{~h}$. The $\mathrm{Cc} / 9$ gene exhibited a unique expression profile, peaking early at $3 \mathrm{~h}$ and then peaking again from 48 to $72 \mathrm{~h}$. Also, the extent of upregulation varied greatly among the genes. The cytokine genes were upregulated by approximately 2- to 32 -fold over control with the $/ 16$ gene being the most and the $/ / 1 \mathrm{~b}$ gene being the least upregulated. These results corroborate a previous study of the response of hippocampal cytokine genes to PIC challenge (Cunningham et al 2007). Among the chemokine genes, Cxc/11, Cxc/10, Cxcl9 and Cxcl1 featured the highest upregulation by more than a thousand-fold over control. The $\mathrm{Cxcl} 2, \mathrm{Cc} / 12$ and $\mathrm{Ccl} 2 \mathrm{2}$ genes were upregulated up to several hundred-fold, whereas several ten-fold upregulations were observed for the $C c / 7, C c / 4$ and $C c / 5$ genes. The $C x c / 13, C c / 19, C x c / 17$ and $C c / 9$ genes were upregulated by less than ten-fold.

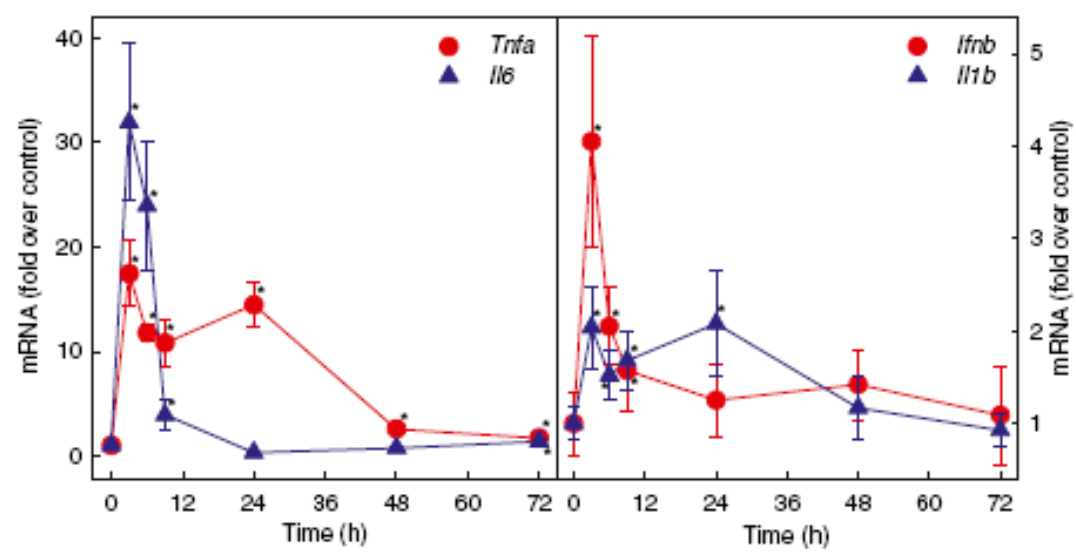

Figure 10. The expression of cytokine genes in the hippocampus following PIC challenge. Mice were i.p. injected with $12 \mathrm{mg} / \mathrm{kg}$ of PIC and the levels of selected cytokine mRNAs were determined in the hippocampi by qRT$P C R$ at different time points as indicated. Data represent means \pm S.D. from 3-8 animals. Values significantly different from baseline levels $(0$ h) are indicated by asterisks $(p \leq 0.05)$. 


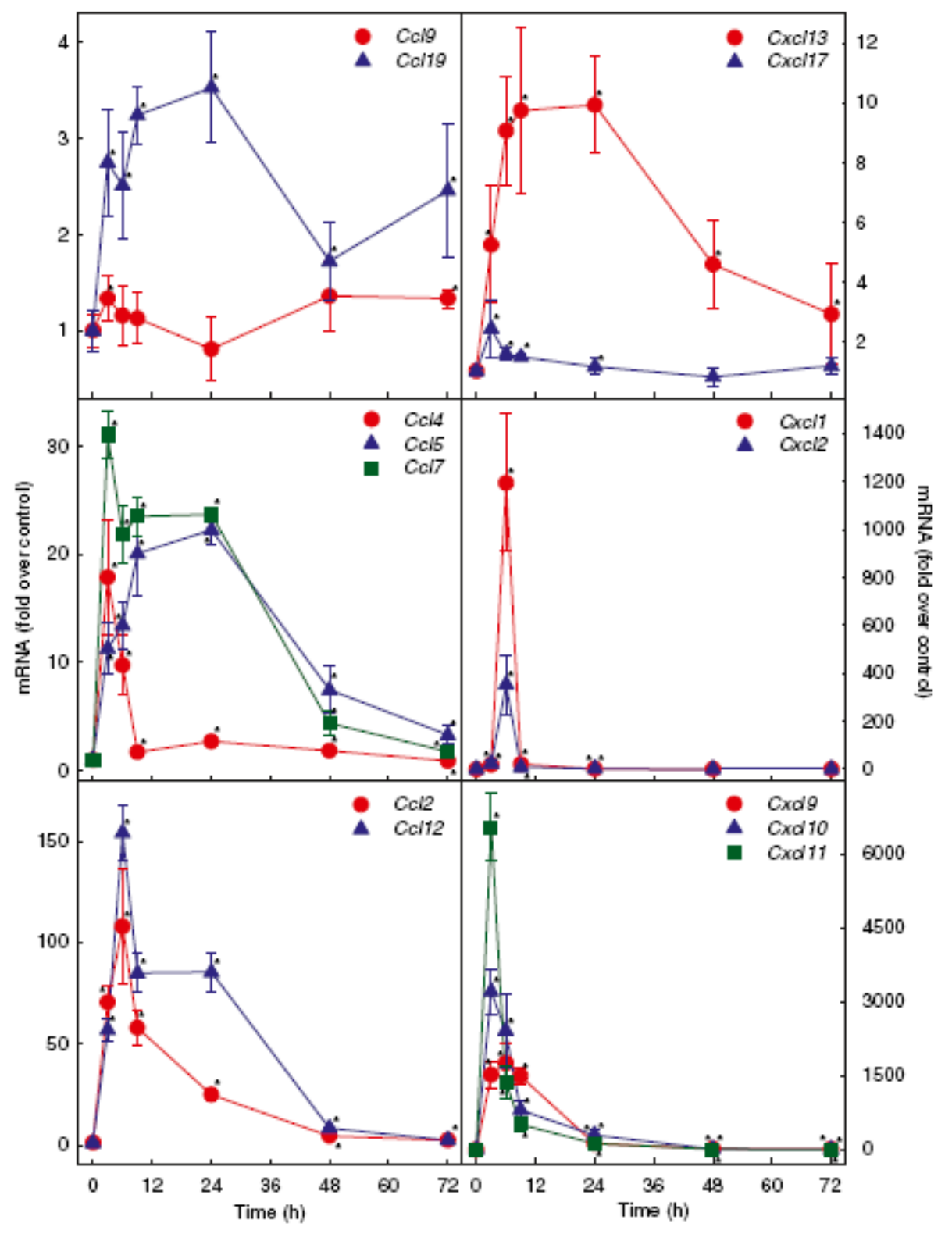

Figure 11. The expression of chemokine genes in the hippocampus following PIC challenge. Mice were i.p. injected with $12 \mathrm{mg} / \mathrm{kg}$ of PIC and the levels of selected chemokine mRNAs were determined in the hippocampi by qRTPCR at different time points as indicated. Data represent means \pm S.D. from 3-8 animals. Values significantly different from baseline levels $(0 \mathrm{~h})$ are indicated by asterisks $(p \leq 0.05)$.

Also, five genes encoding chemokine receptors were significantly upregulated several fold over the baseline by PIC challenge (Fig. 12). The Ccr1, Ccr6 and Ccr7 gene expression peaked at 3 $\mathrm{h}$, whereas the expression of the Cxcr2 and Cxcr5 genes was delayed and peaked at $9 \mathrm{~h}$. By $72 \mathrm{~h}$ after PIC challenge, the Ccr1 and Ccr7 genes featured approximately 2-fold upregulation, while expression of the $\mathrm{Cxcr} 2$ and $\mathrm{Cxcr} 5$ genes dwindled to the baseline levels. In contrast, the Ccr6 gene featured downregulation beginning at $48 \mathrm{~h}$ and dipped to over 2 -fold below control level at $72 \mathrm{~h}$. 


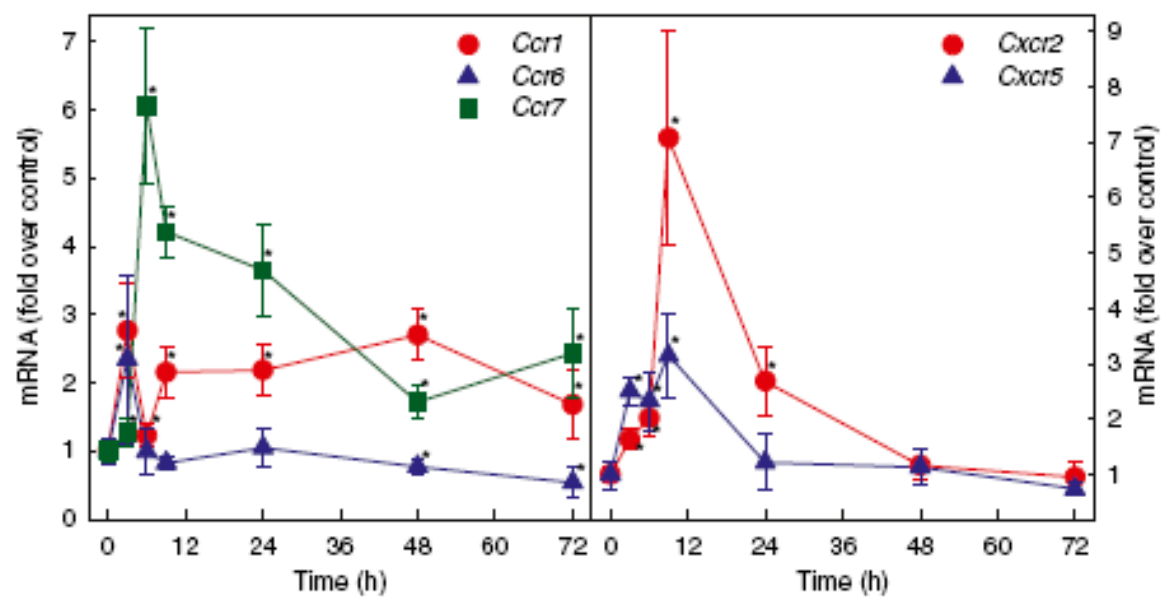

Figure 12. The expression of chemokine receptor genes following PIC challenge. Mice were i.p. injected with $12 \mathrm{mg} / \mathrm{kg}$ of PIC and the levels of selected chemokine receptor mRNAs were determined in the hippocampi by qRT-PCR at different time points as indicated. Data represent means \pm S.D. from 3-8 animals. Values significantly different from baseline levels $(0 \mathrm{~h})$ are indicated by asterisks ( $p \leq$ 0.05).

\section{Discussion}

We have demonstrated that the cytokine surge (Fig. 6; Cunningham et al 2007) is coincident with the upregulation of genes encoding the same cytokines in the hippocampus (Fig. 10). The brain cells including neurons, microglia and astrocytes express receptors for these cytokines (McCusker and Kelley, 2013). Ligation of these receptors with either peripherally-generated or brain-generated cytokines can lead to upregulated expression of the same or different cytokines. These, in turn, can further amplify the response through positive feedback loops. Such loops can also upregulate the expression of a slew of other inflammatory mediators as exemplified by chemokines (Fig. 11) and chemokine receptors (Fig. 12). Altogether, this neuroinflammatory response creates an intricate network of autocrine/paracrine and intracellular signaling pathways that may affect neuronal networks. For example, IL-1 $\beta$ and TNF $\alpha$ have an excitatory effect on hippocampal neurons by increasing ceramide synthesis within neurons and by the ensuing NMDA-mediated calcium influx (Viviani et al., 2007;Wheeler et al., 2009). IL-1 $\beta$ also inhibits glutamate reuptake via the downregulation of GLT-1 expression in astrocytes (Prow and Irani, 2008), which may further enhance excitability of neuronal circuits. Also, the injection of IL-1 $\beta$ into the hippocampus has been shown to increase the severity of limbic seizures (Vezzani et al., 2002). The protracted upregulation of the Tnfa and $/ / 1 \mathrm{~b}$ genes following PIC challenge (Fig. 10) further strengthens their putative role in the induction 
and sustenance of seizure hypersusceptibility. Although IL-6 and IFN $\beta$ seem not to directly affect neuronal networks, they amplify the effects of IL-1 $\beta$ and TNFa (McCusker \& Kelley 2013). Consistent with this amplifying role, overexpression of IL-6 results in severe neurologic impairment including seizures (Campbell et al., 1993).

A body of evidence also implicates several chemokines upregulated in the hippocampus by PIC challenge (Fig. 11) in the induction of neuronal hyperexcitability. Thus, genes encoding ligands of the CXCR3 chemokine receptor, i.e., CXCL9, CXCL10 and CXCL11, featured the highest upregulation. Neurons are the primary cell types that express CXCR3, and its ligation potently enhances electrical activity of hippocampal neurons (Nelson and Gruol, 2004). In addition, CXCR3 ligation alters the expression of several GABA and glutamate receptors (Cho et al., 2009). The genes encoding CXCL1 and CXCL2 chemokines also featured robustly upregulated expression following PIC challenge (Fig. 11). Moreover, the gene encoding their receptor, CXCR2, was also highly upregulated (Fig. 12). Signaling through CXCR2 has been shown to increase neuronal excitability, potentially through the association of CXCR2 with GluR1 AMPA receptors (Lax et al., 2002;Wang et al., 2008). CCL2, CCL4 and CCR7 are elevated in brain tissue from epilepsy patients, as well as in animal models (Fabene et al., 2010;Lehtimaki et al., 2003;Liimatainen et al., 2013;Vezzani et al., 2008; Vezzani et al., 2002;Hung et al., 2013). In concordance with this, we found the Ccl2 and Ccr7 genes to feature a prolonged upregulation following PIC challenge (Figs. 11 and 12). Furthermore, CCL2 and CCL4 seem to be crucial for epileptogenesis (Fabene et al., 2010;Kan et al., 2012). Altogether, the above data strongly implicate the role of cytokine and chemokine gene upregulation in PIC-induced seizure hypersusceptibility.

Although some of the genes discussed above displayed sharply transient upregulation, one has to be cognizant that transient expression of the mRNA does not necessarily translate to transient expression of the cognate protein. For example, the $C x c / 1$ and $C x c / 2$ mRNA peaked at $6 \mathrm{~h}$ but returned to the baseline at $9 \mathrm{~h}$ after PIC challenge (Fig. 11). However, the protein synthesized within 
this 9-h period may persist much longer. This argument also applies to the genes featuring protracted elevation of their mRNA. For example, the Ccl5 mRNA peaked at $24 \mathrm{~h}$ (Fig. 11), and albeit its levels gradually dropped, the cognate protein, CCL5, may have peaked later and been present at high concentrations during the whole period of hypersusceptibility, i.e., up to $72 \mathrm{~h}$. Finally, it should also be considered that even a short-term upregulation of an inflammatory gene may contribute to the hypersusceptible phenotype through the activation of downstream pathways.

Our lab has previously shown a quantitative variability in the response of inflammatory genes to PIC challenge among the major subdivisions of the brain: the forebrain (minus hippocampus), brain stem and cerebellum (Konat et al., 2009; Fil et al., 2011). In general, the cerebellum featured the highest upregulation of these genes. For example, the maximal upregulation of the $111 \mathrm{~b}, 116$ and Cxc/11 genes in the cerebellum was approximately four-fold higher than the respective values for the forebrain. The comparison of the present results from the isolated hippocampus (Figs. 10 and 11) to the whole forebrain (Konat et al., 2009; Fil et al., 2011) reveals further regional heterogeneity. Thus, among the 23 hippocampal genes studied three were significantly less upregulated and four were significantly more upregulated in comparison to the whole forebrain (Table 1). In the most extreme case, the peak upregulation of the Ifnb gene was 50 times lower in the hippocampus than in the whole forebrain. On the other hand, the $C x c / 11$ gene was nine-fold more robustly upregulated in the hippocampus in comparison with the whole forebrain. Clearly, the hippocampal cells feature a highly specific pattern of genetic response to PIC challenge vs. the average forebrain cell.

Table 1. Maximal upregulation of selected cytokine and chemokine genes in the forebrain vs. hippocampus in response to PIC challenge.

\begin{tabular}{|l|c|c|c|}
\hline Gene & Hippocampus $(\mathrm{H})$ & Forebrain $^{(\mathrm{F})}{ }^{\#}$ & $\mathrm{H} / \mathrm{F}$ \\
\hline Ifnb & $4.05 \pm 1.14$ & $201.55 \pm 37.00^{*}$ & 0.02 \\
\hline Ccl5 & $20.03 \pm 3.88$ & $132.60 \pm 30.01^{*}$ & 0.15 \\
\hline Ccl2 & $107.94 \pm 28.26$ & $215.05 \pm 51.11^{*}$ & 0.50 \\
\hline Cxcl11 & $6547.68 \pm 692.19$ & $720.88 \pm 101.16^{*}$ & 9.1 \\
\hline Ccl12 & $154.19 \pm 13.80$ & $20.50 \pm 7.01^{*}$ & 7.5 \\
\hline Cxcl10 & $3213.78 \pm 458.29$ & $1112.07 \pm 93.22^{*}$ & 2.9 \\
\hline Cxcl1 & $1192.98 \pm 285.75$ & $718.50 \pm 111.02^{*}$ & 1.7 \\
\hline \multicolumn{4}{|l}{ \#data from Konat et al $(2009)$ and Fil et al $(2011) ;{ }^{*} p \leq 0.05$}
\end{tabular}




\subsection{Neurotransmission-related genes}

The previous experiments illustrated that peripheral APR results in a robust inflammatory response in the hippocampus (Fig. 10,11, \& 12). Furthermore, a number of the inflammatory genes upregulated by PIC challenge have been linked to changes in neural excitability and the expression of several genes related to neurotransmission. Thusly, inflammation-induced changes in the expression of neurotransmitter receptors (Guo et al., 2002; Harre et al., 2008;Galic et al., 2012) may provide a mechanism by which peripheral APR enhances seizure susceptibility.

While the complexities of the system continue to impede consensus on an overall mechanism for seizure, prevailing theories hinge on neurotransmitter receptors; specifically their relationship to increased glutamatergic neurotransmission and/or decreased GABAergic signaling (CasillasEspinosa et al., 2012;Gonzalez 2013;Werner and Covenas, 2011). There is also strong support for the involvement of metabolic breakdown of the neuron-astrocyte network in seizure development which ultimately results in the persistence of excitatory molecules in the synapse (Seifert and Steinhauser, 2013).

Previously, LPS has been shown to alter the expression of glutamatergic kainate receptor genes in the spinal cord (Guo et al., 2002), as well as genes encoding NMDA receptors in the hippocampus (Harre et al., 2008). Furthermore, a recent study of prenatal PIC exposure found changes in the GluR1 NMDA receptor subunit at post-natal day 21 in mice (Forrest et al., 2012). These studies support our notion that inflammation can instigate changes in neurotransmissionrelated proteins.

To evaluate this theory, we screened the expression of genes encoding all glutamatergic and GABAergic neurotransmitter receptors by qRT-PCR and found nine genes to be significantly altered by PIC challenge (Fig. 13). These genes were: the kainate receptor gene Grik3, the AMPA receptor gene Gria4, the metabotropic glutamate receptor genes Grm1, Grm6, and Grm7, and the GABA $A_{A}$ receptor subunit genes Gabrq, Gabre, Gabrr2, and Gabrr3. The Grik3, Gria4, Grm6, Gabrq, Gabrr2 
and Gabrr3 genes showed initial several-fold upregulation coincident with the blood cytokine surge that peaked 3-6 $\mathrm{h}$ after PIC injection. While the expression of five of these genes gradually returned to the baseline level, the upregulation of the Gabrr3 gene was protracted and its mRNA level at $72 \mathrm{~h}$ was approximately 2-fold over control. The Grm6 gene featured moderate upregulation after $48 \mathrm{~h}$, reaching approximately 1.5 - fold over the control level at $72 \mathrm{~h}$. In contrast, the Grm7, Grm1 and Gabre displayed initial downregulation by approximately 2-fold, followed by normalization.

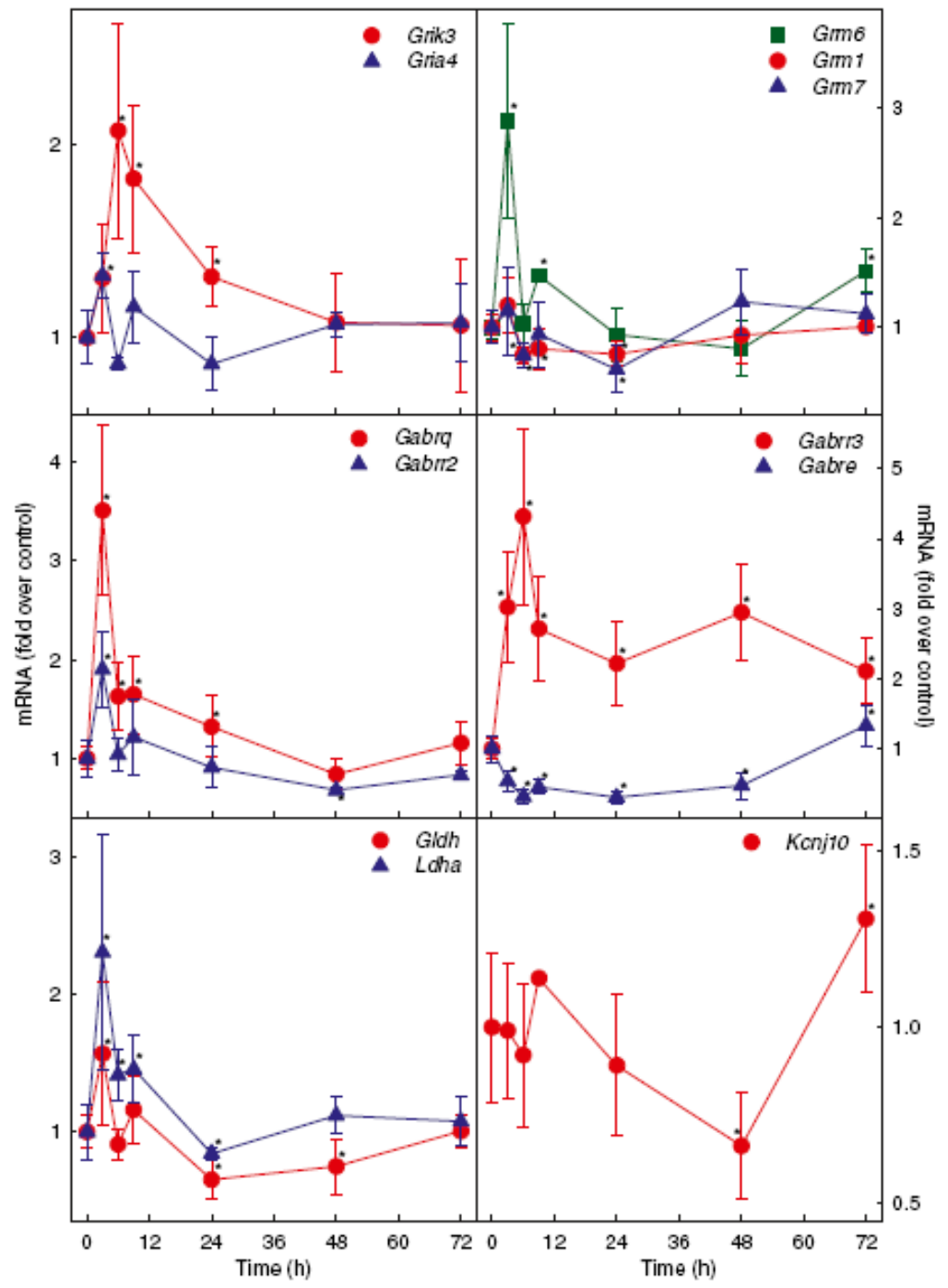

Figure 13. The expression of neurotransmissionrelated genes following PIC challenge. Mice were i.p. injected with $12 \mathrm{mg} / \mathrm{kg}$ of PIC. At different time points, mRNA levels of selected neurotransmitter receptors and proteins involved in synaptic buffering of glutamate and potassium were determined in the hippocampi by qRT-PCR. Data represent means \pm S.D. from 3-6 animals. Values significantly different from baseline levels $(0 \mathrm{~h})$ are indicated by asterisks $(p \leq 0.05)$.

In addition, we found the expression of three genes whose products are involved in synaptic buffering of glutamate and potassium to be significantly altered by PIC challenge. As shown in Fig. 13, the lactate dehydrogenase A gene (Ldha) was rapidly upregulated at $3 \mathrm{~h}$ post-PIC injection and gradually returned to the baseline level. The expression of the glutamate dehydrogenase gene (Gldh) also peaked at $3 \mathrm{~h}$ but featured subsequent downregulation below control level at $24 \mathrm{~h}$. Its expression 
gradually returned to the baseline by $72 \mathrm{~h}$. The expression of the Kcnj10 gene encoding the inward rectifying potassium channel Kir4.1 was not affected during the blood cytokine surge, but featured a gradual downregulation thereafter, reaching a nadir at $48 \mathrm{~h}$ and returning to the baseline level at $72 \mathrm{~h}$ (Fig. 13).

\section{Discussion}

Prevailing theories behind seizure development and epileptogenesis converge upon changes in neuronal excitation and inhibition. In support of this notion, we found altered expression of a number of hippocampal genes encoding neurotransmitter receptors (Fig. 13) in the same time frame as the blood cytokine surge (Fig. 6) and the rapid upregulation of inflammatory genes (Fig. 10, 11, \& 12). Although the significance of these changes must be verified at the protein level and through functional analysis, tentative correlations can be inferred from the changes in the mRNA levels. For example, the upregulation of the Grik3 gene (Fig. 13) may contribute to the hypersusceptible phenotype, as long-lasting kainate receptor-mediated events have been associated with sustained, rhythmic firing in a rodent model of temporal lobe epilepsy (Artinian et al., 2011). This increase in the expression of Grik3 could explain the increased response to kainic acid in our model. However, a preliminary study using extracellular electrophysiological recordings in mouse hippocampal slices found that PIC enhanced both the amplitude and frequency of 4-aminopyridine-evoked interictal activity (data not shown). Further studies are necessary to determine whether the brain is generally hyperexcitable or more responsive to kainic acid. The $\mathrm{GABA}_{A}-\varepsilon$ subunit, encoded by the Gabre gene,

is associated with increased spontaneous channel activity (Bollan et al., 2008), and therefore, the prolonged downregulation of the Gabre gene following PIC challenge (Fig. 13) may increase hyperexcitability by impeding spontaneous inhibitory currents. Also, the GRM7 receptor negatively regulates GABAergic inhibition (Casillas-Espinosa et al., 2012), and knockout of the Grm7 gene results in increased susceptibility to seizures (Sansig et al., 2001). Thus, the downregulation of the 
Grm7 gene induced by PIC challenge (Fig. 13) is consistent with the gene's contribution to the hypersusceptible phenotype. However, two metabotropic glutamate receptor genes revealed unpredicted changes. Thus, while the GRM1 receptor tends to be pro-epileptic (Ure et al., 2006), the Grm1 gene was downregulated following PIC challenge (Fig. 13). Likewise, the upregulation of the Grm6 gene (Fig. 13) is incongruent with the function of GRM6 receptor that negatively regulates glutamate release, and therefore is protective against seizures (Ure et al., 2006).

As noted, LPS challenge has been shown to alter expression of the Grik1 and Grik2 genes in the spinal cord (Guo et al., 2002), as well as the genes encoding NMDA receptors in the hippocampus (Harre et al., 2008). We did not observe changes in these genes following PIC challenge suggesting a divergence in the cerebral effects of APR induced by bacterial vs. viral inflammagens. This is consistent with the differences in seizure response and cytokine production between LPS and PIC discussed previously (see Chapter 2: Conclusions, p. 14).

In addition to neurotransmitter imbalances, dysfunction in the metabolic coupling between neurons and astrocytes may be causative of hyperexcitation, seizure spread and neurotoxicity (Seifert and Steinhauser, 2013). PIC challenge upregulated the Ldha and downregulated the Gldh genes (Fig. 13) that encode two key metabolic enzymes involved in glutamate recycling. Such enzymatic changes are expected to enhance the accumulation of extracellular glutamate resulting in hyperexcitation. Our results are concordant with previous studies that found the same changes in epilepsy patients and animal kindling models (Erakovic et al., 2001;Malthankar-Phatak et al., 2006). Moreover, another astrocytic gene, the Kcnj10 gene that encodes potassium channel Kir4.1 featured a transient downregulation (Fig. 13). Reduced expression of Kir4.1 has been found in patients with congenital epilepsy (Bockenhauer et al., 2009), and conditional knockout of Kcnj10 in mice results in the development of stress-induced seizures through increased synaptic potentiation (Djukic et al., 2007). 


\section{3. microRNAs}

microRNAs (miRs) are short ( 22 nucleotides), endogenously expressed, non-coding RNAs that have emerged as important regulators of gene expression. Typically, miRs exact their control at the post-transcriptional level by binding to target mRNAs and causing the message to be degraded or translation of the message to be repressed (Petersen et al., 2006). However, miRs can also suppress gene transcription (Younger and Corey, 2011). Each miR can bind to hundreds of target genes including regulatory and transcription factors and through their complex interaction with each other and their target genes can execute system wide regulation of the genome. Most interestingly, several miRs that are highly expressed in the brain are also involved in immune function, identifying them as potential targets of immune-to-brain communication (Soreq and Wolf, 2010).

The regulation of cerebral miRs is associated with several physiological and pathological processes. Recent research has implicated a few of these miRs in the pathology of seizures (Jimenez-Mateos et al., 2011; Hu et al., 2011;Aronica et al., 2010;Liu et al., 2010). Furthermore, these miRs can influence neurotransmitter receptor signaling and synaptic activity (Edbauer et al., 2010; Siegel et al., 2011;Soreq and Wolf, 2010). Taken together, these observations suggest that miR signaling, specifically of those shown to modulate both neural and immune functions (Soreq \& Wolfe, 2011) and miRs associated with seizure pathology (Jimenez-Mateos et al., 2011;Hu et al., 2011;Liu et al., 2010;Aronica et al., 2010), represent a potential mechanism for the immune-to-brain communication responsible for "sickness behavior" and PIC-induced seizure hypersusceptibility.

We screened expression of these miRs in the hippocampus following PIC challenge and identified ten species whose expression underwent significant changes (Fig. 14). Generally, the levels of these miRs changed in an oscillating manner. During the first $9 \mathrm{~h}$ after PIC challenge, the levels of miR-128-3p, miR-509-5p, miR-28a-5p, miR-138-5p and miR-466i-5p were initially increased and then decreased below control, whereas the levels of miR-188-5p, miR-302a-5p and miR-221-3p were initially downregulated. At $24 \mathrm{~h}$, the levels either returned to baseline (miR-28a-5p, miR-138-5p, miR- 
128-3p, miR-509-5p, miR-188-5p and miR-302a-5p) or underwent secondary upregulation (miR-466i$5 p$ and miR-221-3p). Two species, miR-132-3p and miR-181a-5p, were not changed during the blood cytokine surge but were upregulated at $24 \mathrm{~h}$. At $72 \mathrm{~h}$, the expression of miR-302a-5p was downregulated by approximately 2 -fold below the baseline. miR-28a-5p and miR-138-5p were slightly downregulated, while miR-466i-5p, miR-221-3p and miR-128-3p were slightly upregulated.

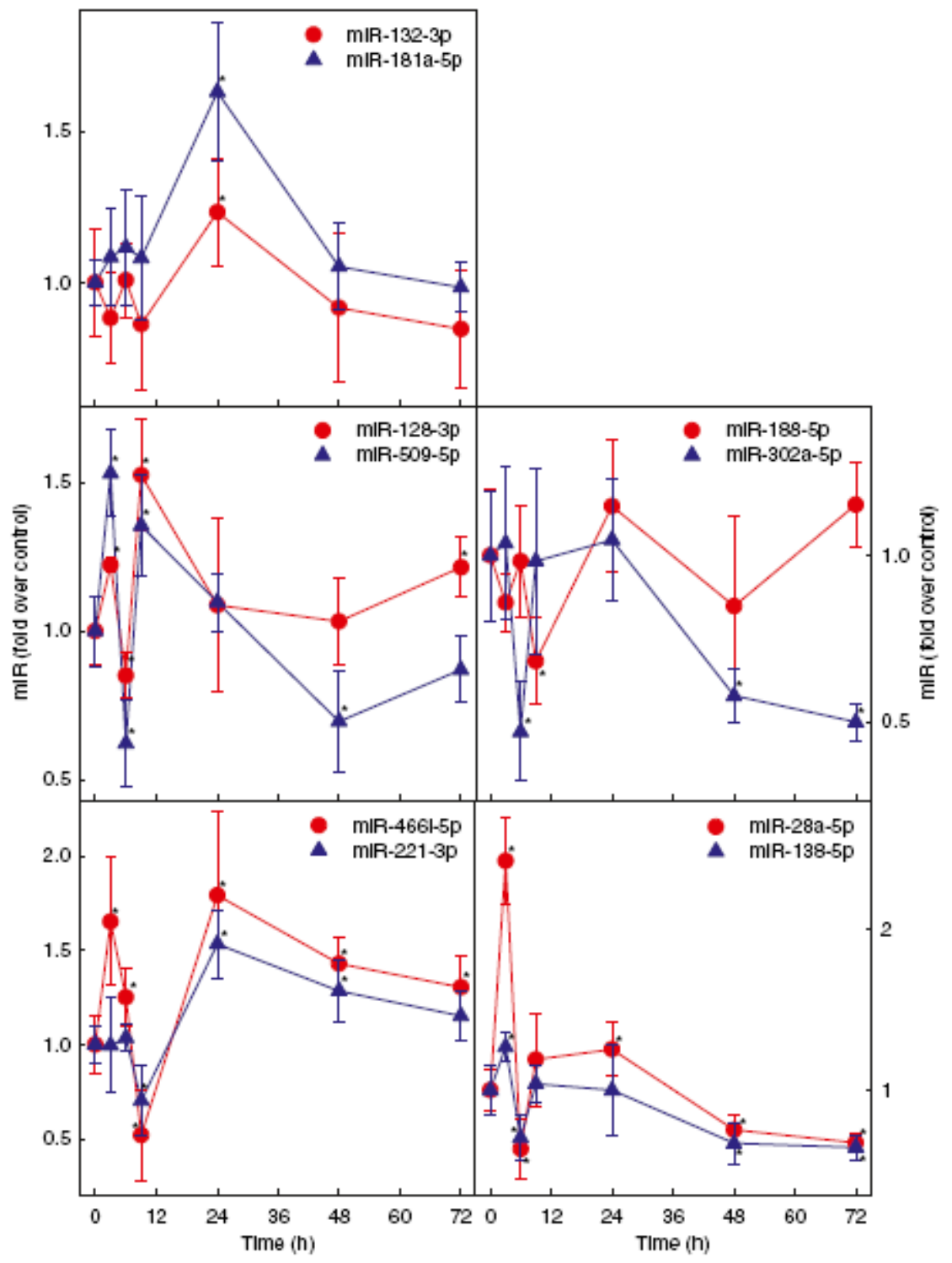

Figure 14. The expression of hippocampal miRs following PIC challenge. Mice were i.p. injected with $12 \mathrm{mg} / \mathrm{kg} P I C$ and the levels of selected miRs were determined in the hippocampi by qRT-PCR at different time points as indicated. Data represent means \pm S.D. from 3-8 animals. Values significantly different from baseline levels $(0 h)$ are indicated by asterisks $(p \leq 0.05)$.

\section{Discussion}

Current knowledge regarding miR expression in seizures is exclusive to post-epileptic tissue, while we are investigating a "pre"-seizure event. Therefore, the putative involvement of miRs in peripheral APR-induced seizure hypersusceptibility is a novel concept. Although it is hard to interpret 
the role of these miRs in the development of hyperexcitability, other studies provide some clues. For example, miR-132 and miR-138 are associated with changes in synaptic spine morphology and excitability. Specifically, the upregulation of miR-132-3p and downregulation of miR-138-5p observed in our study has been shown to result in larger, stubby spines and an increase in mEPSC frequency (Edbauer et al., 2010;Siegel et al., 2009). Alterations in other miRs have been associated with changes in cell migration, proliferation and differentiation, the features involved in the development of hippocampal hyperexcitability (Parent et al., 1997). Thus, the upregulation of miR-128 has been associated with increased cell number and neurite length (Guidi et al., 2010), as well as with enhanced mobility through the downregulation of reelin and doublecortin (Evangelisti et al., 2009). Doublecortin seems to be critical for normal hippocampal excitability, as doublecortin knockout mice exhibit spontaneous seizures that originate in the hippocampus (Nosten-Bertrand et al., 2008). In the adult brain, doublecortin expression is associated with seizure-induced neurogenesis in the hippocampus (Couillard-Despres et al., 2005), which is believed to facilitate aberrant neural connections (reviewed in Kokaia 2011). Furthermore, miR-302a-5p negatively regulates the CXCR4 pathway (Fareh et al., 2012) that is important in cell migration in the developing and adult hippocampus (Bagri et al., 2002; Stumm and Höltt, 2007). Therefore, the downregulation of miR-302a in response to PIC challenge might result in the upregulation of CXCR4 leading to hyperexcitability. Finally, a recent microarray study identified several miRs, including miR-132-3p, miR-138-5p, miR181a and miR-221-3p analyzed in this study, that are differentially expressed following pilocarpineinduced status epilepticus (Risbud and Porter, 2013).

\subsection{Genome-wide microarray}

The polygenic response observed in the previous experiments indicating a widespread genetic reprograming of hippocampal cells warranted further, more comprehensive genetic studies to delineate molecular/cellular pathways that govern the development of hippocampal hyperexcitability. 
To gather a more global perspective of the genomic alterations induced in the hippocampus by peripheral inflammation, we performed a genome-wide array study of the hippocampus of PIC challenged mice. A total of 625 differentially expressed genes (DEGs) were identified across all time points $(6,24$, and $48 \mathrm{~h})$ when compared to control $(0 \mathrm{~h})$, with 98 DEGs common amongst the three comparison groups (Fig. 15). Bioinformatics analysis revealed the complement and coagulation pathway to be the most significantly affected pathway in the hippocampus by the peripheral inflammation (Table 1, $P=9.27 \times 10^{-5}$ ). Furthermore, four other pathways were significantly affected by PIC challenge (Table 1). In agreement with the robust inflammatory response seen in the brain following peripheral inflammation (Fil et al., 2011; Konat et al., 2009; Fig. 10, 11, \& 12), the majority of these pathways are related to immune function or pathology.

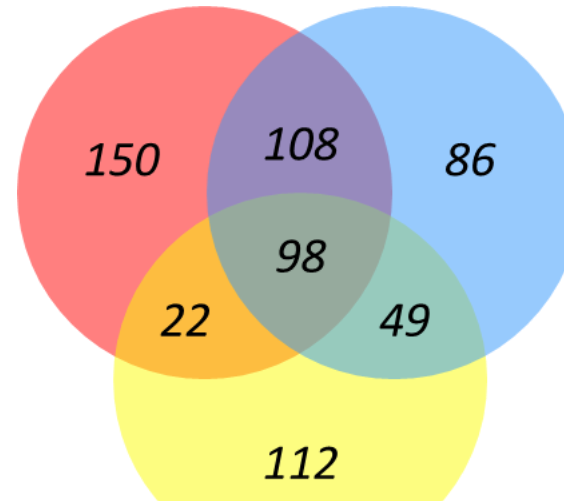

Figure 15. Peripheral inflammation triggered by PIC challenge alters hippocampal gene expression. Mice were i.p. injected with $12 \mathrm{mg} / \mathrm{kg}$ of PIC. After 0, 6, 24 and 48 h, hippocampal gene expression was profiled by microarray analysis as described in Materials and Methods (Chapter 5). The Venn diagram shows differentially expressed genes (DEGs) identified by the average difference from three animals $(n=3)$. Red circle, difference between 0 and $6 h$; blue circle, difference between 0 and $24 h$; yellow circle, difference between 0 and $48 h$ after PIC injection. The numbers denote the number of genes.

Table 2. Hippocampal pathways significantly affected by i.p. injection of PIC.

\begin{tabular}{|c|c|c|c|}
\hline Rank & Pathway name & No. of DEGs & $p$-value \\
\hline 1 & Complement and coagulation & 9 & $9.27 \times 10^{-5}$ \\
\hline 2 & Toll-like receptor signaling & 10 & $4.40 \times 10^{-4}$ \\
\hline 3 & Systemic lupus erythematous & 9 & $3.26 \times 10^{-3}$ \\
\hline 4 & Proteosome & 4 & $2.79 \times 10^{-2}$ \\
\hline 5 & Epithelial cell signaling in H. pylori infection & 5 & $3.43 \times 10^{-2}$ \\
\hline
\end{tabular}

\subsection{Conclusions}

The experiments presented in this chapter illustrate that peripheral APR induced by PIC challenge results in extensive genomic reprogramming of the hippocampus. This is exemplified by the gene expression changes observed for inflammatory (Fig. 10, 11, \& 12) and neurotransmission- 
related genes (Fig. 13), miRs (Fig. 14), and the 625 DEGs identified by the microarray (Fig. 15). Consistent with the robust cerebral inflammatory response presented in previous studies (Cunningham et al., 2007;Konat et al., 2009;Fil et al., 2011), the five significantly altered pathways identified from the microarray data comprise mostly immune-related pathways (i.e. complement and coagulation, toll-like receptor signaling, systemic lupus erythematous, and cell signaling in $\mathrm{H}$. pylori infection) (Table 2). The association of a number of the altered hippocampal genes identified in these studies with seizure and/or neuronal hyperexcitability exemplifies their potential involvement in the development of seizure hypersusceptibility following peripheral challenge with PIC.

\subsection{Contributions}

Portions of this chapter were taken from a previously published manuscript (Michalovicz and Konat 2014); see Appendix I. The microarray experiment was performed at the University of Pittsburgh Genomics and Proteomics Core Laboratories. 


\section{Chapter 4: Peripheral challenge with PIC upregulates complement and activates microglia}

\subsection{Complement genes}

Classically, the complement system functions as part of innate immunity where its component proteins aid in the opsonization and clearance of pathogens. However, complement has more recently been identified to serve a role in brain development and neuropathology. By opsonizing extraneous synapses, complement aids in the pruning of these synapses by microglia, a necessary process for the proper development of neural circuits (Schafer et al., 2012;Stephan et al., 2012; Stevens et al., 2007). Complement is also found to be highly upregulated in the brain in multiple sclerosis, Alzheimer's disease, Parkinson's disease, and Huntington's disease (Stephan et al., 2012). In this instance, the system targets degenerating neurons for phagocytosis and may also perpetuate neurodegeneration through the weakening of complement-tagged synapses. Furthermore, increases in cerebral complement have been associated with epilepsy and epileptogenesis, both clinically and experimentally (Jamali et al., 2010; Kharatishvili et al., 2013;Libbey et al., 2010).

Expanding upon the results of the microarray study, we evaluated the temporal hippocampal expression of the genes encoding the complement proteins by qRT-PCR (Fig. 16). Bioinformatics analysis identified 9 DEGs from our data set that are involved in complement and coagulation (Table 2). qRT-PCR confirmed 8 of the 15 complement genes screened to be dysregulated in the hippocampus by PIC challenge. Of these genes, all were significantly up-regulated (C1qa, C1qb, C1qc, C2, C3, C4, C6, and Cfb) and peaked at $24 \mathrm{~h}$ post-PIC challenge. Furthermore, all but C1qC demonstrated protracted upregulation over the time frame of hyperexcitability (24-72 h; Fig. 4). The genes encoding complement factor B (Cfb), 6 , and $\mathrm{C} 3$ showed the highest levels of up-regulation of 53-, 40-, and 12-fold, respectively. The genes encoding C5, C7, C8 complex and C9 displayed very low and highly variable expression in all regions of the brain resulting in no significant dysregulation of these genes following PIC challenge. The upregulation of the $\mathrm{Cfb}, \mathrm{C} 3$ and $\mathrm{C} 1 \mathrm{q}$ mRNA also resulted in 
the upregulation of the protein levels as revealed by immunohistofluorescence (Fig. 17). All three proteins featured neuronal expression in control (saline injected) mouse hippocampi. This basal expression was profoundly elevated by PIC challenge. The increased staining was evident within the neuronal perikarya and in the extracellular milieu. No expression of these proteins was detectable in microglia or astrocytes (not shown).

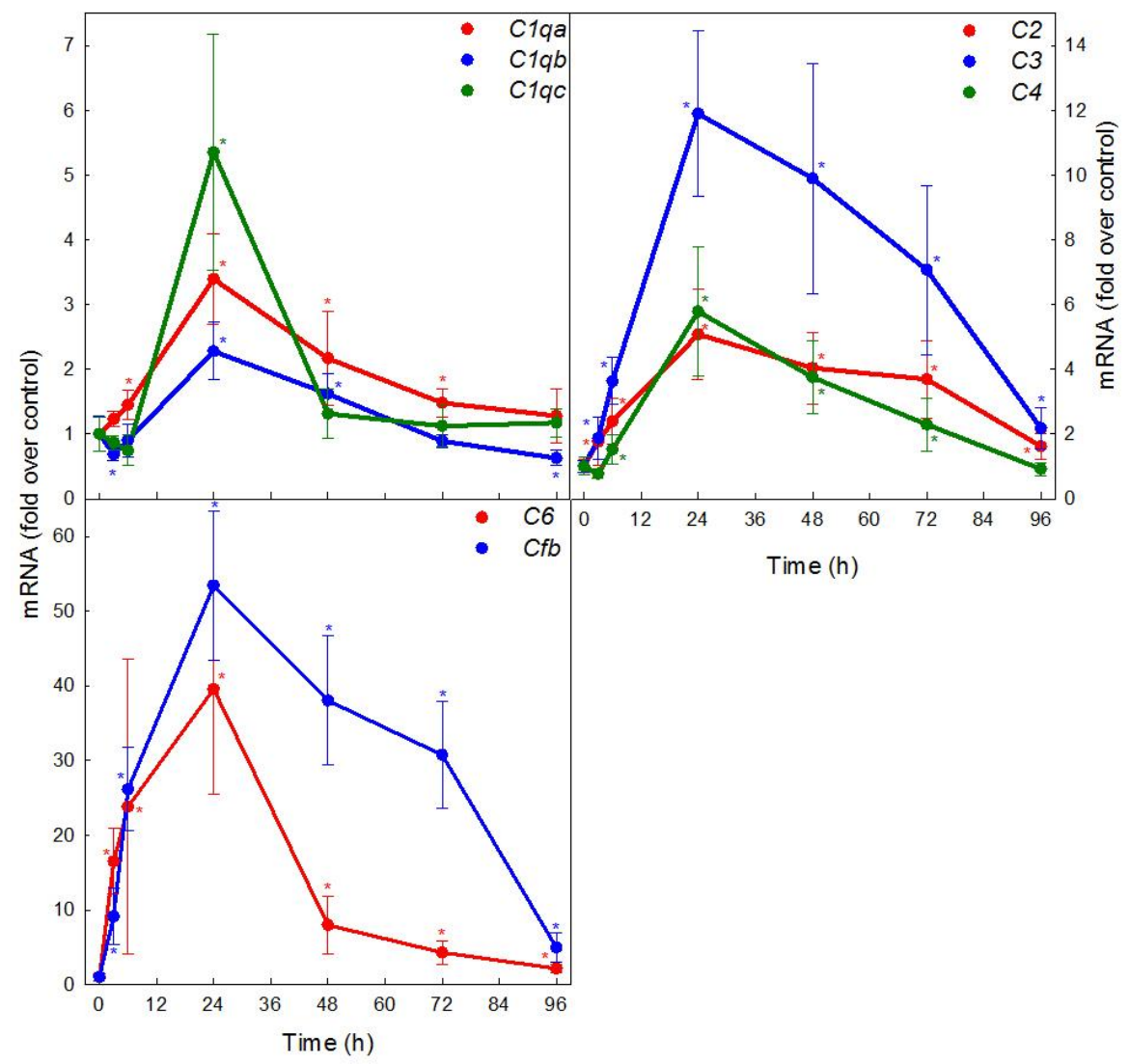

Figure 16. PIC challenge alters the expression of complement genes in the hippocampus. Mice were i.p. injected with $12 \mathrm{mg} / \mathrm{kg}$ of PIC and the levels of complement mRNAs were determined in the hippocampi by qRT-PCR at different time points as indicated. Data represent means \pm S.D. from 3-8 animals. Values significantly different from baseline levels $(0 \mathrm{~h})$ are indicated by asterisks $(p \leq 0.05)$.

$\mathrm{C} 1 \mathrm{q}$
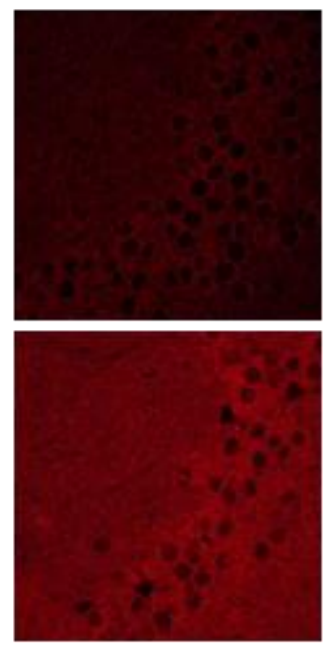

$\mathrm{CfB}$
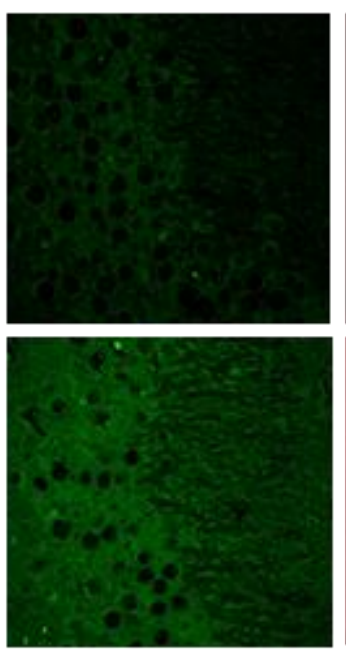

$\mathrm{C} 3$
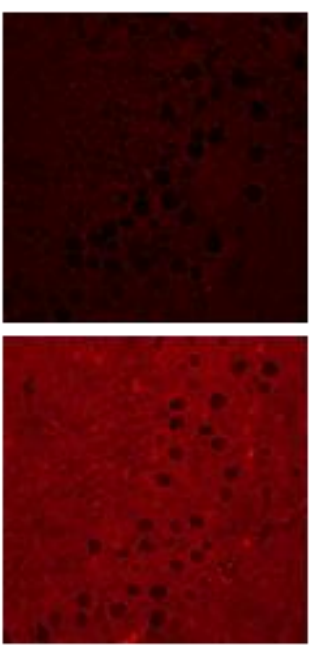

Figure 17. Expression of complement proteins in the hippocampus instigated by PIC challenge. Following PIC challenge, the brains were prepared and analyzed by immunofluorescence as described in Materials and Methods (Chapter 5). The expression of complement proteins was analyzed by confocal microscopy at 0 and 24 $h$. 
Previous studies from our lab have shown that the robust upregulation of chemokine and cytokine genes by peripheral PIC challenge is not restricted to particular brain regions, but occurs globally across all areas of the brain (Fil et al., 2011; Konat et al., 2009). In the current study, we found that the complement encoding genes showed similar temporal expression patterns across all brain regions (data not shown). However, there were differences in the magnitude of upregulation in the forebrain, cerebellum, and brain stem in comparison to the hippocampus for several genes (Fig. 18). At $24 \mathrm{~h}$ post-challenge, $C 1 \mathrm{qb}$ and $C 4$ were more strongly upregulated in forebrain, cerebellum, and brain stem when compared to hippocampal expression. We also found C1qa to have a more robust upregulation in the forebrain and brainstem. In contrast, $C 6$ was not as highly upregulated in forebrain and cerebellum and was nearly undetectable in the brain stem by qRT-PCR. We found the overexpression of $C 3$ to be less pronounced in the forebrain and brain stem when compared to the hippocampus. The upregulation of $\mathrm{C} 2$ and $\mathrm{Cfb}$ mRNAs was relatively consistent across all brain regions except in the cerebellum and forebrain, respectively.

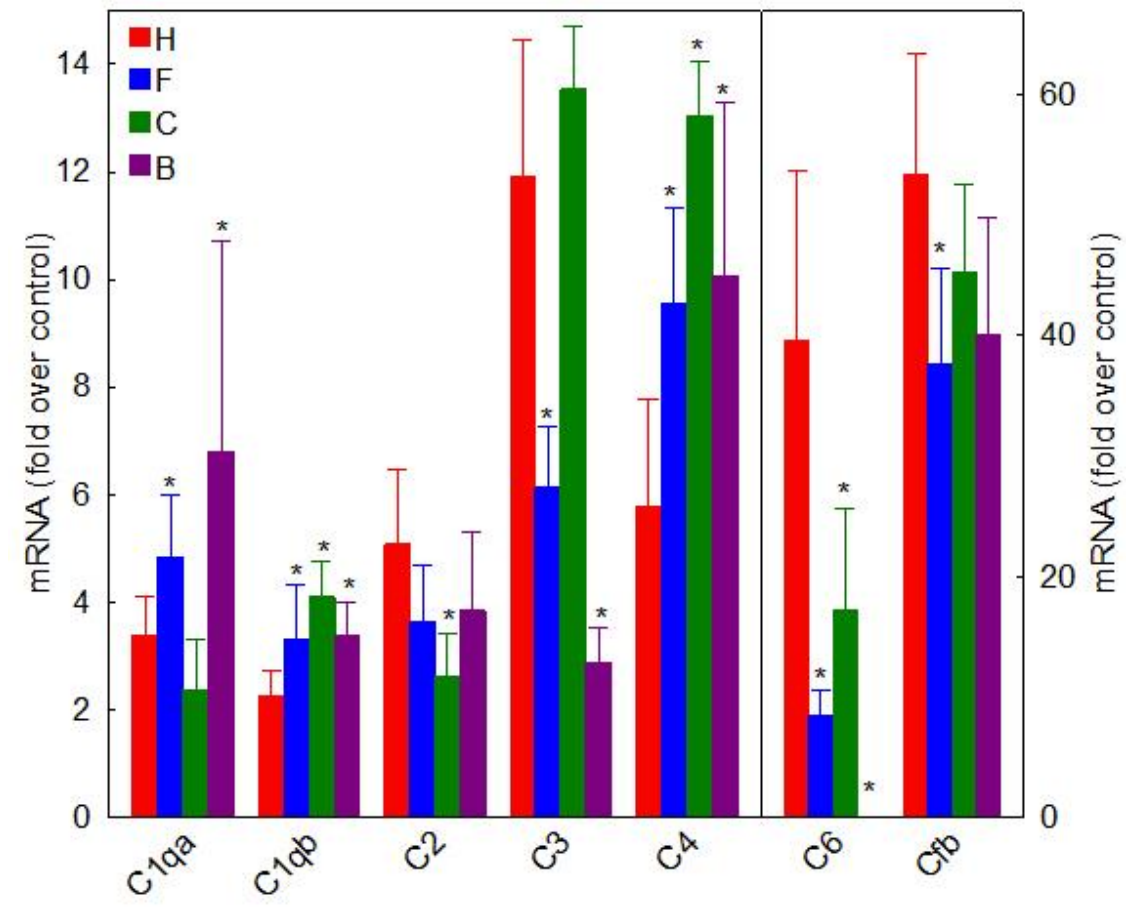

Figure 18. Regional expression differences of complement genes following i.p. PIC challenge. Mice were i.p. injected with 12 $\mathrm{mg} / \mathrm{kg}$ of PIC and the levels of complement mRNAs were determined in the hippocampus $(H)$, forebrain $(F)$, cerebellum (C), and brain stem (B). All data points represent the 24 h post-PIC challenge time point. Data represent means \pm S.D. from 38 animals. Values significantly different from hippocampus levels $(H)$ are indicated by asterisks $(p \leq 0.05)$.

\subsection{Activation of microglia}

Complement has been demonstrated to promote synaptic stripping by microglia (Schafer et al., 2012; Stevens et al., 2007). Resting microglia establish frequent but transient contacts with synapses 
(Wake et al., 2009). Because microglia express complement receptor 3 that recognizes C3 and/or C5, synapses tagged with complement complexes activate microglia (Ilschner et al., 1996; Schafer et al., 2012; Zhang et al., 2014). Activated microglia migrate to and engulf neuronal perikarya and proximal dendrites. Their processes extend to and modify complement-tagged synapses ( $\mathrm{Ji}$ et al., 2013; Kettenmann et al., 2013). In a preliminary investigation, we found that PIC challenge induces activation of hippocampal microglia as evident from their hypertrophied "bushy" morphology (Fig. 19, top panel). We also observed microglia in close apposition to neuronal perikarya and proximal dendrites in the hippocampi of PIC challenged mice (Fig. 19, bottom panel).

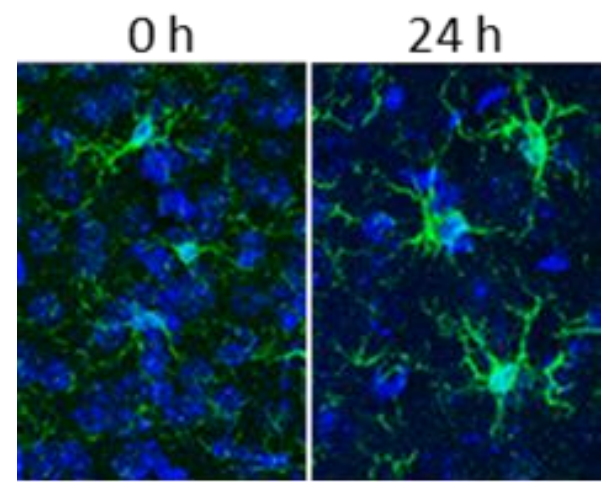

Figure 19. Morphological changes and migration of microglial cells instigated by PIC challenge. Following PIC challenge, the brains were prepared and analyzed by immunofluorescence. Microglia were stained with Iba1 (green) while neurons were stained with NeuN (red), and the

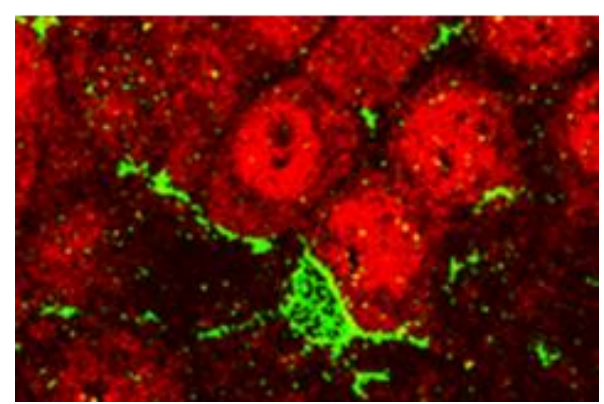
cells were visualized by confocal microscopy. Top panel; Hypertrophy of microglia. Bottom panel; Close apposition of a microglial cell to a neuron 24 h post-PIC challenge.

\subsection{Conclusions}

We chose to do more in-depth investigation into the complement pathway due to its recent emergence as a regulator of neuronal excitability through synaptic pruning (Chen et al., 2014;Schafer et al., 2012;Stephan et al., 2012;Stevens et al., 2007). In contrast to the expression of inflammatory cytokines, chemokines, and chemokine receptors (Fig. 10, 11, \& 12) which peaked around 3-6 h, the complement genes universally reached maximal upregulation at $24 \mathrm{~h}$ (Fig. 16). Furthermore, while the majority of cytokines and chemokines were only transiently upregulated (Fig. 10 \& 11), most 
complement genes remained significantly elevated over the full time frame of seizure hypersusceptibility (24-72 h; Fig. 4). This upregulation of complement was also seen at the protein level (Fig. 17). The expression pattern observed in the hippocampus was generally consistent across all areas of the brain, with discrete regions exhibiting differences in the magnitude of upregulation (Fig. 18).

The complement system consists of three overlapping pathways: classical, alternative, and lectin. The classical pathway is activated by $\mathrm{C} 1 \mathrm{q}$, while the alternative pathway is activated by the spontaneous cleavage of $\mathrm{C} 3$ and it's binding to $\mathrm{Cfb}$ (outlined in Fig. 20). The lectin pathway is less likely to be involved in our PIC model, as it is generally activated by bacterial, not viral, infection. Our gene expression data for the complement components suggests that the classical and alternative pathways are highly likely to be affected by PIC challenge due to the upregulation of the genes encoding C1q, C3 and Cfb (Fig. 16). The robust expression of C3 combined with the overexpression of the components of the $\mathrm{C} 3$ convertases (C2, C4 and Cfb) (Fig. 16) increase the potential for high levels of the C3b fragment in the hippocampus. This is an important observation, because C3b is the main complement component responsible for opsonization of synapses resulting in their pruning by microglia (Schafer et al., 2012). Activation of the complement pathways leads to the downstream formation of the membrane attack complex (MAC), which forms pores in the membranes of target cells. While C6, a component of the MAC, is highly upregulated following PIC (Fig. 16), none of the other components (C5, C7, C8, or C9) are altered. However, as evidenced from the detectable basal expression of C1q, C3 and Cfb (Fig. 17, Oh), these other complement proteins may have a significant basal level of expression in the brain that would allow for the activation of the complement pathway leading to the formation of the MAC.

In accordance with this, we also have preliminary observations of the activation of microglia and their close association with neuronal cell bodies (Fig. 19), suggesting that PIC-induced complement expression may promote synaptic stripping (Fig. 21). Furthermore, microglia have been 
shown to selectively displace presynaptic terminals of inhibitory neurons resulting in neuronal hyperexcitability (Chen et al., 2014). Figure 21 depicts a putative mechanism of this process.

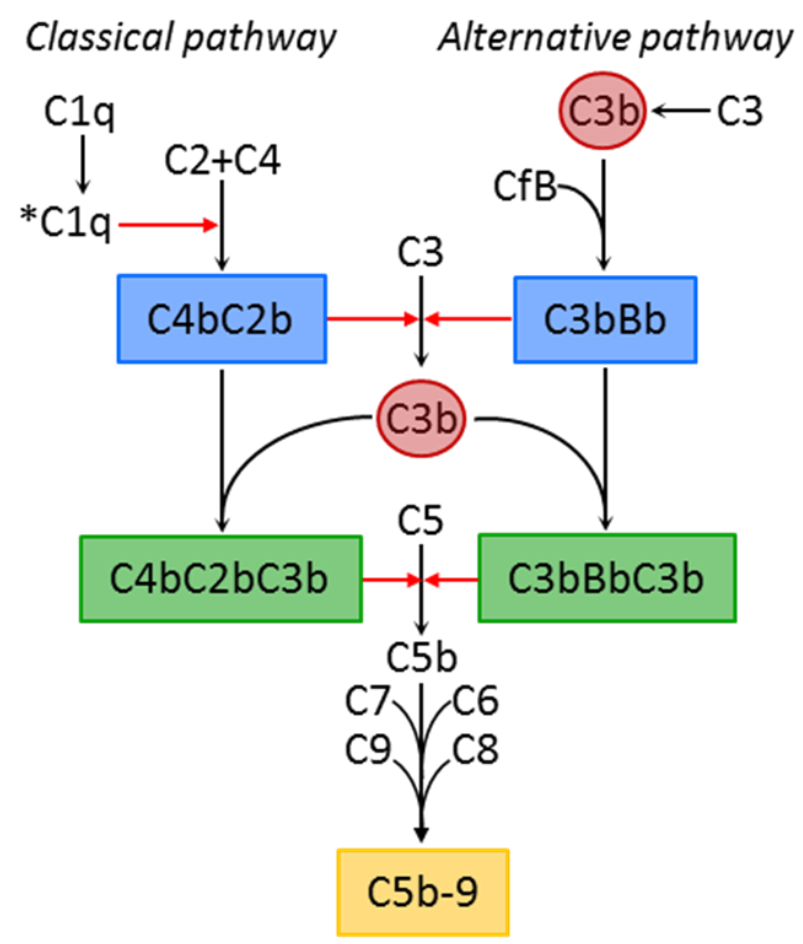

Figure 20. Complement pathways. In the classical pathway, the initiating protein, C1q, binds to antigen-antibody complexes or membrane domains of apoptotic cells, and becomes activated ( $\left.{ }^{*} \mathrm{C} 1 \mathrm{q}\right)$. Subsequent steps include proteolytic cleavage of C2-5 components into "a" and " $b$ " fragments. For simplicity only the "b" fragments are shown. ${ }^{*}$ C1q catalyzes formation of the classical pathway C3 convertase (blue) that cleaves C3. The C3b fragment binds to the C3 convertase generating the classical pathway C5 convertase (green). The production of $\mathrm{C} 5 \mathrm{~b}$ fragment leads to formation of the membrane attack complex (MAC; yellow). The alternative pathway is activated by spontaneous hydrolysis of $\mathrm{C} 3$ leading to the production of $\mathrm{C} 3 \mathrm{~b}$ that combines with the "b" fragment of CfB $(B b)$ resulting in the alternative pathway C3 convertase (b/ue). Subsequent C3b production generates the alternative pathway $C 5$ convertase (green) that, in turn, leads to the formation of MAC (yellow). $B y$ generating $C 3 b$, the classical pathway activates the alternative pathway, and thus, amplifies the complement cascades.

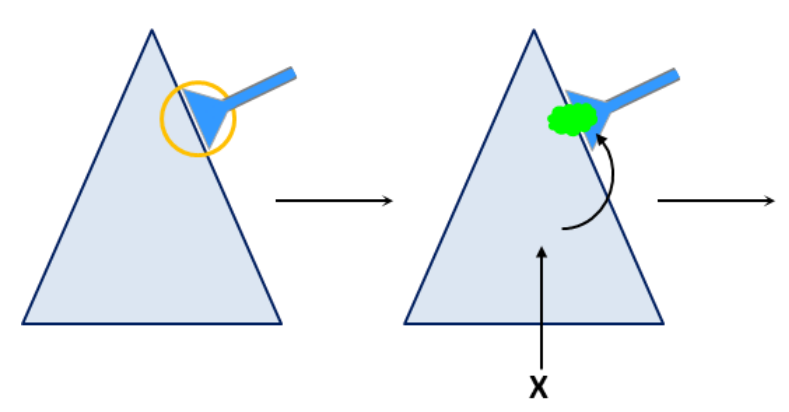

$\triangle$ - neuron inhibitory presynaptic terminal

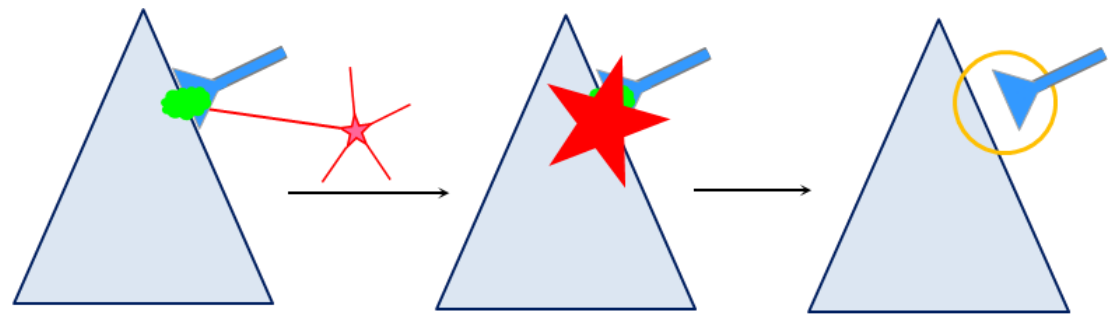

$\hbar$ - microglial cell

- complement

Figure 21. Mechanism of PIC-induced complement-mediated synaptic stripping. Upstream signaling leads to the expression of complement in the neuron, which is targeted to inhibitory synapses. Microglia appose themselves between the pre- and post-synaptic membranes and displace the inhibitory presynaptic terminal. 


\section{Chapter 5: Conclusions and Future Directions}

In this body of work, we have established that peripheral challenge with a viral mimic elicits seizure hypersusceptibility over a three day period following exposure (Fig. $2 \& 4$ ). While the mechanism by which peripheral APR signals the brain remains somewhat elusive, we have shown that peripheral APR-induced seizure susceptibility is concurrent with extensive genomic changes in the hippocampus. These changes were observed in cytokine (Fig. 10), chemokine (Fig. 11), neurotransmission-related (Fig. 13), and miR (Fig. 14) genes.

This study has demonstrated that peripheral PIC challenge upregulates the expression of the complement components (Fig. 16, 17, \& 18). Moreover, we have shown that the complement upregulation is preceded by a robust upregulation of several genes encoding cytokines and chemokines (Fig. $10 \& 11$ ). The cytokine and chemokine receptors (Fig. 12) are expressed by neurons and modulate neuronal activity (reviewed in Rostène et al., 2011 and Vitkovic et al., 2000). It is well established that cytokine receptor signaling results in the transcription of complement genes through the activation of NF-kB, p38 and JAK/STAT (Barnum 1995; Volanakis 1995;Kaczorowski et al., 2010; Chen et al., 2011). Chemokine signaling may also be able to promote complement synthesis through the activation of the same transcription factors (Rodriguez-Frede et al., 2001;Wang and Richmond, 2001;Ye 2001;Mehla et al., 2012). Specifically, a recent report from Trapp's group identified CXCL10 as a factor essential for synaptic stripping (Hu et al., 2014). Because synaptic stripping is mediated by complement (Schafer et al., 2012), it is highly probable that the CXCL10 effect is coupled to the activation of the complement. Therefore, we hypothesize that inflammatory signaling mediates the upregulation of complement expression following PIC challenge and creates a pro-seizure brain environment (proposed mechanism diagramed in Fig. 21 \& 22). Thusly, this pathway might represent mechanisms by which peripheral inflammation increases the likelihood of 
seizures in populations that are already at high-risk, e.g. epileptics, neural injury, dehydration, and exhaustion.

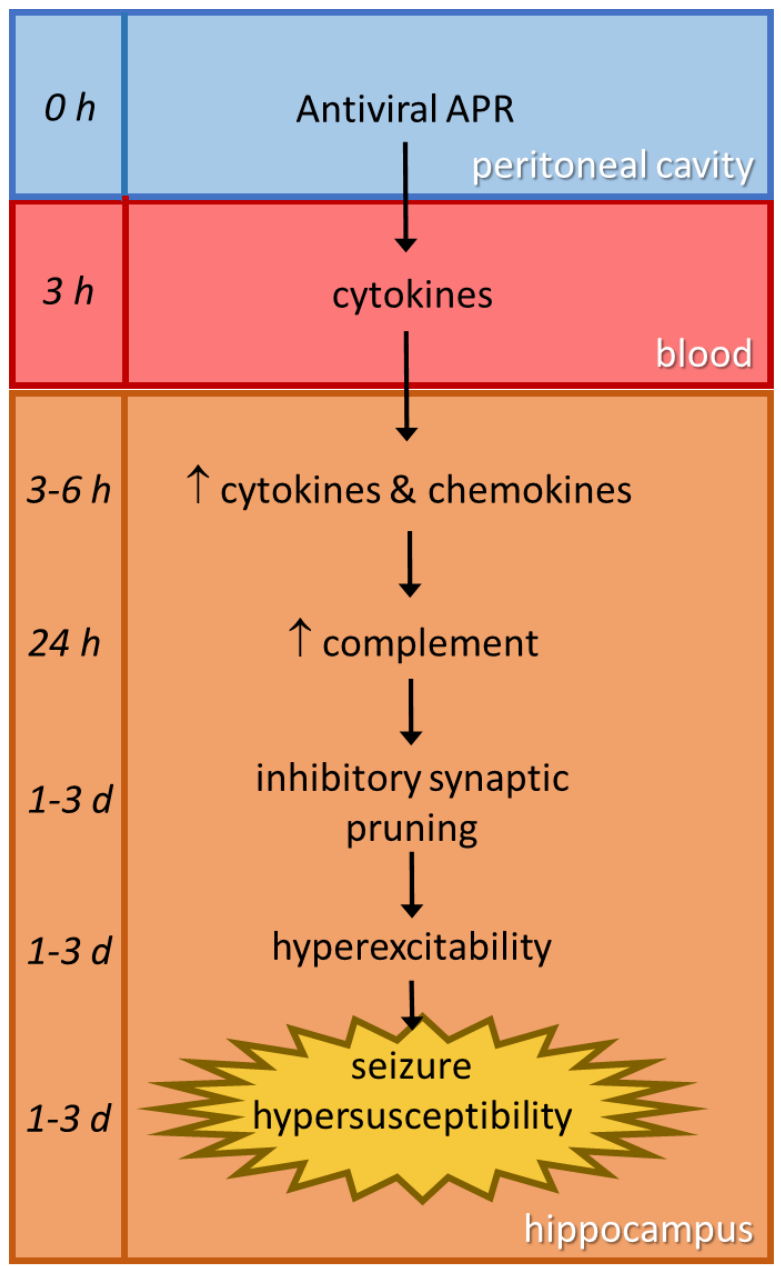

Figure 22. Proposed mechanism of peripheral APR-induced seizure hypersusceptibility. Antiviral APR in the peritoneal cavity generates cytokines which enter blood circulation. These cytokines diffuse into the brain where they stimulate the production of cytokine and chemokines. These factors then stimulate the production of complement components. The complement facilitates the pruning of inhibitory synapses, leading to decreased inhibitory inputs. This decreased inhibition causes hyperexcitability and, subsequently, leads to the development of seizure hypersusceptibility. A proposed time frame, with $0 \mathrm{~h}$ being the time of injection, is outlined on the left.

The discovery that complement is upregulated in response to peripheral APR is a novel finding. Most current literature on complement expression in the brain focuses on roles in development and neurodegenerative disease (Schafer et al. 2012;Stephan et al. 2012). In these pathways, complement signals a seemingly irreversible pruning of synapses or clearance of dying cells by microglia. Clearly, these responses are extreme when applied to "sickness behavior," a benign and evolutionarily protective behavioral response to infection/inflammation. Timing is likely a key issue when it comes to complement's role in peripheral inflammation-induced seizure hypersusceptibility. Activated microglia have been shown to transiently displace inhibitory synapses and increase neural excitability in LPS-injected mice (Chen et al. 2014). Therefore, the three day 
period of enhanced complement expression in the hippocampus could facilitate a reversible displacement of inhibitory synapses that results in the transient hypersusceptible phenotype we observe in our model.

The results presented in this dissertation represent the first step in a line of translational research aimed at developing novel therapeutic strategies to prevent seizures associated with peripheral inflammations. The genes identified in this study, e.g. chemokine and complement component encoding genes, will serve as potential therapeutic targets for preventing the enhancement of seizure susceptibility associated with peripheral infection. Furthermore, we have established that the period of seizure risk extends well beyond the time frame of active inflammation, illustrating the need for increased vigilance even in seemingly healthy patients. In addition, our results can be extended to understand the mechanisms in other neurological conditions that feature inflammatory insult as a putative causal factor, e.g., depression, autism and schizophrenia (Miller et al. 2009; Meyer et al. 2011).

Further studies stemming from this dissertation will test the model proposed in Figure 22. To evaluate the role of hippocampal chemokine signaling in complement expression and seizure hypersusceptibility, animals i.c.v. injected with CXCL10 can be tested for increases in hippocampal complement gene and protein expression (as shown in Fig.16 \& 17) and evaluated for sensitivity to kainic acid-induced seizures (as shown in Fig. 2). The role of CXCL10 in these processes can be further verified by challenging CXCR3 knockout mice with PIC and determining if knockout of this CXCL10 receptor is capable of blocking the upregulation of the complement proteins and the development of the hypersusceptible phenotype. In the event that manipulation of the CXCL10 pathway is insufficient to either mimic or repress complement expression and seizure hypersusceptibility, other cytokines and chemokines, e.g. TNFa, CXCL1, CXCL2, etc (Fig. 10 \& 11), can be tested in a similar fashion. 
Another line of future studies would evaluate the potential for inhibitory synaptic pruning in the PIC model. The first step in these experiments would be to expand upon the preliminary immunohistochemical studies presented in Chapter 4.2 by verifying and quantifying the extent of PICinduced microglial activation and neuronal cell body apposition over the time course of seizure hypersusceptibility. These studies would also be expanded to determine whether PIC challenge results in a preferential loss of inhibitory synapses as observed in Chen et al. (2014) by immunohistochemistry of the inhibitory neuronal marker, GAD. Furthermore, the effect on inhibitory currents can be evaluated in slice cultures by patch-clamp electrophysiology. By blocking excitatory signaling either pharmacologically or by voltage-clamp, spontaneous and evoked inhibitory (outward) currents can be measure in hippocampal pyramidal neurons. If inhibitory synapses are pruned in response to PIC challenge, treated mice should exhibit changes in the characteristics of the inhibitory currents (e.g. frequency, amplitude, etc.). Similar studies can be performed to evaluate the role of complement in inhibitory synaptic pruning by either i.c.v. injecting complement components to mimic their upregulation by PIC, or knocking down the expression of complement components in the brain following PIC treatment. Mice with complete knockout of complement genes exhibit immunological defects, therefore, it would be best to use either siRNA to knockdown gene expression locally in the brain or a conditional knockout paradigm that would only eliminate the complement in the hippocampus. It would also be prudent to determine the mechanism by which complement mediates the disruption of synapses. For example, does opsonization result in morphological changes of synapses? This could be determined by evaluating the shape of the synapses as well as the size of the post-synaptic densities by electron microscopy. Alternatively, if complement does not instigate synaptic pruning, other mechanisms of hyperexcitability can be evaluated (as described in Chapter 1). For example, it is possible that complement interacts with ion channels in the neuronal membrane to alter their function and increase the probability of action potential firing or increase calciummediated neurotransmitter release. While our preliminary data suggest that complement is produced 
by neurons, the complement proteins are secreted into the extracellular space and, therefore, are capable of interacting with other cells. For example, the complement proteins could disrupt potassium and glutamate buffering by astrocytes by affecting the function or expression of the potassium channels and glutamate transporters, leading to hyperexcitability.

It is also necessary to evaluate the role of complement in seizure hypersusceptibility. In these experiments, animals would be treated with kainic acid after either i.c.v injection of the complement proteins or after the complement gene knockdown to determine if complement is sufficient or necessary, respectively, for seizure hypersusceptibility. If complement is not a key component in PICinduced seizure hypersusceptibility, the data set from the microarray study can be further evaluated to uncover other potential mediators of seizure hypersusceptibility that could affect the function of neurons or glia. Taken together, these studies would greatly expand upon the data presented in this dissertation and help to tease out the mechanism by which peripheral inflammation enhances seizure susceptibility. 


\section{Chapter 6: Materials and Methods}

\subsection{Animals}

Eight-week old C57BL/6J mice were obtained from Charles River Laboratories (Wilmington, MA) or Hilltop Lab Animals, Inc. (Scottdale, PA), and housed under 12-h light/dark conditions (lights on at 6 am) with unrestricted access to food and water. All procedures were approved by the West Virginia University Animal Care and Use Committee and conducted in compliance with the guidelines published in the NIH Guide for the Care and Use of Laboratory Animals.

\subsection{PIC treatment and blood plasma transfer}

Animals were i.p. injected with $12 \mathrm{mg} / \mathrm{kg}$ of PIC (Invivogen, San Diego, CA) in $100 \mu \mathrm{l}$ of saline. Mice received either three daily injections or a single injection of PIC. Control mice were injected with saline only. After $3 \mathrm{~h}$, the development of sickness behavior was assessed by the rearing test (Michalovicz \& Konat, 2014) to confirm successful i.p. injection.

For blood plasma transfer, blood samples were collected $3 \mathrm{~h}$ after PIC treatment by cardiac puncture and citrated. The blood was immediately centrifuged and $300 \mu \mathrm{L}$ of plasma was i.p. injected into naïve mice. Control mice were injected with blood plasma collected from saline injected mice.

\subsection{Cytokine treatment}

Animals were i.p. injected with one of two mixtures of recombinant IL-6 and IFN $\beta$ : 1) $30 \mathrm{ng}$ of IL-6 and $40 \mathrm{ng}$ of IFN $\beta$, or 2$) 1 \mu \mathrm{g}$ of IL-6 and $1 \mu \mathrm{g}$ of IFN $\beta$. Control mice were injected with saline only. As the recombinant mouse cytokine proteins were isolated from bacteria, a second set of controls were injected with $200 \mathrm{pg}$ of LPS to account for trace levels of endotoxin potentially present with the recombinant proteins. 


\subsection{COX inhibitor treatment}

Animals were i.p. injected with $30 \mathrm{mg} / \mathrm{kg}$ of ibuprofen or $10 \mathrm{mg} / \mathrm{kg}$ of piroxicam, non-selective COX inhibitors, or saline $1 \mathrm{~h}$ prior to receiving an i.p. injection of $12 \mathrm{mg} / \mathrm{kg}$ of PIC. Control mice were injected with saline only.

\subsection{Open-field test}

Locomotor activity was assessed using the automated activity monitoring system PAS-Open field (41 $\mathrm{cm} \times 41 \mathrm{~cm} \times 38 \mathrm{~cm}$; San Diego Instruments, San Diego, CA). The chambers were equipped with a $16 \times 16$ array of infrared photo-beams to measure horizontal $(\mathrm{XY})$ movement and an additional frame of 16 beams to monitor rearing. Locomotor activity was recorded for 15 min.

\subsection{Evaluation of seizure susceptibility}

At different time points (1-7 days) following PIC challenge, mice received subcutaneous injections of $15 \mathrm{mg} / \mathrm{kg}$ or $20 \mathrm{mg} / \mathrm{kg}$ of KA (Sigma Chemical Co., St. Louis, MO) in saline, depending on the animal supplier (Hilltop Lab Animals, Inc. or Charles River Laboratories, respectively). Saline injected mice served as controls. Seizure severity was scored by blinded observers in 5 min intervals. The behavioral scores were as follows: 0 , no response; 1 , immobility; 2, rigid posture; 3 , scratching/circling/head bobbing; 4, forelimb clonus/rearing/falling; 5 , repetitious pattern 4; 6 , severe tonic-clonic seizures (Morrison et al. 1996). Cumulative seizure scores were assessed as the summation of all scores over the $2 \mathrm{~h}$ observation period.

\subsection{Blood cytokine measurement}

Mice were deeply anesthetized with $65 \mathrm{mg} / \mathrm{ml}$ of pentobarbital (Fatal Plus, Vortech Pharmaceutical, Dearborn, MI) administered i.p. and sacrificed by pneumothorax. Blood was quickly collected by heart puncture and citrated. IFN $\beta$ was measured using the VeriKine Mouse Interferon Beta ELISA kit (PBL 
Interferon Source, Piscataway, NJ) per manufacturer's instructions. IL-6 levels were measured using the Milliplex MAP Mouse Cytokine/Chemokine panel (Millipore, Billerica, MA) per manufacturer's instructions and analyzed using a Luminex 200 System (Luminex, Austin, TX).

\section{8. $q R T-P C R$}

Mice were anesthetized and sacrificed as described above, and transaortically perfused with saline. Brains were removed from the skull and hippocampi were dissected out. The brainstem, cerebellum and forebrain (minus the hippocampus) were also isolated. The tissue was immediately homogenized in TRI Reagent (Molecular Research Center, Inc., Cincinnati, OH), and RNA was isolated per manufacturer's protocol. For quantitation of mRNA, cDNA was synthesized using SuperScript III Firststrand Synthesis kit (Invitrogen, Carlsbad, CA) and quantified using $\mathrm{RT}^{2}$ SYBRGreen (Qiagen, Valencia, CA). For miR quantitation, cDNA was synthesized using NCode VILO miRNA cDNA Synthesis kit (Invitrogen, Carlsbad, CA) and quantified using EXPRESS SYBR GreenER miRNA qRT-PCR kit (Invitrogen, Carlsbad, CA). qRT-PCR was performed in an ABI7500 Real-Time PCR system (Applied Biosystems, Foster City, CA). Glyceraldehyde phosphate dehydrogenase (GAPDH) mRNA or snRNA U6 were used as internal controls for mRNAs and miRs, respectively. The $\Delta \triangle \mathrm{Ct}$ method was used for quantitation. Primer sequences are listed in Tables $\mathrm{X}$ and $\mathrm{Y}$.

\subsection{Microarray analysis}

Mice were deeply anesthetized with $65 \mathrm{mg} / \mathrm{kg}$ of pentobarbital (Fatal Plus, Vortech Pharmaceutical, Dearborn, MI) administered i.p., sacrificed by pneumothorax, and transaortically perfused with saline. The hippocampi were dissected out, homogenized in TRI Reagent (Molecular Research Center, Inc., Cincinnati, $\mathrm{OH}$ ), and total RNA was isolated per manufacturer's protocol. RNA integrity was verified by the Agilent Bioanalyzer 2100. The microarray analysis was performed using the Illumina BeadChip mouse WG-6 format. The BeadChips were scanned using the Illumina iSCAN system and analyzed 
by Illumina's GenomeStudio 2011.1 Gene Expression Analysis Module 1.9.0 (Illumina). Data were normalized using the caGEDA web application (Patel and Lyons-Weiler, 2004), and differentially expressed genes (DEGs) were identified using the $\mathrm{J} 5$ test. Pathways analysis was performed using the Pathway Express application (Draghici et al., 2007).

\subsection{Immunohistochemistry}

Mice were deeply anesthetized with $65 \mathrm{mg} / \mathrm{kg}$ of pentobarbital (Fatal Plus, Vortech Pharmaceutical, Dearborn, MI) administered i.p., sacrificed by pneumothorax, and transaortically perfused with saline and then 4\% paraformaldehyde. Brains were removed from the skull and infused in $4 \%$ paraformaldehyde for a minimum of $24 \mathrm{~h}$ at $4^{\circ} \mathrm{C}$. The brains were cryoprotected in $30 \%$ sucrose for $24 \mathrm{~h}$ at $4^{\circ} \mathrm{C}$ before sectioning. $35 \mu \mathrm{m}$ slices were cut on a freezing microtome and stored in $4 \%$ paraformaldehyde.

For immunofluorescent staining, free-floating sections were blocked in PBS with 5\% FBS (Atlanta Biologicals, Lawrenceville, GA) and $0.5 \%$ Triton-X 100 (Fisher Scientific, Waltham, MA) for $1 \mathrm{~h}$ at room temperature and then incubated in primary antibody overnight at $4^{\circ} \mathrm{C}$. After washing in PBS, sections were incubated in secondary antibody for $1 \mathrm{~h}$ at room temperature. Sections were then washed and mounted on slides using Vectashield hard set (Vector Laboratories, Burlingame, CA). Confocal imaging was performed at the WVU Microscope Imaging Facility with a Zeiss LSM 510 laser scanning confocal on a LSM Axiolmager upright microscope. Primary antibodies were: rat-anti-C3 (11H9; Abcam, Cambridge, MA), goat-anti-Cfb (N-14; Santa Cruz Biotechnology, Dallas, TX), rat-antiC1q (7H8; Abcam, Cambridge, MA), mouse-anti-NeuN (A60; Millipore, Billerica, MA), and rabbit-antiIba1 (Wako, Richmond, VA). Secondary antibodies were anti-rat, anti-goat, anti-mouse or anti-rabbit conjugated to either Alexa Fluor 488 or Alexa Fluor 555 (Invitrogen, Carlsbad, CA). All antibodies were diluted in PBS with 1\% FBS and 0.1\% Triton-X 100. 


\subsection{Statistical Analysis}

Data were analyzed by ANOVA and expressed as means \pm SD. Statistical comparisons between groups were performed using Student's $t$ test. Differences between groups were considered significant at $P \leq 0.05$. 
Table 3. Primer sequences for mRNA targets.

\begin{tabular}{|c|c|c|}
\hline mRNA & Forward primer & Reverse primer \\
\hline C1qa & CTGGCATCCGGACTGGTATC & CTTTCACGCCCTTCAGTCCT \\
\hline$C 1 q b$ & ACGAGAACTATGAGCCACGC & TTTCTGCATGCTGTCCCGAT \\
\hline C1qc & GGCCTGAAGTCCCTTACACC & CTGAGTGGTAGGGCCAGAAG \\
\hline C2 & ACCTGTAAAGATCATGAGACAGAAC & GGAGACAGCCTGGATACACC \\
\hline C3 & TGCTGGCCTCTGGAGTAGAT & AGGCAGTCTTCTTCGGTGTG \\
\hline C4 & CACCATGGGTTGGACGTCTT & GCCTTCTGCCCCAAGAATGA \\
\hline C6 & CGCCAGGAGCTACAGAACTC & TTTGGTGCACGTGTCTTCCT \\
\hline Cc/12 & TTGGCTGGACCAGATGCGGTGA & GGGGACACTGGCTGCTTGTGAT \\
\hline Cc/19 & CTGGACCCTTCCCAGCCCCAACT & CAGGCACCCTGCAGCCATCTTC \\
\hline $\mathrm{Ccl} 2$ & CCTCCACCACTATGCAGGTCTC & GCACGTGGATGCTACAGGC \\
\hline Cc/4 & AGCACCAATGGGCTCTGACCCT & ACCACAGCTGGCTTGGAGCA \\
\hline Ccl5 & GCCTCTGCCGCGGGTACCAT & CCGAGCCATATGGTGAGGCAGG \\
\hline $\mathrm{Ccl} 7$ & CAACCAGATGGGCCCAATGCATCC & AGCTTCCCAGGGACACCGACT \\
\hline Cc/9 & GGGCCAGGAACAGCAAGCAGTC & TCTGTTGCATTGTGTGATCTGGGC \\
\hline Ccr1 & GGCAGCTGTTTCAAAGGCATGTGGC & AGCCAGCAGAGAGCTCATGTTCTCC \\
\hline Ccr6 & ACACGGTGCTAGTAACCTGCAGTTCG & TGTCGGGAGAGCAGAGGTGAAGCAA \\
\hline Ccr7 & GCACCATGGACCCAGGGAAACCCA & GCACACCGACTCGTACAGGGTGT \\
\hline$C f b$ & GGGGCCCTCTCATTGTTCAC & GGAAGTCCCGGGCATAAGAG \\
\hline $\mathrm{CxCl1}$ & TGAAGCTCCCTTGGTTCAGAAA & GTTGTCAGAAGCCAGCGTTCAC \\
\hline $\mathrm{Cxcl10}$ & AAGTGCTGCCGTCATTTTCTG & CCTATGGCCCTCATTCTCACTG \\
\hline Cxcl11 & AGCTGCTCAAGGCTTCCTTATG & AACTITGTCGCAGCCGTTACTC \\
\hline$C x c / 13$ & GCCTCTCTCCAGGCCACGGTAT & TTTTGGGGCAGCCATTCCCAGG \\
\hline$C x c / 17$ & AACCCAGGGGTCGCCAGAAGCC & TCCTTGGTGGCCCCAGCACT \\
\hline Cxcl2 & CGCTGTCAATGCCTGAAG & GGCGTCACACTCAAGCTCT \\
\hline Cxcl9 & GGACTCGGCAAATGTGAAGAAG & GGGGTGTTTTGGGTTITCTGTT \\
\hline Cxcr2 & ACCGGGCCATGCGGGTCATCTT & TCATCGCGGCGCTCACAGGTCT \\
\hline Cxcr5 & ACCCTGGACATGGGCTCCATCACA & AGGCCACAGGCATGAATACCGCC \\
\hline Gabre & CTGGCATTGGAGAGAAGCCTA & CGTTGCCATGCAGAATAAGGG \\
\hline Gabrq & CCAGATGGGACAGTGCGATA & GTAGCCATAGCTCTCCACCTC \\
\hline Gabrr2 & GGAGTCACGGGTCAAGTTGT & TTGTACTCGCCGACCTTCAC \\
\hline Gabrr3 & TTCATCCACGACACAACCGT & AAAGCGGCTGAAGTCCATGA \\
\hline Gldh & CTGCAACCATGTGTTGAGCC & TGCTGTAACGGATACCTCCC \\
\hline Gria4 & AAGGCTATGGTGTAGCGACG & GTCTTGTCCTTGCTTCCCGA \\
\hline Grik3 & GTTCCTAGTGTGCGCCTTCT & ATCGAAAGGCGTGCTCTTCA \\
\hline Grm1 & GTAGTGCGCATGCACGTCGG & GTTAGAATTGGCGTTCCCTGCCC \\
\hline Grm6 & GACATCAGGAGGGTCTTGGAG & AATCATCTGACTGGCCACCTG \\
\hline Grm7 & TTTTTGGCACAGCGCAATCA & GCAGGGCTGTTTGGGTCTAC \\
\hline Ifnb & GTGGTCCGAGCAGAGATCTTCAGG & ACTACCAGTCCCAGAGTCCGCC \\
\hline$\| 1 b$ & GAAGATGGAAAAACGGTTTG & GTACCAGTTGGGGAACTCTGC \\
\hline 116 & ACACATGTTCTCTGGGAAATC & AGTGCATCATCGTTGTTCATA \\
\hline Kcnj10 & ACCTTCGAGCCAAGATGACG & CATTCTCACATTGCTCCGGC \\
\hline Ldha & AGCTTCCATTTAAGGCCCCG & TCTTITGAGACCGCTAGTGC \\
\hline Serping1 & TGAAGCTGCCTAGTGACCAAG & CTGGTAGCTTCGGGATCTGAG \\
\hline Tnfa & GCGATGGGTTGTACCTTGTCT & GTGGGTGAGGAGCACGTAGT \\
\hline Gapdh & TGCACCACCAACTGCTTAGC & GGATGCAGGGATGATGTTCT \\
\hline
\end{tabular}


Table 4. Primer sequences for mature miRNA targets.

\begin{tabular}{|c|c|}
\hline miRNA & Primer \\
\hline $128-3 p$ & GTCACAGTGAACCGGTCTCTTTA \\
\hline $132-3 p$ & CAGTCTACAGCCATGGTCGAAA \\
\hline $138-3 p$ & TGTTGTGAATCAGGCCGAAA \\
\hline $181 a-5 p$ & ATTCAACGCTGTCGGTGAGTA \\
\hline $188-5 p$ & TTGCATGGTGGAGGGAAA \\
\hline $221-3 p$ & AGCTACATTGTCTGCTGGGTTC \\
\hline $28 a-5 p$ & GAAGGAGCTCACAGTCTATTGAGAA \\
\hline $302 a-5 p$ & GACTTAAACGTGGTTGTACTTGC \\
\hline $466 i-5 p$ & TTCTGTGTGTGTGTGTGTGTGTG \\
\hline $509-5 p$ & TACTCCAGAATGTGGCAATCATA \\
\hline snRNA U6 & AAATTCGTGAAGCGTTCCATA \\
\hline
\end{tabular}




\section{References}

Anisman H, Gibb J, Hayley S (2008) Influence of continuous infusion of interleukin-1beta on depression-related processes in mice: corticosterone, circulating cytokines, brain monoamines, and cytokine mRNA expression. Psychopharmacology (Berl) 199:231-244.

Aronica E, Fluiter K, lyer A, Zurolo E, Vreijling J, van Vliet EA, Baayen JC, Gorter JA (2010) Expression pattern of miR-146a, an inflammation-associated microRNA, in experimental and human temporal lobe epilepsy. Eur J Neurosci 31:1100-1107.

Artinian J, Peret A, Marti G, Epsztein J, Crepel V (2011) Synaptic kainate receptors in interplay with INaP shift the sparse firing of dentate granule cells to a sustained rhythmic mode in temporal lobe epilepsy. J Neurosci 31:10811-10818.

Badwy RAB, Harvey AS, Macdonne RAL (2009a) Cortical hyperexcitability and epileptogenesis: Uncerstanding the mechanisms of epilepsy - Part 1. J Clin Neurosci 16: 355-365.

Badwy RAB, Harvey AS, Macdonne RAL (2009b) Cortical hyperexcitability and epileptogenesis: Uncerstanding the mechanisms of epilepsy - Part 2. J Clin Neurosci 16: 485-500.

Bagri A, Gurney T, He X, Zou YR, Littman DR, Tessier-Lavigne M, Pleasure SJ (2002) The chemokine SDF1 regulates migration of dentate granule cells. Development 129:4249-4260.

Balter-Seri J, Yuhas Y, Weizman A, Nofech-Mozes Y, Kaminsky E, Ashkenazi S (1999) Role of nitric oxide in the enhancement of pentylenetetrazole-induced seizures caused by Shigella dysenteriae. Infect. Immun. 67, 6364-6368.

Barnum SR (1995) Complement biosynthesis in the central nervous system. Crit Rev Oral Biol Med 6:132-146.

Ben-Ari Y, Cossart R (2000) Kainate, a double agent that generates seizures: two decades of progress. Trends Neurosci 23:580-587.

Berke IC, Li Y, Modis Y (2013) Structural basis of innate immune recognition of viral RNA. Cell Microbiol 15:386-394.

Bluthé RM, Kelley KW, Dantzer R (2006) Effects of insulin-like growth factor-I on cytokine-induced sickness behavior in mice. Brain Behav Immun 20:57-63.

Bluthé RM, Pawlowski M, Suarez S, Parnet P, Pittman Q, Kelley KW, Dantzer R (1994) Synergy between tumor necrosis factor alpha and interleukin-1 in the induction of sickness behavior in mice. Psychoneuroendocrinology 19:197-207.

Bockenhauer D, et al. (2009) Epilepsy, ataxia, sensorineural deafness, tubulopathy, and KCNJ10 mutations. N Engl J Med 360:1960-1970.

Bollan KA, Baur R, Hales TG, Sigel E, Connolly CN (2008) The promiscuous role of the epsilon subunit in GABAA receptor biogenesis. Mol Cell Neurosci 37:610-621. 
Campbell IL, Abraham CR, Masliah E, Kemper P, Inglis JD, Oldstone MB, Mucke L (1993) Neurologic disease induced in transgenic mice by cerebral overexpression of interleukin 6. Proc Natl Acad Sci $U$ S A 90:10061-10065.

Casillas-Espinosa PM, Powell KL, O'Brien TJ (2012) Regulators of synaptic transmission: roles in the pathogenesis and treatment of epilepsy. Epilepsia 53 Suppl 9:41-58.

Catterwall WA (2014) Sodium channels, inheritied epilepsy, and antiepileptic drugs. Annu Rev Parmacol Toxicol 54:317-338.

Chen Z, Jalabi W, Hu W, Park HJ, Gale JT, Kidd GJ, Bernatowicz R, Gossman ZC, Chen JT, Dutta R, Trapp BD (2014) Microglial displacement of inhibitory synapses provides neuroprotection in the adult brain. Nat Commun 5:4486.

Chen G, Tan CS, Teh BK, Lu J (2011) Molecular mechanisms for synchronized transcription of three complement C1q subunit genes in dendritic cells and macrophages. J Biol Chem 286:34941-34950.

Cho J, Nelson TE, Bajova H, Gruol DL (2009) Chronic CXCL10 alters neuronal properties in rat hippocampal culture. J Neuroimmunol 207:92-100.

Couillard-Despres S, Winner B, Schaubeck S, Aigner R, Vroemen M, Weidner N, Bogdahn U, Winkler J, Kuhn HG, Aigner L (2005) Doublecortin expression levels in adult brain reflect neurogenesis. Eur J Neurosci 21:1-14.

Cunningham C, Campion S, Teeling J, Felton L, Perry VH (2007) The sickness behaviour and CNS inflammatory mediator profile induced by systemic challenge of mice with synthetic double-stranded RNA (poly I:C). Brain Behav Immun 21:490-502.

Dantzer R. (2006) Cytokine, sickness behavior, and depression. Neurol Clin 24, 441-460.

Dantzer R, Kelley KW (2007) Twenty years of research on cytokine-induced sickness behavior. Brain Behav Immun 21, 153-160.

Das A, McDowell M, O'Dell CM, Busch ME, Smith JA, Ray SK, Banik NL (2010) Post-treatment with voltage-gated $\mathrm{Na}(+)$ channel blocker attenuates kainic acid-induced apoptosis in rat primary hippocampal neurons. Neurochem Res 35, 2175-2183.

Djukic B, Casper KB, Philpot BD, Chin LS, McCarthy KD (2007) Conditional knock-out of Kir4.1 leads to glial membrane depolarization, inhibition of potassium and glutamate uptake, and enhanced shortterm synaptic potentiation. J Neurosci 27:11354-11365.

Draghici S, Khatri P, Tarca AL, Amin K, Done A, Voichita C, Georgescu C, Romero R (2007) A systems biology approach for pathway level analysis. Genome Res 17:1537-1545.

Dubois RN, Abramson SB, Crofford L, Gupta RA, Simon LS, Van De Putte LB, Lipsky PE (1998) Cyclooxygenase in biology and disease. FASEB J 12:1063-1073.

Edbauer D, Neilson JR, Foster KA, Wang CF, Seeburg DP, Batterton MN, Tada T, Dolan BM, Sharp PA, Sheng M (2010) Regulation of synaptic structure and function by FMRP-associated microRNAs miR-125b and miR-132. Neuron 65:373-384. 
Erakovic V, Zupan G, Varljen J, Laginja J, Simonic A (2001) Altered activities of rat brain metabolic enzymes caused by pentylenetetrazol kindling and pentylenetetrazol--induced seizures. Epilepsy Res 43:165-173.

Evangelisti C, Florian MC, Massimi I, Dominici C, Giannini G, Galardi S, Bue MC, Massalini S, McDowell HP, Messi E, Gulino A, Farace MG, Ciafre SA (2009) MiR-128 up-regulation inhibits Reelin and DCX expression and reduces neuroblastoma cell motility and invasiveness. FASEB J 23:42764287.

Fabene PF, Bramanti P, Constantin G (2010) The emerging role for chemokines in epilepsy. J Neuroimmunol 224:22-27.

Fareh M, Turchi L, Virolle V, Debruyne D, Almairac F, de la Forest DS, Paquis P, Preynat-Seauve O, Krause KH, Chneiweiss H, Virolle T (2012) The miR 302-367 cluster drastically affects self-renewal and infiltration properties of glioma-initiating cells through CXCR4 repression and consequent disruption of the SHH-GLI-NANOG network. Cell Death Differ 19:232-244.

Fil D, Borysiewicz E, Konat GW (2011) A broad upregulation of cerebral chemokine genes by peripherally-generated inflammatory mediators. Metab Brain Dis 26:49-59.

Finney SJ, Leaver SK, Evans TW, Burke-Gaffney A (2012) Differences in lipopolysaccharide- and lipoteichoic acid-induced cytokine/chemokine expression. Intensive Care Med 38:324-332.

Fisher RS, van Emde BW, Blume W, Elger C, Genton P, Lee P, Engel J, Jr (2005) Epileptic seizures and epilepsy: definitions proposed by the International League Against Epilepsy (ILAE) and the International Bureau for Epilepsy (IBE). Epilepsia 46, 470-472.

Forrest CM, Khalil OS, Pisar M, Smith RA, Darlington LG, Stone TW (2012) Prenatal activation of Toll-like receptors-2 by administration of the viral mimetic poly(I:C) changes synaptic proteins, $\mathrm{N}$ methy-D-aspartate receptors and neurogenesis markers in offspring. Mol Brain 5, 22.

Galic MA, Riazi K, Pittman QJ (2012) Cytokines and brain excitability. Front Neuroendocrinol 33:116125.

Gandhi R, Hayley S, Gibb J, Merali Z, Anisman H (2007) Influence of poly I:C on sickness behaviors, plasma cytokines, corticosterone and central monoamine activity: moderation by social stressors. Brain Behav Immun 21:477-489.

Gibb J, Hayley S, Gandhi R, Poulter MO, Anisman H (2008) Synergistic and additive actions of a psychosocial stressor and endotoxin challenge: Circulating and brain cytokines, plasma corticosterone and behavioral changes in mice. Brain Behav Immun 22:573-589.

Gonzalez MI (2013) The possible role of GABAA receptors and gephyrin in epileptogenesis. Front Cell Neurosci 7:113.

Guerrini R, Dobyns WB (2014) Malformations of cortical developme: clinical features and genetic causes. Lancet Neurol 13:710-726.

Guha-Thakurta N, Majde JA (1997) Early induction of proinflammatory cytokine and type I interferon mRNAs following Newcastle disease virus, poly [rl:rC], or low-dose LPS challenge of the mouse. J Interferon Cytokine Res 17:197-204. 
Guidi M, Muinos-Gimeno M, Kagerbauer B, Marti E, Estivill X, Espinosa-Parrilla Y (2010) Overexpression of miR-128 specifically inhibits the truncated isoform of NTRK3 and upregulates BCL2 in SH-SY5Y neuroblastoma cells. BMC Mol Biol 11:95.

Guo W, Zou S, Tal M, Ren K (2002) Activation of spinal kainate receptors after inflammation: behavioral hyperalgesia and subunit gene expression. Eur J Pharmacol 452:309-318.

Harre EM, Galic MA, Mouihate A, Noorbakhsh F, Pittman QJ (2008) Neonatal inflammation produces selective behavioural deficits and alters N-methyl-D-aspartate receptor subunit mRNA in the adult rat brain. Eur J Neurosci 27:644-653.

Hauser WA (1997) Incidence and prevalence, in Epilepsy: a Comprehensive Textbook, (Engel J., Jr. and Pedley T. A., eds), pp. 47-57. Lippincott-Raven, Philadelphia.

Heron SE, Sheffer IE, Berkovic SF, Dibbens LM, Mulley JC (2007) Channelopathies in idiopathic epilepsy. Neurotherapeutics 4: 295-304.

Hu K, Zhang C, Long L, Long X, Feng L, Li Y, Xiao B (2011) Expression profile of microRNAs in rat hippocampus following lithium-pilocarpine-induced status epilepticus. Neurosci Lett 488:252-257.

Hu WW, Chen ZH, Phares T, Gossman Z, Erokwu C, Trapp B (2014) Interferon induced protein 10 is critical for synaptic stripping exerted by activated microglia. Transactions of the American Society for Neurochemistry PS03-11.

Huckans M, Seelye A, Parcel T, Mull L, Woodhouse J, Bjornson D, Fuller BE, Loftis JM, Morasco BJ, Sasaki AW, Storzbach D, Hauser P (2009) The cognitive effects of hepatitis C in the presence and absence of a history of substance use disorder. J Int Neuropsychol Soc 15:69-82.

Hung YW, Lai MT, Tseng YJ, Chou CC, Lin YY (2013) Monocyte chemoattractant protein-1 affects migration of hippocampal neural progenitors following status epilepticus in rats. J Neuroinflammation 10:11.

Ilschner S, Nolte C, Kettenmann H (1996) Complement factor C5a and epidermal growth factor trigger the activation of outward potassium currents in cultured murine microglia. Neuroscience 73 : 1109-1120.

Jacobs BL, Langland JO (1996) When two strands are better than one: the mediators and modulators of the cellular responses to double-stranded RNA. Virology 219:339-349.

Jamali S, Salzmann A, Perroud N, Ponsole-Lenfant M, Cillario J, Roll P, Roeckel-Trevisiol N, Crespel A, Balzar J, Schlachter K, Gruber-Sedlmayr U, Pataraia E, Baumgartner C, Zimprich A, Zimprich F, Malafosse A, Szepetowski P (2010) Functional variant in complement C3 gene promoter and genetic susceptibility to temporal lobe epilepsy and febrile seizures. PLoS One 5: e12740.

Ji K, Miyauchi J, Tsirka SE (2013) Microglia: an active player in the regulation of synaptic activity. Neural Plast 627325.

Jimenez-Mateos EM, Bray I, Sanz-Rodriguez A, Engel T, McKiernan RC, Mouri G, Tanaka K, Sano T, Saugstad JA, Simon RP, Stallings RL, Henshall DC (2011) miRNA Expression profile after status epilepticus and hippocampal neuroprotection by targeting miR-132. Am J Pathol 179:2519-2532. 
Kaczorowski DJ, Afrazi A, Scott MJ, Kwak JH, Gill R, Edmonds RD, Liu Y, Fan J, Billiar TR (2010) Pivotal advance: The pattern recognition receptor ligands lipopolysaccharide and polyinosinepolycytidylic acid stimulate factor $B$ synthesis by the macrophage through distinct but overlapping mechanisms. J Leukoc Biol 88:609-618.

Kan AA, van der Hel WS, Kolk SM, Bos IW, Verlinde SA, van NO, de Graan PN (2012) Prolonged increase in rat hippocampal chemokine signalling after status epilepticus. J Neuroimmunol 245:15-22.

Kettenmann H, Kirchhoff F, Verkhratsky A (2013) Microglia: new roles for the synaptic stripper. Neuron 77: 10-18.

Kharatishvili I, Shan ZY, She DT, Foong S, Kurniawan ND, Reutens DC (2014) $\mathrm{MRI}$ changes and complement activation correlate with epileptogenicity in a mouse model of temporal lobe epilepsy. Brain Struct Funct 219:683-706.

Kirschman LT, Borysiewicz E, Fil D, Konat GW (2011) Peripheral immune challenge with dsRNA enhances kainic acid-induced status epilepticus. Metab Brain Dis 26:91-93.

Kokaia M (2011) Seizure-induced neurogenesis in the adult brain. Eur J Neurosci 33:1133-1138.

Konat GW, Borysiewicz E (2009) Cerebellar expression of inflammatory genes triggered by peripheral challenge with dsRNA. J Neurochem 108(Suppl. 1):133.

Konat GW, Borysiewicz E, Fil D, James I (2009) Peripheral challenge with double-stranded RNA elicits global up-regulation of cytokine gene expression in the brain. J Neurosci Res 87:1381-1388.

Krasowska-Zoladek A, Banaszewska M, Kraszpulski M, Konat GW (2007) Kinetics of inflammatory response of astrocytes induced by TLR3 and TLR4 ligation. J Neurosci Res 85:2015-212.

Lax P, Limatola C, Fucile S, Trettel F, Di BS, Renzi M, Ragozzino D, Eusebi F (2002) Chemokine receptor CXCR2 regulates the functional properties of AMPA-type glutamate receptor GluR1 in HEK cells. J Neuroimmunol 129:66-73.

Lehtimaki KA, Peltola J, Koskikallio E, Keranen T, Honkaniemi J (2003) Expression of cytokines and cytokine receptors in the rat brain after kainic acid-induced seizures. Brain Res Mol Brain Res 110:253-260.

Lenczowski MJ, Van Dam AM, Poole S, Larrick JW, Tilders FJ (1997) Role of circulating endotoxin and interleukin- 6 in the ACTH and corticosterone response to intraperitoneal LPS. Am J Physiol 273:R1870-R1877.

Libbey JE, Kirkman NJ, Wilcox KS, White HS, Fujinami RS (2010) Role for complement in the development of seizures following acute viral infection. J Virol 84:6452-6460.

Liimatainen S, Kai L, Johanna P, Tiina A, Jukka P (2013) Immunological perspectives of temporal lobe seizures. J Neuroimmunol 263:1-7.

Liu DZ, Tian Y, Ander BP, Xu H, Stamova BS, Zhan X, Turner RJ, Jickling G, Sharp FR (2010) Brain and blood microRNA expression profiling of ischemic stroke, intracerebral hemorrhage, and kainate seizures. J Cereb Blood Flow Metab 30:92-101. 
Loftis JM, Huckans M, Ruimy S, Hinrichs DJ, Hauser P (2008) Depressive symptoms in patients with chronic hepatitis $C$ are correlated with elevated plasma levels of interleukin-1beta and tumor necrosis factor-alpha. Neurosci Lett 430:264-268.

Maljevic S, Lerche H (2013) Potassium channels: a review of the broadening therapeutic possibilities for neurological diseases. J Neurol 260:2201-2211.

Malthankar-Phatak GH, de LN, Eid T, Spencer DD, Behar KL, Spencer SS, Kim JH, Lai JC (2006) Differential glutamate dehydrogenase $(\mathrm{GDH})$ activity profile in patients with temporal lobe epilepsy. Epilepsia 47:1292-1299.

McCusker RH, Kelley KW (2013) Immune-neural connections: how the immune system's response to infectious agents influences behavior. J Exp Biol 216:84-98.

Mehla R, Guha D, Ayyavoo V (2012) Chemokine deregulation in HIV infection: Role of interferon gamma induced Th1-chemokine signaling. J Clin Cell Immunol S7:004.

Meyer U., Feldon J. and Dammann O. (2011) Schizophrenia and autism: both shared and disorderspecific pathogenesis via perinatal inflammation? Pediatr Res 69, 26R-33R.

Michalovicz LT, Konat GW (2014) Peripherally restricted acute phase response to a viral mimic alters hippocampal gene expression. Metab Brain Dis 29:75-86.

Miller A. H., Maletic V. and Raison C. L. (2009) Inflammation and its discontents: the role of cytokines in the pathophysiology of major depression. Biol Psychiatry 65, 732-741

Morrison RS, Wenzel HJ, Kinoshita Y, Robbins CA, Donehower LA, Schwartzkroin PA (1996) Loss of the p53 tumor suppressor gene protects neurons from kainate-induced cell death. J Neurosci 16:1337-1345.

Muller U, Steinhoff U, Reis LF, Hemmi S, Pavlovic J, Zinkernagel RM, Aguet M (1994) Functional role of type I and type II interferons in antiviral defense. Science 264:1918-1921.

Nelligan JA, Loftis JM, Matthews AM, Zucker BL, Linke AM, Hauser P (2008) Depression comorbidity and antidepressant use in veterans with chronic hepatitis $C$ : results from a retrospective chart review. J Clin Psychiatry 69:810-816.

Nelson TE, Gruol DL (2004) The chemokine CXCL10 modulates excitatory activity and intracellular calcium signaling in cultured hippocampal neurons. J Neuroimmunol 156:74-87.

Nosten-Bertrand M, Kappeler C, Dinocourt C, Denis C, Germain J, Phan Dinh Tuy F, Verstraeten S, Alvarez C, Métin C, Chelly J, Giros B, Miles R, Depaulis A, Francis F (2008) Epilepsy in Dcx knockout mice associated with discrete lamination defects and enhanced excitability in the hippocampus. PLoS One 3:e2473.

Parent JM, Yu TW, Leibowitz RT, Geschwind DH, Sloviter RS, Lowenstein DH (1997) Dentate granule cell neurogenesis is increased by seizures and contributes to aberrant network reorganization in the adult rat hippocampus. J Neurosci 17:3727-3738.

Patel S, Lyons-Weiler J (2004) caGEDA: a web application for the integrated analysis of global gene expression patterns in cancer. Appl Bioinformatics 3:49-62. 
Petersen CP, Bordeleau ME, Pelletier J, Sharp PA (2006) Short RNAs repress translation after initiation in mammalian cells. Mol Cell 21:533-542.

Prow NA, Irani DN (2008) The inflammatory cytokine, interleukin-1 beta, mediates loss of astroglial glutamate transport and drives excitotoxic motor neuron injury in the spinal cord during acute viral encephalomyelitis. J Neurochem 105:1276-1286.

Quan N, Banks WA (2007) Brain-immune communication pathways. Brain Behav Immun 21:727-735.

Rao RS, Medhi B, Saikia UN, Arora SK, Toor JS, Khanduja KL, Pandhi P (2008) Experimentally induced various inflammatory models and seizure: understanding the role of cytokine in rat. Eur. Neuropsychopharmacol 18, 760-767.

Ravizza T., Balosso S. and Vezzani A. (2011) Inflammation and prevention of epileptogenesis. Neurosci Lett 497, 223-230.

Riazi K, Galic MA, Kuzmiski JB, Ho W, Sharkey KA, Pittman QJ (2008) Microglial activation and TNFalpha production mediate altered CNS excitability following peripheral inflammation. Proc Natl Acad Sci USA 105, 17151-17156.

Riazi K, Galic MA, Pittman QJ (2010) Contributions of peripheral inflammation to seizure susceptibility: cytokines and brain excitability. Epilepsy Res 89:34-42.

Riazi K, Honar H, Homayoun H, Demehri S, Bahadori M, Dehpour AR (2004) Intestinal inflammation alters the susceptibility to pentylenetetrazole-induced seizure in mice. J. Gastroenterol Hepatol 19, 270-277.

Risbud RM, Porter BE (2013) Changes in microRNA expression in the whole hippocampus and hippocampal synaptoneurosome fraction following pilocarpine induced status epilepticus. PLoS ONE 8:e53464.

Rodríguez-Frade JM, Mellado M, Martínez-A C (2001) Chemokine receptor dimerization: two are better than one. Trends Immunol 22:612-617.

Romanovsky AA, Ivanov AI, Lenczowski MJ, Kulchitsky VA, Van Dam AM, Poole S, Homer LD, Tilders FJ (2000) Lipopolysaccharide transport from the peritoneal cavity to the blood: is it controlled by the vagus nerve? Auton Neurosci 85:133-140.

Rostène W, Dansereau MA, Godefroy D, Van Steenwinckel J, Reaux-Le Goazigo A, MélikParsadaniantz S, Apartis E, Hunot S, Beaudet N, Sarret P (2011) Neurochemokines: a menage a trois providing new insights on the functions of chemokines in the central nervous system. $J$ Neurochem 118:680-694.

Sansig G, Bushell TJ, Clarke VR, Rozov A, Burnashev N, Portet C, Gasparini F, Schmutz M, Klebs K, Shigemoto R, Flor PJ, Kuhn R, Knoepfel T, Schroeder M, Hampson DR, Collett VJ, Zhang C, Duvoisin RM, Collingridge GL, van Der PH (2001) Increased seizure susceptibility in mice lacking metabotropic glutamate receptor 7 . J Neurosci 21:8734-8745.

Sayyah M, Javad-Pour M, Ghazi-Khansari M (2003) The bacterial endotoxin lipopolysaccharide enhances seizure susceptibility in mice: involvement of proinflammatory factors: nitric oxide and prostaglandins. Neuroscience 122:1073-1080. 
Schafer DP, Lehrman EK, Kautzman AG, Koyama R, Mardinly AR, Yamasaki R, Ransohoff RM, Greenberg ME, Barres BA, Stevens B (2012) Microglia sculpt postnatal neural circuits in an activity and complement-dependent manner. Neuron 74:691-705.

Seifert G, Steinhauser C (2013) Neuron-astrocyte signaling and epilepsy. Exp Neurol 244:4-10.

Siegel G, et al. (2009) A functional screen implicates microRNA-138-dependent regulation of the depalmitoylation enzyme APT1 in dendritic spine morphogenesis. Nat Cell Biol 11:705-716.

Siwek M, Henseler C, Broich K, Papazoglou A, Weiergraber M (2012) Voltage-gated Ca(2+_ channel mediated $\mathrm{Ca}(2+)$ influx in epileptogenesis. Adv Exp Med Biol 740:1219-1247.

Stephan AH, Barres BA, Stevens B (2012) The complement system: an unexpected role in synaptic pruning during development and disease. Annu Rev Neurosci 35:369-89.

Stevens B, Allen NJ, Vazquez LE, Howell GR, Christopherson KS, Nouri N, Micheva KD, Mehalow AK, Huberman AD, Stafford B, Sher A, Litke AM, Lambris JD, Smith SJ, John SW, Barres BA (2007) The classical complement cascade mediates CNS synapse elimination. Cell 131:1164-1178.

Stumm R, Höllt V (2007) CXC chemokine receptor 4 regulates neuronal migration and axonal pathfinding in the developing nervous system: implications for neuronal regeneration in the adult brain. J Mol Endocrinol 38:377-382

Soreq $\mathrm{H}$, Wolf $\mathrm{Y}$ (2011) NeurimmiRs: microRNAs in the neuroimmune interface. Trends Mol Med 17:548-555.

Taniguchi Y, Yokoyama K, Inui K, Deguchi Y, Furukawa K, Noda K (1997) Inhibition of brain cyclooxygenase-2 activity and the antipyretic action of nimesulide. Eur J Pharmacol 330:221-229.

Teeling JL, Cunningham C, Newman TA, Perry VH (2010) The effect of non-steroidal antiinflammatory agents on behavioural changes and cytokine production following systemic inflammation: Implications for a role of COX-1. Brain Behav Immun 24:409-419.

Tellez-Zenteno JF, Matijevic S, Wiebe S (2005) Somatic comorbidity of epilepsy in the general population in Canada. Epilepsia 46:1955-1962.

Tellez-Zenteno JF, Patten SB, Jette N, Williams J, Wiebe S (2007) Psychiatric comorbidity in epilepsy: a population-based analysis. Epilepsia 48, 2336-2344.

Ure J, Baudry M, Perassolo M (2006) Metabotropic glutamate receptors and epilepsy. J Neurol Sci 247:1-9.

Van Dam AM, Bol JG, Gaykema RP, Goehler LE, Maier SF, Watkins LR, Tilders FJ (2000) Vagotomy does not inhibit high dose lipopolysaccharide-induced interleukin-1beta immunoreactivity in rat brain and pituitary gland. Neurosci Lett 285:169-172

Vezzani A, Balosso S, Ravizza T (2008) The role of cytokines in the pathophysiology of epilepsy. Brain Behav Immun 22:797-803.

Vezzani A, Moneta D, Richichi C, Aliprandi M, Burrows SJ, Ravizza T, Perego C, De Simoni MG (2002) Functional role of inflammatory cytokines and antiinflammatory molecules in seizures and epileptogenesis. Epilepsia 43 Suppl 5:30-35. 
Vitkovic L, Bockaert J, Jacque C (2000) "Inflammatory" cytokines: neuromodulators in normal brain? J Neurochem 74:457-471.

Viviani B, Gardoni F, Marinovich M (2007) Cytokines and neuronal ion channels in health and disease. Int Rev Neurobiol 82:247-263.

Volanakis JE (1995) Transcriptional regulation of complement genes. Annu Rev Immunol 13:277-305.

Wake, H., Moorhouse, A. J., Jinno, S., Kohsaka, S., Nabekura, J., 2009. Resting microglia directly monitor the functional state of synapses in vivo and determine the fate of ischemic terminals. J. Neurosci. 29, 3974-3980.

Wang D, Richmond A (2001) Nuclear factor-kappa B activation by the CXC chemokine melanoma growth-stimulatory activity/growth-regulated protein involves the MEKK1/p38 mitogen-activated protein kinase pathway. J Biol Chem 276:3650-3659.

Wang JG, Strong JA, Xie W, Yang RH, Coyle DE, Wick DM, Dorsey ED, Zhang JM (2008) The chemokine CXCL1/growth related oncogene increases sodium currents and neuronal excitability in small diameter sensory neurons. Mol Pain 4:38.

Weber F, Wagner V, Rasmussen SB, Hartmann R, Paludan SR (2006) Double-stranded RNA is produced by positive-strand RNA viruses and DNA viruses but not in detectable amounts by negative-strand RNA viruses. J Virol 80:5059-5064.

Werner FM, Covenas R (2011) Classical neurotransmitters and neuropeptides involved in generalized epilepsy: a focus on antiepileptic drugs. Curr Med Chem 18:4933-4948.

Wheeler D, Knapp E, Bandaru VV, Wang Y, Knorr D, Poirier C, Mattson MP, Geiger JD, Haughey NJ (2009) Tumor necrosis factor-alpha-induced neutral sphingomyelinase-2 modulates synaptic plasticity by controlling the membrane insertion of NMDA receptors. J Neurochem 109:1237-1249.

Ye RD (2001) Regulation of nuclear factor kappaB activation by G-protein-coupled receptors. J Leukoc Biol 70:839-848.

Younger ST, Corey DR (2011) Transcriptional gene silencing in mammalian cells by miRNA mimics that target gene promoters. Nucleic Acids Res 39, 5682-5691.

Zhang J, Malik A, Choi HB, Ko RW, Dissing-Olesen L, MacVicar BA (2014) Microglial CR3 activation triggers long-term synaptic depression in the hippocampus via NADPH oxidase. Neuron 82: 195-207. 
Appendix I. Published Manuscripts 


\title{
Peripheral immune challenge with dsRNA enhances kainic acid-induced status epilepticus
}

\author{
Lindsay T. Kirschman • Elizabeth Borysiewicz • \\ Daniel Fil • Gregory W. Konat
}

Received: 18 January 2011 / Accepted: 21 January 2011 /Published online: 9 February 2011

(C) Springer Science+Business Media, LLC 2011

\begin{abstract}
Clinical evidence implicates peripheral inflammatory diseases as comorbid factors in epilepsy. The present study was designed to determine the effect of the acute phase of antiviral response on seizure susceptibility. Young adult mice were intraperitoneally injected with $12 \mathrm{mg} / \mathrm{kg}$ of a viral mimic, polyinosinic:polycytidylic acid (PIC). After $48 \mathrm{~h}$, seizures were induced by subcutaneous injection of kainic acid (KA). PIC-pretreatment profoundly enhances vulnerability to excitotoxic insult as evidenced by increased seizure intensity and extended duration of status epilepticus. These results support the notion that peripheral viral infections may alter brain function resulting in enhanced predilection to seizures.
\end{abstract}

Keywords Polyinosinic:polycytidylic acid · Acute antiviral response $\cdot$ Seizures $\cdot$ Excitotoxic insult $\cdot$ Inflammation .

Immune-to-brain communication

\section{Introduction}

Epilepsy is one of the most common neuropathologies characterized by recurrent seizures that result from excessive neuronal activity due to increased excitability, decreased inhibition, or both (Fisher et al. 2005). Brain inflammation associated with a number of conditions, e.g., metabolic, infectious, ischemic and traumatic insults to the brain, is a major factor contributing to seizure propensity (Vezzani and Granata 2005). Moreover, epidemiological

L. T. Kirschman • E. Borysiewicz • D. Fil • G. W. Konat $(\square)$

Department of Neurobiology and Anatomy,

West Virginia University School of Medicine,

4052 HSCN, P.O. Box 9128,

Morgantown, WV 26506-9128, USA

e-mail: gkonat@wvu.edu evidence indicates that also peripheral inflammatory diseases increase seizure propensity (Tellez-Zenteno et al. 2005). The putative mechanism entails immune-tobrain communication, whereby blood-borne inflammatory mediators generated in the periphery elicit an inflammatory response in the brain (Quan and Banks 2007; Dantzer 2006) that lowers seizure threshold. Experimental systems to study this pathological link have utilized bacteria, bacterial components or chemicals as inflammagens (reviewed by Riazi et al. 2010). Although these systems model clinical sepsis, their intricate pathological pattern makes it difficult to discern the underlying mechanisms. For example, intraperitoneally administered lipopolysaccharide (LPS), a commonly used inflammagen, rapidly reaches circulation (Lenczowski et al. 1997), and thus, the brain. Therefore, it is not certain whether the increased seizure susceptibility results from brain inflammation induced directly by LPS, or from brain response to peripherally generated inflammatory mediators.

Double-stranded RNA (dsRNA) is a common intermediate during replication of most viruses (Weber et al. 2006). The administration of dsRNA or its synthetic analog, PIC, mimics the acute phase response to viral infection (Traynor et al. 2004). Recently, we have demonstrated that intraperitoneal injection of PIC elicits a robust inflammatory response in the brain (Konat et al. 2009; Fil et al. 2011), yet the inflammagen does not pass into the circulation, and the brain response is mediated by blood-borne factors (Fil et al. 2011). Therefore, this model may circumvent the inherent complications of the sepsis models and facilitate the elucidation of mechanisms by which peripherally generated inflammatory factors affect brain function. The present study was undertaken to evaluate applicability of this model by determining whether peripheral challenge of mice with dsRNA will 
increase vulnerability of the animals to kainic acid (KA)induced status epilepticus.

\section{Materials and methods}

Eight-week-old C57BL/6 female mice obtained from Hilltop Lab Animals, Inc. (Scottdale, PA) were housed under 12-h light/dark conditions and fed ad libitum. All procedures were approved by the West Virginia University Animal Care and Use Committee and conducted in compliance with the guidelines published in the NIH Guide for the Care and Use of Laboratory Animals. Peripheral inflammation was induced by intraperitoneal injection of $12 \mathrm{mg} / \mathrm{kg}$ of PIC (Invivogene, San Diego, CA) in saline. Mice received either three daily injections or a single injection of PIC. Respective control groups received equivolume $(100 \mu \mathrm{l})$ saline injections. Seizures were induced $48 \mathrm{hr}$ after the last PIC injection by subcutaneous injection of 10,15 , or $20 \mathrm{mg} / \mathrm{kg}$ of KA (Sigma Chemical Co., St Louis, MO) or saline $(50 \mu \mathrm{l})$. Seizure severity was graded by blinded observers in 5 min increments for $2 \mathrm{~h}$. The behavioral scores were as follows: 0 , no response; 1 , immobility; 2, rigid posture; 3, scratching/circling/head bobbing; 4, forelimb clonus/rearing/falling; 5, repetitious pattern 4; 6, severe tonic-clonic seizures (Morrison et al. 1996). Statistical analysis was performed by ANOVA followed by the Student t-test and differences with $p<$ 0.05 were considered to be statistically significant.

\section{Results}

A time course of KA-induced status epilepticus in mice pretreated three times with PIC is shown in Fig. 1. Peripheral PIC challenge profoundly increased the intensity of seizures in comparison to saline pretreated animals. Cumulative seizure scores (CSS) calculated by summation of the incremental scores over the 2-h observation period revealed a 5.2-fold enhancement by PIC over the saline group (Fig. 2a). PIC challenge also altered the kinetics of status epilepticus (Fig. 1). Thus, seizure intensity peaked at approximately $35 \mathrm{~min}$ in the saline group, and at approximately $80 \mathrm{~min}$ in the PIC group. Whereas the seizures ceased in the saline group at approximately $110 \mathrm{~min}$ after KA injection, the PIC pretreated animals were still in a fullblown status epilepticus at that time point. Seizure intensity was directly related to doses of the excitotoxin (Fig. 2a). In saline pretreated mice CSS were 11,25 and 46 at 10,15 and $20 \mathrm{mg} / \mathrm{kg}$ of KA, respectively. PIC challenge increased seizure intensities by approximately $6.9,5.2$ and 2.7-fold over the saline groups at KA doses of 10,15 , and $20 \mathrm{mg} / \mathrm{kg}$, respectively. Although no mortality was observed at 10 or

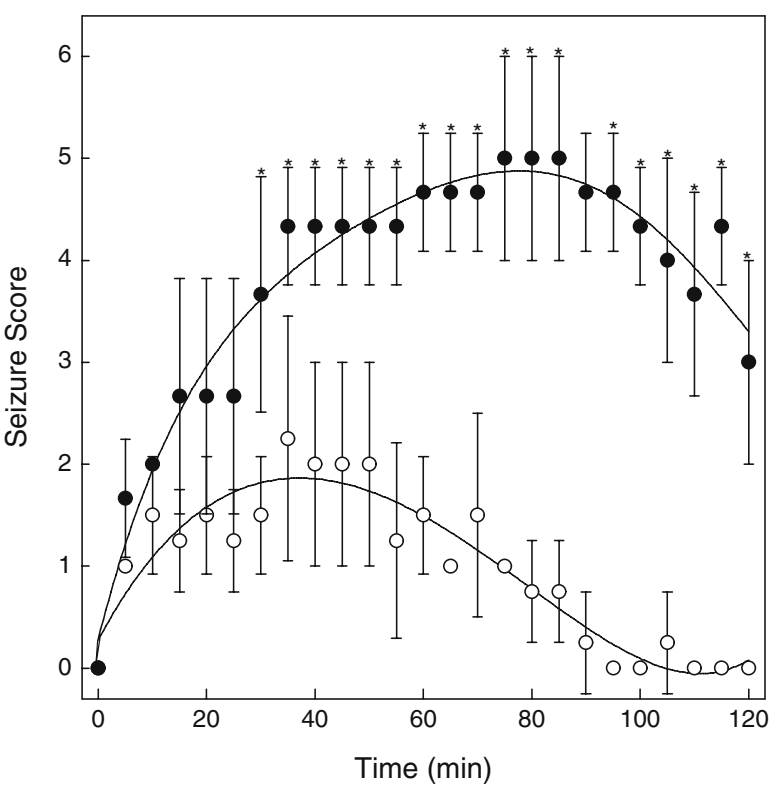

Fig. 1 Time course of KA-induced status epilepticus. Mice were pretreated daily with PIC (filled circles) or saline (open circles) for three consecutive days. After $48 \mathrm{~h}$, seizures were induced by the administration of $15 \mathrm{mg} / \mathrm{kg}$ of KA, and their intensity was scored over a period of 2 h. For details see "Materials and methods". Points represent averages \pm S.D. from 3-4 animals. Asterisks indicate values significantly different from the corresponding control values (saline)

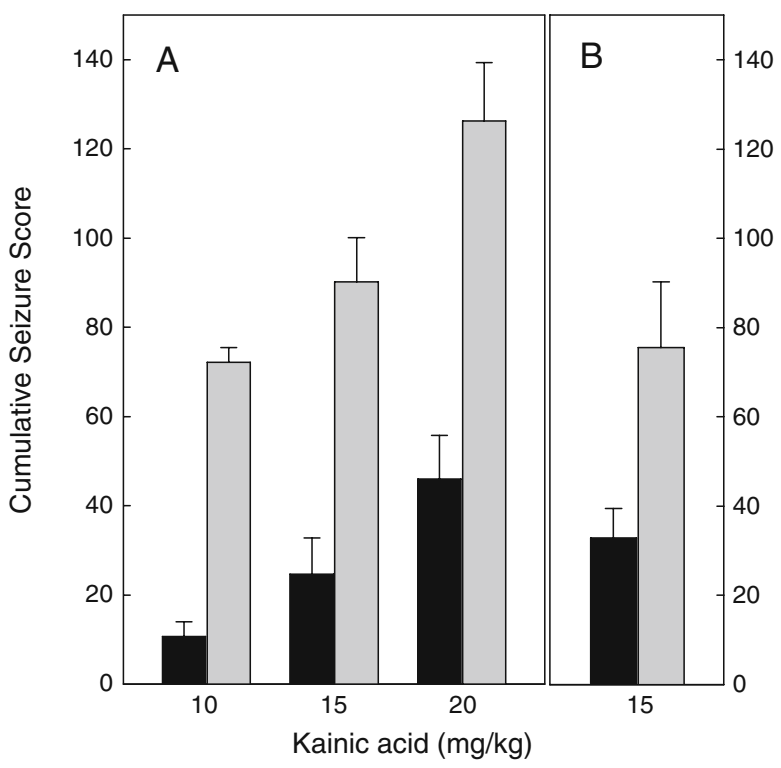

Fig. 2 Effect of KA and PIC doses on seizure intensity. In panel a, mice were pretreated daily with PIC (gray bars) or saline (black bars) for three consecutive days. After $48 \mathrm{~h}$, seizures were induced by the administration of different doses of KA. In panel $\mathbf{b}$, mice were pretreated with a single dose of PIC, and after $48 \mathrm{~h}$, seizures were induced by the administration of $15 \mathrm{mg} / \mathrm{kg}$ of KA. The intensity of seizures was scored over a period of $2 \mathrm{~h}$. For details see "Materials and methods". The results are expressed as cumulative seizure scores (CSS). Bars represent averages \pm S.D. from 3-4 animals. Asterisks indicate values significantly different from the corresponding control values (saline) 
$15 \mathrm{mg} / \mathrm{kg}$ doses, intense seizures induced by $20 \mathrm{mg} / \mathrm{kg}$ of KA in triply injected mice occasionally resulted in death. Finally, as shown in Fig. 2b, even a single peripheral challenge with PIC profoundly enhanced seizure intensity. CSS of this group did not differ significantly from CSS of the corresponding triple injection group (Fig. 2a) indicating that a single dose provides a saturating effect.

\section{Discussion}

The present study showed an enhancing effect of prior peripheral challenge with PIC, a common tool for the induction of the acute antiviral response (Traynor et al. 2004), on cerebral vulnerability to KA-induced status epilepticus. Thus, our results complement previous reports showing enhanced seizure susceptibility following bacterially-induced peripheral inflammation (Riazi et al. 2010), and support a causative link between peripheral infections and seizures (Tellez-Zenteno et al. 2005). Moreover, because PIC is a strictly peripheral inflammagen (Fil et al. 2011), our results prove that the cerebral effects are mediated by the immune-to-brain signaling. In contrast, the bacterial models featured a highly possible direct interaction of the inflammagen with the brain. Consequently, the PIC paradigm provides a unique model to study mechanisms by which blood-borne inflammatory mediators generated in the periphery alter neural function within the brain rendering it more vulnerable to excitotoxic insult.

We have previously showed that the cerebral inflammatory response to PIC challenge features a robust but transient upregulation of a plethora of cytokine and chemokine genes (Konat et al. 2009; Fil et al. 2011). However, $48 \mathrm{~h}$ after the last PIC injection, i.e., at the time of KA challenge, expression of these genes returned to the baseline (not shown). Therefore, the cerebral inflammatory response must have induced protracted alterations of brain function that manifested as KA hypersusceptibility. A plausible mechanism may involve changes in the neurotransmitter signaling induced by inflammatory mediators. This notion is buttressed by previous observations that cerebral expression of glutamate receptors can be altered by peripheral inflammation (Guo et al. 2002; Harre et al. 2008). We are currently pursuing studies to verify these mechanisms.

In conclusion, our data support a causative link between viral infections in the periphery and epileptogenesis. Moreover, the paradigm based on intraperitoneal challenge with PIC provides a unique model system to address the underlying mechanisms.

Conflict of Interest The authors declare that they have no conflict of interest.

\section{References}

Dantzer R (2006) Cytokine, sickness behavior, and depression. Neurol Clin 24:441-460

Fil D, Borysiewicz E, Konat GW (2011) A broad upregulation of cerebral chemokine genes by peripherally-generated inflammatory mediators. Metab Brain Dis (in press)

Fisher RS, van Emde BW, Blume W, Elger C, Genton P, Lee P, Engel J Jr (2005) Epileptic seizures and epilepsy: definitions proposed by the International League Against Epilepsy (ILAE) and the International Bureau for Epilepsy (IBE). Epilepsia 46:470-472

Guo W, Zou S, Tal M, Ren K (2002) Activation of spinal kainate receptors after inflammation: behavioral hyperalgesia and subunit gene expression. Eur J Pharmacol 452:309-318

Harre EM, Galic MA, Mouihate A, Noorbakhsh F, Pittman QJ (2008) Neonatal inflammation produces selective behavioural deficits and alters N-methyl-D-aspartate receptor subunit mRNA in the adult rat brain. Eur J Neurosci 27:644-653

Konat GW, Borysiewicz E, Fil D, James I (2009) Peripheral challenge with double-stranded RNA elicits global up-regulation of cytokine gene expression in the brain. J Neurosci Res 87:13811388

Lenczowski MJ, Van Dam AM, Poole S, Larrick JW, Tilders FJ (1997) Role of circulating endotoxin and interleukin-6 in the ACTH and corticosterone response to intraperitoneal LPS. Am J Physiol 273:R1870-R1877

Morrison RS, Wenzel HJ, Kinoshita Y, Robbins CA, Donehower LA, Schwartzkroin PA (1996) Loss of the p53 tumor suppressor gene protects neurons from kainate-induced cell death. J Neurosci 16:1337-1345

Quan N, Banks WA (2007) Brain-immune communication pathways. Brain Behav Immun 21:727-735

Riazi K, Galic MA, Pittman QJ (2010) Contributions of peripheral inflammation to seizure susceptibility: cytokines and brain excitability. Epilepsy Res 89:34-42

Tellez-Zenteno JF, Matijevic S, Wiebe S (2005) Somatic comorbidity of epilepsy in the general population in Canada. Epilepsia 46:1955-1962

Traynor TR, Majde JA, Bohnet SG, Krueger JM (2004) Intratracheal double-stranded RNA plus interferon-gamma: a model for analysis of the acute phase response to respiratory viral infections. Life Sci 74:2563-2576

Vezzani A, Granata T (2005) Brain inflammation in epilepsy: experimental and clinical evidence. Epilepsia 46:1724-1743

Weber F, Wagner V, Rasmussen SB, Hartmann R, Paludan SR (2006) Double-stranded RNA is produced by positive-strand RNA viruses and DNA viruses but not in detectable amounts by negative-strand RNA viruses. J Virol 80:5059-5064 


\title{
Peripherally restricted acute phase response to a viral mimic alters hippocampal gene expression
}

\author{
Lindsay T. Michalovicz • Gregory W. Konat
}

Received: 27 November 2013 / Accepted: 13 December 2013 / Published online: 24 December 2013

(C) Springer Science+Business Media New York 2013

\begin{abstract}
We have previously shown that peripherally restricted acute phase response (APR) elicited by intraperitoneal (i.p.) injection of a viral mimic, polyinosinic-polycytidylic acid (PIC), renders the brain hypersusceptible to excitotoxic insult as seen from profoundly exacerbated kainic acid (KA)induced seizures. In the present study, we found that this hypersusceptibility was protracted for up to $72 \mathrm{~h}$. RT-PCR profiling of hippocampal gene expression revealed rapid upregulation of 23 genes encoding cytokines, chemokines and chemokine receptors generally within $6 \mathrm{~h}$ after PIC challenge. The expression of most of these genes decreased by $24 \mathrm{~h}$. However, two chemokine genes, i.e., $\mathrm{Ccl} 19$ and $\mathrm{Cxcll} 3$ genes, as well as two chemokine receptor genes, $\mathrm{Ccr} 1$ and $\mathrm{Ccr}$, remained upregulated for $72 \mathrm{~h}$ suggesting their possible involvement in the induction and sustenance of seizure hypersusceptibility. Also, 12 genes encoding proteins related to glutamatergic and GABAergic neurotransmission featured initial upregulation or downregulation followed by gradual normalization. The upregulation of the Gabrr3 gene remained upregulated at $72 \mathrm{~h}$, congruent with its plausible role in the hypersusceptible phenotype. Moreover, the expression of ten microRNAs (miRs) was rapidly affected by PIC challenge, but their levels generally exhibited oscillating profiles over the time course of seizure hypersusceptibility. These results indicate that protracted seizure susceptibility following peripheral APR is associated with a robust polygenic response in the hippocampus.
\end{abstract}

Keywords Polyinosinic-polycytidylic acid · Seizures · Inflammation $\cdot$ Neurotransmission $\cdot$ Cytokines $\cdot$ MicroRNA

L. T. Michalovicz $\cdot$ G. W. Konat $(\triangle)$

Department of Neurobiology and Anatomy, West Virginia University

School of Medicine, 1 Medical Center Dr., 4052 HSCN,

P.O. Box 9128, Morgantown, WV 26506-9128, USA

e-mail: Gkonat@wvu.edu

\section{Introduction}

The acute phase response (APR) is the first line of defense against viral infection and is mediated by innate immune cells that recognize molecular signatures of viral replication. dsRNA is an intermediate generated by most viruses during their replication cycle (Jacobs and Langland 1996; Weber et al. 2006). Mammalian cells have several receptors that detect the presence of extra- and intracellular dsRNA, i.e., Toll-like receptor 3 (TLR3), retinoic acid-inducible gene 1 (RIG-1), melanoma differentiation-associated protein 5 (MDA-5) and protein kinase R (PKR) (Berke et al. 2013). The ligation of these receptors leads to the production of type I interferons and other inflammatory cytokines with antiviral activity (Muller et al. 1994). Although the primary role of APR is to combat infections, the cytokines released into the circulation have significant effects on the brain. Thus, intraperitoneal injection of a synthetic dsRNA, polyinosinicpolycytidylic acid (PIC), in mice induces behavioral symptoms collectively referred to as "sickness behavior" (Muller et al. 1994; Guha-Thakurta and Majde 1997; Cunningham et al. 2007) that are congruent with behavioral effects of peripheral viral infections in humans (Loftis et al. 2008; Huckans et al. 2009; Nelligan et al. 2008). The PIC-induced symptoms peak at $6 \mathrm{~h}$ after the injection and subside by $48 \mathrm{~h}$ (Cunningham et al. 2007). The induction of sickness behavior is concomitant with transient upregulation of genes encoding IL-1 $\beta$, IL-6, TNF $\alpha$ and IFN $\beta$ in the hippocampus and hypothalamus (Cunningham et al. 2007). We have confirmed the expression of these cerebral genes and shown that their upregulation is global rather than regional, as it is featured in all parts of the brain, i.e., the forebrain, cerebellum and brain stem (Konat et al. 2009). We have further shown that the brain also features upregulation of a plethora of chemokines and their receptors (Fil et al. 2011). Generally, the upregulation of respective mRNAs peaks between 3 and $6 \mathrm{~h}$ following the 
PIC challenge and reaches from several- to several thousandfold over control. After $24 \mathrm{~h}$, the expression of most of the genes returns to the baseline levels. We also demonstrated that APR is restricted to the peritoneal cavity as PIC does not enter the blood circulation. Moreover, the cerebral inflammatory response can be induced in naïve mice by a passive transfer of blood from PIC-challenged mice indicating that the response is mediated by circulating inflammatory factors.

Furthermore, we have found that this robust, albeit generally transient, genomic response to PIC-induced APR renders the brain hypersusceptible to excitotoxic insult (Kirschman et al. 2011). In this study, mice were i.p. injected with PIC and after 2 days challenged with kainic acid (KA). The PIC pretreatment profoundly increased both the intensity and duration of KA-induced seizures as compared to naïve animals challenged with KA alone. This finding indicates that the brain inflammatory response instigated by peripheral APR induces protracted remodeling of neural circuits. This finding also supports a causative role of peripheral viral infections in the increased seizure propensity inferred from epidemiological studies (Tellez-Zenteno et al. 2005). Possible mechanisms of APR-induced seizure hypersusceptibility may entail increased neuronal excitability and/or decreased neuronal inhibition instigated by inflammatory mediators. Inflammationinduced changes in the expression of neurotransmitter receptors (Guo et al. 2002; Harre et al. 2008; Galic et al. 2012) support such mechanisms. Moreover, several microRNAs (miRs), important regulators of gene expression at the neuroimmune interface (Soreq and Wolf 2011), have been implicated in the pathology of seizures (Jimenez-Mateos et al. 2011; Hu et al. 2011; Aronica et al. 2010; Liu et al. 2010), suggesting their role as upstream determinants of PICinduced seizure hypersusceptibility.

The present study was undertaken to gain insight into the genetic mechanisms underlying seizure hypersusceptibility following PIC-induced APR. We focused on the hippocampus because this structure is the primary region of ictal onset instigated by KA administration (Ben-Ari and Cossart 2000). We profiled the expression of several inflammatory, neurotransmission-related as well as miR genes during the period of seizure hypersusceptibility.

\section{Materials and methods}

Animals

Eight-week old C57BL/6 J mice obtained from Charles River Laboratories (Wilmington, MA) were housed under 12-h light/dark conditions (lights on at $6 \mathrm{am}$ ) and fed ad libitum. Peripheral APR was induced by a single intraperitoneal (i.p.) injection of $12 \mathrm{mg} / \mathrm{kg}$ of PIC (Invivogen, San Diego, CA) in $100 \mu \mathrm{l}$ of saline. Saline injected mice served as controls. All procedures were approved by the West Virginia University Animal Care and Use Committee and conducted in compliance with the guidelines published in the NIH Guide for the Care and Use of Laboratory Animals.

Open-field test

Locomotor activity was assessed using the automated activity monitoring system PAS-Open field $(41 \mathrm{~cm} \times 41 \mathrm{~cm} \times 38 \mathrm{~cm}$; San Diego Instruments, San Diego, CA). The chambers were equipped with a $16 \times 16$ array of infrared photo-beams to measure horizontal (XY) movement and an additional frame of 16 beams to monitor rearing. Locomotor activity was recorded for $15 \mathrm{~min}$.

\section{Evaluation of seizure susceptibility}

At different time points (1-7 days) following PIC challenge, mice received subcutaneous injections of $20 \mathrm{mg} / \mathrm{kg}$ of KA (Sigma Chemical Co., St. Louis, MO) in saline. Saline injected mice served as controls. Seizure severity was scored by blinded observers in $5 \mathrm{~min}$ intervals as described previously (Kirschman et al. 2011). Cumulative seizure scores were assessed as the summation of all scores over the $2 \mathrm{~h}$ observation period.

\section{Blood cytokine measurement}

Mice were deeply anesthetized with $65 \mathrm{mg} / \mathrm{ml}$ of pentobarbital (Fatal Plus, Vortech Pharmaceutical, Dearborn, MI) administered i.p. and sacrificed by pneumothorax. Blood was quickly collected by heart puncture and citrated. IFN $\beta$ was measured using the VeriKine Mouse Interferon Beta ELISA kit (PBL Interferon Source, Piscataway, NJ) per manufacturer's instructions. IL-6 levels were measured using the Milliplex MAP Mouse Cytokine/Chemokine panel (Millipore, Billerica, MA) per manufacturer's instructions and analyzed using a Luminex 200 System (Luminex, Austin, TX).

\section{qRT-PCR}

Mice were anesthetized and sacrificed as described above, and transaortically perfused with saline. Brains were removed from the skull and hippocampi were dissected out. The tissue was immediately homogenized in TRI Reagent (Molecular Research Center, Inc., Cincinnati, OH), and RNA was isolated per manufacturer's protocol. For quantitation of mRNA, cDNA was synthesized using SuperScript III First-strand Synthesis kit (Invitrogen, Carlsbad, CA) and quantified using $\mathrm{RT}^{2}$ SYBRGreen (Qiagen, Valencia, CA). For miR quantitation, cDNA was synthesized using NCode VILO miRNA cDNA Synthesis kit (Invitrogen, Carlsbad, CA) and quantified using EXPRESS SYBR GreenER miRNA qRT-PCR kit 
(Invitrogen, Carlsbad, CA). qRT-PCR was performed in an ABI7500 Real-Time PCR system (Applied Biosystems, Foster City, CA). Glyceraldehyde phosphate dehydrogenase (GAPDH) mRNA or U6 snRNA were used as internal controls for mRNAs and miRs, respectively. The $\Delta \Delta \mathrm{Ct}$ method was used for quantitation. Specific primer sequences are available upon request.

\section{Statistical analysis}

Data were analyzed by ANOVA and expressed as means \pm SD. Statistical comparisons between groups were performed using Student's $t$ test. Differences between groups were considered significant at $P \leq 0.05$.

\section{Results}

Verification of sickness behavior

PIC-induced sickness behavior strongly suppresses the burrowing activity of mice (Cunningham et al. 2007; Konat et al. 2009). Although at nadir (6 $\mathrm{h}$ post-injection), the burrowing activity of PIC-challenged animals drops below $10 \%$ of the respective controls, the test is rather cumbersome and lengthy $(2 \mathrm{~h})$. Cunningham et al. also found suppression of locomotor activity using the open field test, albeit to a much lesser extent than the burrowing activity. In concordance with this study, we observed the locomotion of mice to be reduced by approximately 30 and $60 \%$ at 3 and $6 \mathrm{~h}$ after PIC injection, respectively (Fig. 1). However, we found that the rearing activity was suppressed equally to the burrowing activity as

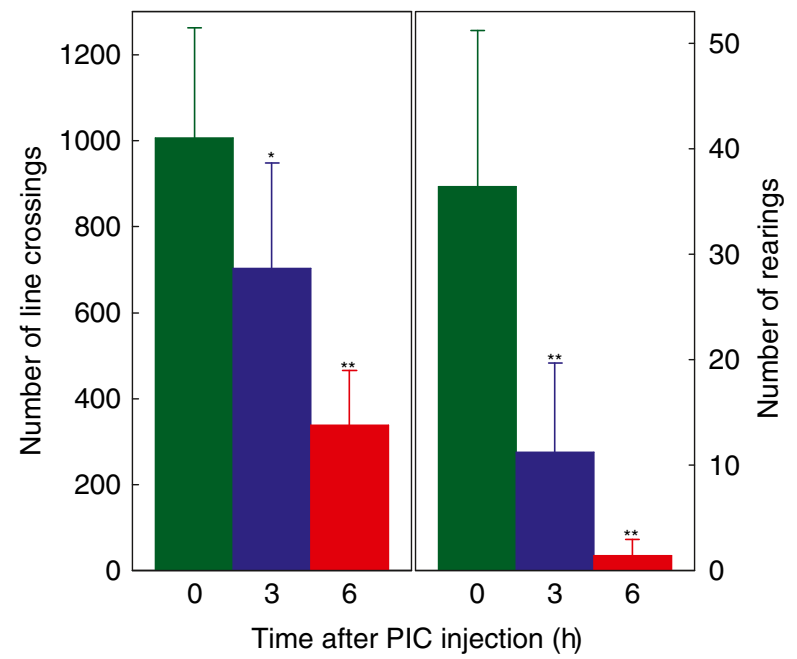

Fig. 1 The suppression of locomotor and rearing behavior by PIC challenge. Mice were i.p. injected with $12 \mathrm{mg} / \mathrm{kg}$ of PIC and after 3 or $6 \mathrm{~h}$ the locomotor and rearing activities were evaluated (for details see Materials and Methods). Saline injected mice served as controls $(0 \mathrm{~h})$. Bars represent means \pm S.D. from 6 to 10 animals. Values significantly different from controls are indicated by asterisks. ${ }^{*} p \leq 0.05 ;{ }^{* *} p \leq 0.01$ it dropped by 70 and $96 \%$ at 3 and $6 \mathrm{~h}$, respectively. Consequently, the rearing test, which lasts only $15 \mathrm{~min}$, provides a convenient, highly sensitive method to verify successful induction of sickness behavior.

Duration of seizure hypersusceptibility

We have previously demonstrated that PIC challenge strongly enhances the susceptibility of mice to KA-induced seizures (Kirschman et al. 2011). However, this feature was analyzed only $48 \mathrm{~h}$ after PIC injection. Therefore, we determined the duration of this hypersusceptible phenotype to provide a time frame for the subsequent genetic analysis. As seen from Fig. 2, the seizure response measured as cumulative seizure scores was highest 1 day post-PIC, reaching nearly 3 -fold over saline injected controls. Although the hypersuceptiblity gradually decreased, it was still significant at 2 and 3 days post-PIC. By days 4 and 7, the response of the PIC challenged animals was indistinguishable from that of controls.

\section{Cytokine surge}

Intraperitoneal PIC injection induces the synthesis of IFN $\beta$, IL-6, IL-1 $\beta$ and TNF $\alpha$ that rapidly reach the circulation as seen from the surge of these inflammatory cytokines in the blood (Cunningham et al. 2007). Their levels peak sharply at $3 \mathrm{~h}$ post-injection and then quickly decline. We confirmed these kinetics for IFN $\beta$ and IL-6 as shown in Fig. 3. Thus,

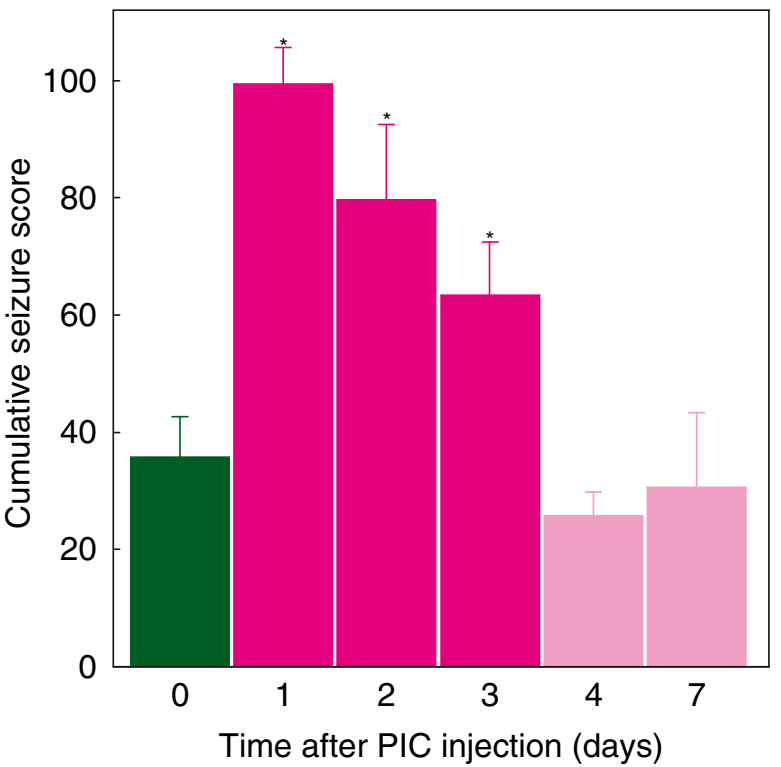

Fig. 2 Time course of seizure susceptibility following PIC challenge. Mice were i.p. injected with $12 \mathrm{mg} / \mathrm{kg}$ of PIC. At different time points after PIC challenge, the animals were s.c. injected with $20 \mathrm{mg} / \mathrm{kg}$ of KA and seizure severity was evaluated in $5 \mathrm{~min}$ increments for $2 \mathrm{~h}$ and expressed as cumulative seizure scores (for details see Materials and Methods). Mice injected with saline instead of PIC served as controls. Bars represent means \pm S.D. from 3 to 7 animals. Values significantly different from controls are indicated by asterisks $(p \leq 0.05)$ 


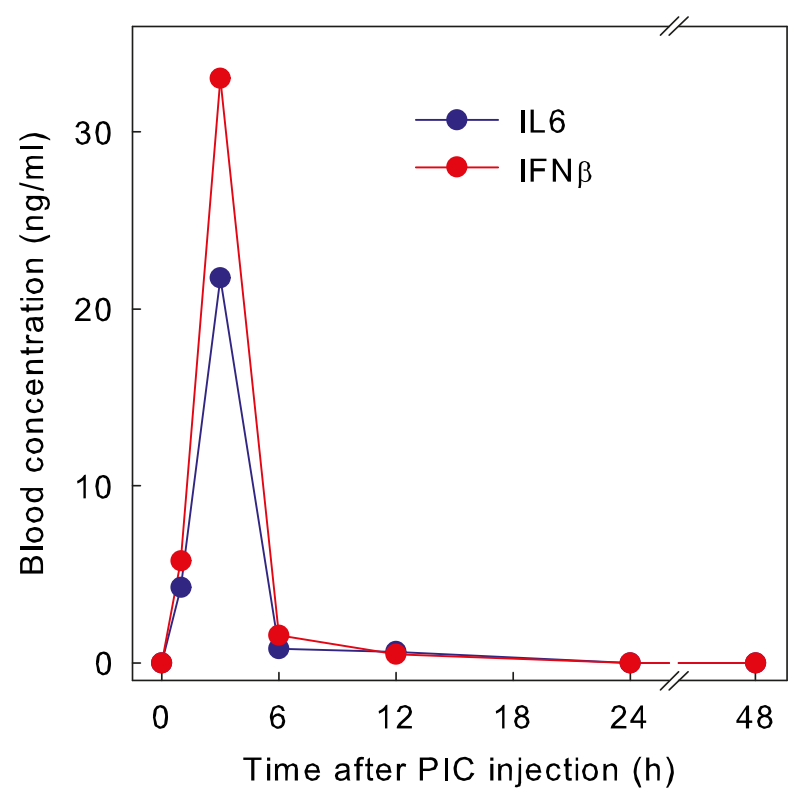

Fig. 3 Blood cytokine surge induced by PIC challenge. Mice were i.p. injected with $12 \mathrm{mg} / \mathrm{kg}$ of PIC and the levels of IFN $\beta$ and IL-6 in the blood plasma were determined at various time points as indicated. Data represent averages from 2 animals

both cytokines reached the highest levels $3 \mathrm{~h}$ after PIC challenge, and decreased rapidly thereafter, reaching baseline levels at $12 \mathrm{~h}$ post-injection. The maximal blood concentrations of IFN $\beta$ and IL- 6 were 33.5 and $21.5 \mathrm{ng} / \mathrm{ml}$, respectively, which is in concordance with the values observed by Cunningham et al. (2007).

\section{Expression of hippocampal genes}

\section{Inflammatory genes}

Based on our previous studies (Konat et al. 2009; Fil et al. 2011), we selected 23 inflammation-related genes comprising cytokines, chemokines and chemokine receptors, and profiled their expression in the hippocampus following PIC challenge. The blood cytokine surge was associated with a rapid upregulation of cytokine (Fig. 4) and chemokine (Fig. 5) genes, buttressing the cause-effect relationship between the circulating cytokines and the genetic response of the hippocampal cells. However, differences in the expression pattern of the genes were evident. The expression of the Il6, IFNb, Cxcll7, Ccl4, Cxcl1, Cxcl2, Cxcl9, Cxcl10 and Cxcl11 genes peaked between 3 and $6 \mathrm{~h}$ after PIC injection and dwindled rapidly thereafter. The Tnfa, Illb, Ccl7, Ccl12 and Ccl2 genes featured an extended timeframe of upregulation with high levels of their mRNA remaining at $24 \mathrm{~h}$. The expression of the Ccl19, Cxcll 3 and $C c l 5$ genes actually peaked at $24 \mathrm{~h}$. Most of the genes, except the Ifnb, Illb, Cxcl17, Cxcll, and Cxcl2 genes, were significantly upregulated even at $72 \mathrm{~h}$. The $C c l 9$ gene exhibited a unique expression profile, peaking early at $3 \mathrm{~h}$ and then peaking again from 48 to $72 \mathrm{~h}$. Also, the extent of upregulation varied greatly among the genes. The cytokine genes were upregulated by approximately 2 - to 32 -fold over control with the $I l 6$ gene being the most and the $I l 1 b$ gene being the least upregulated. These results corroborate a previous study of the response of hippocampal cytokine genes to PIC challenge (Cunningham et al. 2007). Among the chemokine genes, Cxcl11, Cxcl10, Cxcl9 and Cxcll featured the highest upregulation by more than a thousand-fold over control. The $\mathrm{Cxcl} 2, \mathrm{Ccl} 12$ and $\mathrm{Ccl} 2$ genes were upregulated up to several hundred-fold, whereas several ten-fold upregulations were observed for the $C c l 7, C c l 4$ and $C c l 5$ genes. The $C x c l 13$, Ccl19, Cxcl17 and Ccl9 genes were upregulated by less than ten-fold.

Also, five genes encoding chemokine receptors were significantly upregulated several fold over the baseline by PIC challenge (Fig. 6). The $\mathrm{Ccr} 1, \mathrm{Ccr} 6$ and $\mathrm{Ccr} 7$ gene expression peaked at $3 \mathrm{~h}$, whereas the expression of the $\mathrm{Cxcr} 2$ and $\mathrm{Cxcr} 5$ genes was delayed and peaked at $9 \mathrm{~h}$. By $72 \mathrm{~h}$ after PIC challenge, the $\mathrm{Crr} 1$ and $\mathrm{Crr} 7$ genes featured approximately 2-fold upregulation, while expression of the $C x c r 2$ and $C x c r 5$ genes dwindled to the baseline levels. In contrast, the Ccr6 gene featured downregulation beginning at $48 \mathrm{~h}$ and dipped to over 2-fold below control level at $72 \mathrm{~h}$.

\section{Neurotransmission genes}

Seizure hypersusceptibility can result from increased neural excitability, decreased neural inhibition, or both. The most direct effectors of these potential changes in excitability are the neurotransmitter receptors. Therefore, we screened the expression of genes encoding all glutamatergic and GABAergic neurotransmitter receptors and found nine genes to be significantly altered by PIC challenge (Fig. 7). These genes were: the kainate receptor gene Grik3, the AMPA receptor gene Gria4, the metabotropic glutamate receptor genes Grm1, Grm6, and Grm7, and the $\mathrm{GABA}_{\mathrm{A}}$ receptor subunit genes Gabrq, Gabre, Gabrr2, and Gabrr3. The Grik3, Gria4, Grm6, Gabrq, Gabrr2 and Gabrr3 genes showed initial several-fold upregulation coincident with the blood cytokine surge that peaked 3-6 h after PIC injection. While the expression of five of these genes gradually returned to the baseline level, the upregulation of the Gabrr3 gene was protracted and its mRNA level at $72 \mathrm{~h}$ was approximately 2fold over control. The Grm6 gene featured moderate upregulation after $48 \mathrm{~h}$, reaching approximately 1.5 - fold over the control level at $72 \mathrm{~h}$. In contrast, the Grm7, Grm1 and Gabre displayed initial downregulation by approximately 2-fold, followed by normalization.

In addition, we found the expression of three genes whose products are involved in synaptic buffering of glutamate and potassium to be significantly altered by PIC challenge. As shown in Fig. 7, the lactate dehydrogenase A gene ( $L d h a)$ was 
Fig. 4 The expression of cytokine genes in the hippocampus following PIC challenge. Mice were i.p. injected with $12 \mathrm{mg} / \mathrm{kg}$ of PIC and the levels of selected cytokine mRNAs were determined in the hippocampi by qRT-PCR at different time points as indicated. Data represent means \pm S.D. from 3 to 8 animals. Values significantly different from baseline levels $(0 \mathrm{~h})$ are indicated by asterisks $(p \leq 0.05)$

Fig. 5 The expression of chemokine genes in the hippocampus following PIC challenge. Mice were i.p. injected with $12 \mathrm{mg} / \mathrm{kg}$ of PIC and the levels of selected chemokine mRNAs were determined in the hippocampi by qRT-PCR at different time points as indicated. Data represent means \pm S.D. from 3 to 8 animals. Values significantly different from baseline levels $(0 \mathrm{~h})$ are indicated by asterisks ( $p \leq 0.05$ )
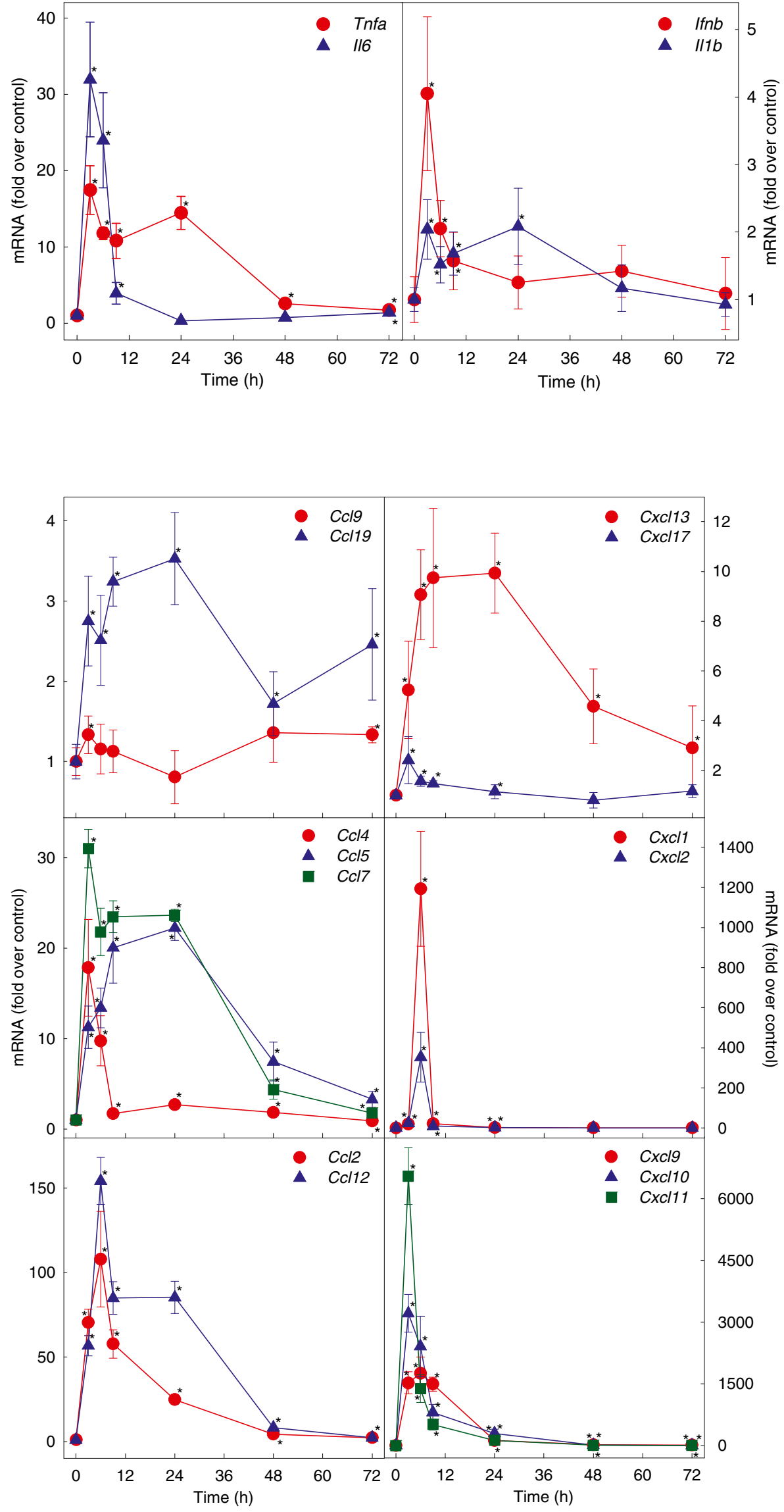
Fig. 6 The expression of chemokine receptor genes following PIC challenge. Mice were i.p. injected with $12 \mathrm{mg} / \mathrm{kg}$ of PIC and the levels of selected chemokine receptor mRNAs were determined in the hippocampi by qRT-PCR at different time points as indicated. Data represent means \pm S.D. from 3 to 8 animals Values significantly different from baseline levels $(0 \mathrm{~h})$ are indicated by asterisks $(p \leq 0.05)$

Fig. 7 The expression of neurotransmission-related genes following PIC challenge. Mice were i.p. injected with $12 \mathrm{mg} / \mathrm{kg}$ of PIC. At different time points, mRNA levels of selected neurotransmitter receptors and proteins involved in synaptic buffering of glutamate and potassium were determined in the hippocampi by qRT-PCR. Data represent means \pm S.D. from 3 to 6 animals. Values significantly different from baseline levels $(0 \mathrm{~h})$ are indicated by asterisks $(p \leq 0.05)$
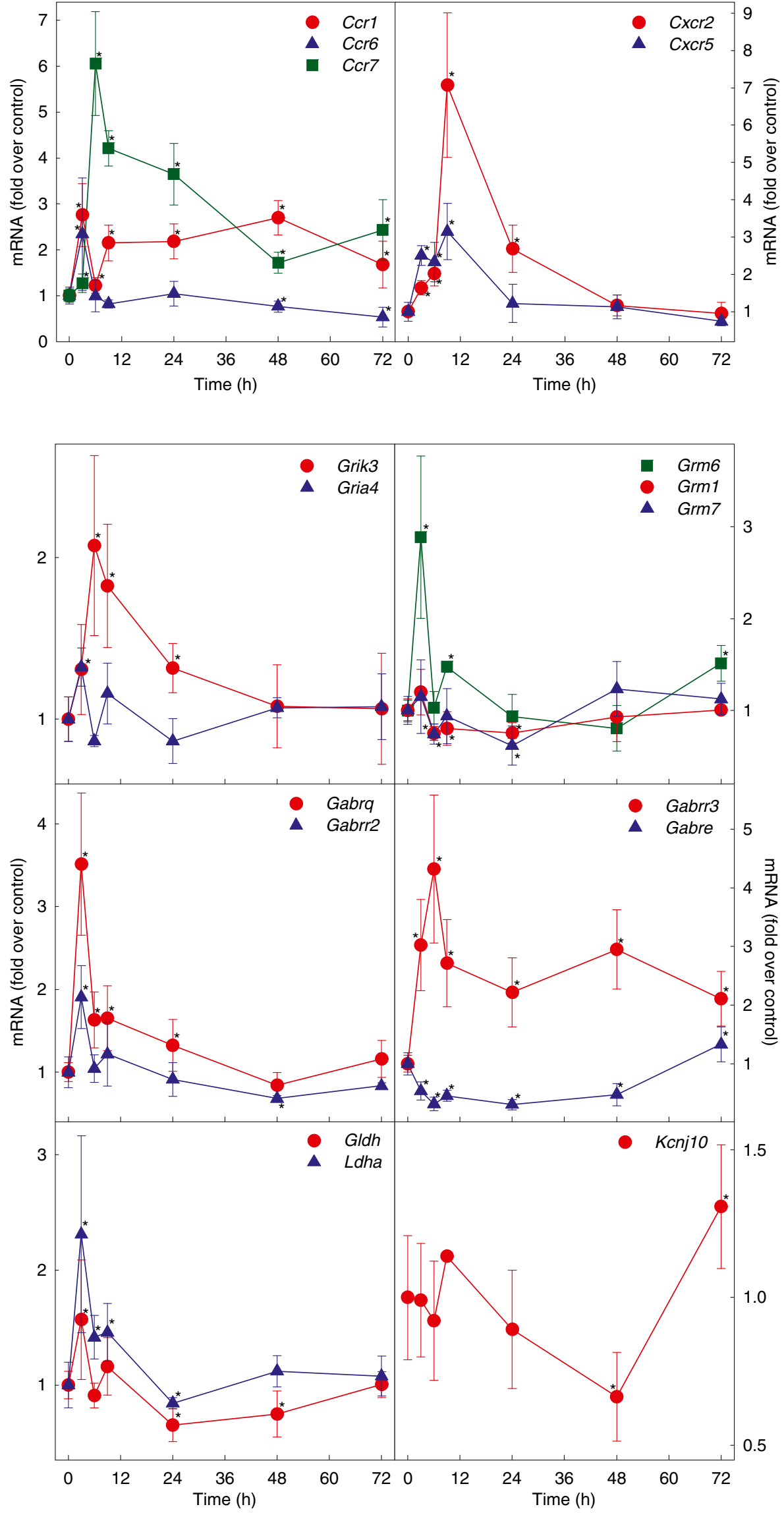
rapidly upregulated at $3 \mathrm{~h}$ post-PIC injection and gradually returned to the baseline level. The expression of the glutamate dehydrogenase gene $(G l d h)$ also peaked at $3 \mathrm{~h}$ but featured subsequent downregulation below control level at $24 \mathrm{~h}$. Its expression gradually returned to the baseline by $72 \mathrm{~h}$. The expression of the Kcnj 10 gene encoding the inward rectifying potassium channel Kir4.1 was not affected during the blood cytokine surge, but featured a gradual downregulation thereafter, reaching a nadir at $48 \mathrm{~h}$ and returning to the baseline level at $72 \mathrm{~h}$ (Fig. 7).

\section{miR genes}

miRs are important regulators of gene expression. Of a particular interest here were miRs that modulate both neural and immune functions (Soreq and Wolf 2011) and miRs associated with seizure pathology (Jimenez-Mateos et al. 2011; Hu et al. 2011; Liu et al. 2010; Aronica et al. 2010). We screened expression of these miRs in the hippocampus following PIC challenge and identified ten species whose expression underwent significant changes (Fig. 8). Generally, the levels of these miRs changed in an oscillating manner. During the first $9 \mathrm{~h}$ after PIC challenge, the levels of miR-128-3p, miR509-5p, miR-28a-5p, miR-138-5p and miR-466i-5p were initially increased and then decreased below control, whereas the levels of miR-188-5p, miR-302a-5p and miR-221-3p were initially downregulated. At $24 \mathrm{~h}$, the levels either returned to baseline (miR-28a-5p, miR-138-5p, miR-128-3p, miR-509$5 p$, miR-188-5p and miR-302a-5p) or underwent secondary upregulation (miR-466i-5p and miR-221-3p). Two species, miR-132-3p and miR-181a-5p, were not changed during the blood cytokine surge but were upregulated at $24 \mathrm{~h}$. At $72 \mathrm{~h}$, the expression of miR-302a-5p was downregulated by approximately 2 -fold below the baseline. miR-28a-5p and miR-138-5p were slightly downregulated, while miR-466i$5 p$, miR-221-3p and miR-128-3p were slightly upregulated.

\section{Discussion}

The present study extends our previous finding that peripheral APR induced by a viral mimic, PIC, increases the susceptibility to KA-induced excitotoxicity (Kirschman et al. 2011). Here, we have demonstrated that the window of increased susceptibility lasts up to 3 days after PIC challenge (Fig. 2). This is in contrast to a previous report on hypersusceptibility induced by i.p. injection of LPS (Sayyah et al. 2003). In that model of bacterial infection/sepsis, seizure hypersusceptibility was limited to the initial $24 \mathrm{~h}$. Several factors may contribute to the observed differences in the duration of the hypersusceptible phenotype induced by PIC vs. LPS. For example, LPS rapidly enters the circulation (Lenczowski et al. 1997; Romanovsky et al. 2000) and thus, the brain is exposed simultaneously to peripherally-generated inflammatory factors and the LPS itself. On the contrary, PIC does not reach the circulation (Fil et al. 2011) and therefore, elicits the cerebral response solely through blood-borne inflammatory mediators. Moreover, the composition of the blood-borne mediators induced by PIC vs. LPS challenge may differ. For example, IFN $\gamma$ is produced in response to LPS (Gibb et al. 2008; Finney et al. 2012) but not in response to PIC (Gandhi et al. 2007). Regardless of the mechanisms, our finding has important clinical implications because it indicates that viral infections may increase the risk of ictal attacks even several days after the active phase of infection has subsided. This should be particularly relevant to populations of vulnerable individuals, e.g., epileptics and post-stroke victims, or individuals exposed to seizure-inducing conditions such as heat stroke or exhaustion.

The augmentation of neuronal excitability is likely induced by inflammatory mediators generated in the peritoneal cavity that reach the brain via circulation. There are several possible mechanisms (Quan and Banks 2007). For instance, the bloodborne inflammatory mediators per se may be transported through the blood-brain barrier (BBB) or circumventricular organs (CVO). Alternatively, the mediators may activate BBB and/or CVO cells, resulting in the secretion of secondary mediators that are released into the brain parenchyma. Four major inflammatory cytokines, IFN $\beta$, IL-6, IL-1 $\beta$ and TNF $\alpha$, surge in the blood, reaching peak concentrations at $3 \mathrm{~h}$ after PIC injection and then rapidly diminish (Cunningham et al. 2007; Fig. 3). IFN $\beta$ and IL-6 reach the highest concentrations and thus, could be plausible triggers of the hypersusceptible phenotype. However, we found that systemic injection of IFN $\beta$ and IL- 6 at respective concentrations failed to induce seizure hypersusceptibility (results not shown). This result is reminiscent of the previous observation that IFN $\beta$ injection does not elicit the fatigue phenotype observed with PIC challenge (Matsumoto et al. 2008). Therefore, other inflammatory mediators are likely requisite for the induction of seizure hypersusceptibility and fatigue response. Finally, it should also be considered that the peripheral inflammatory signals can be conveyed by vagal afferents and activate the expression of cytokine genes within the brain (Marquette et al. 2003).

The cytokine surge is coincident with the upregulation of genes encoding the same cytokines in the hippocampus (Cunningham et al. 2007; Fig. 4). The brain cells including neurons, microglia and astrocytes express receptors for these cytokines (McCusker and Kelley 2013). Ligation of these receptors with either peripherally-generated or braingenerated cytokines can lead to upregulated expression of the same or different cytokines. These, in turn, can further amplify the response through positive feedback loops. Such loops can also upregulate the expression of a slew of other inflammatory mediators as exemplified by chemokines (Fig. 5) and chemokine receptors (Fig. 6). Altogether, this 
Fig. 8 The expression of hippocampal miRs following PIC challenge. Mice were i.p. injected with $12 \mathrm{mg} / \mathrm{kg}$ PIC and the levels of selected miRs were determined in the hippocampi by qRT-PCR at different time points as indicated. Data represent means \pm S.D. from 3 to 8 animals. Values significantly different from baseline levels $(0 \mathrm{~h})$ are indicated by asterisks $(p \leq 0.05)$

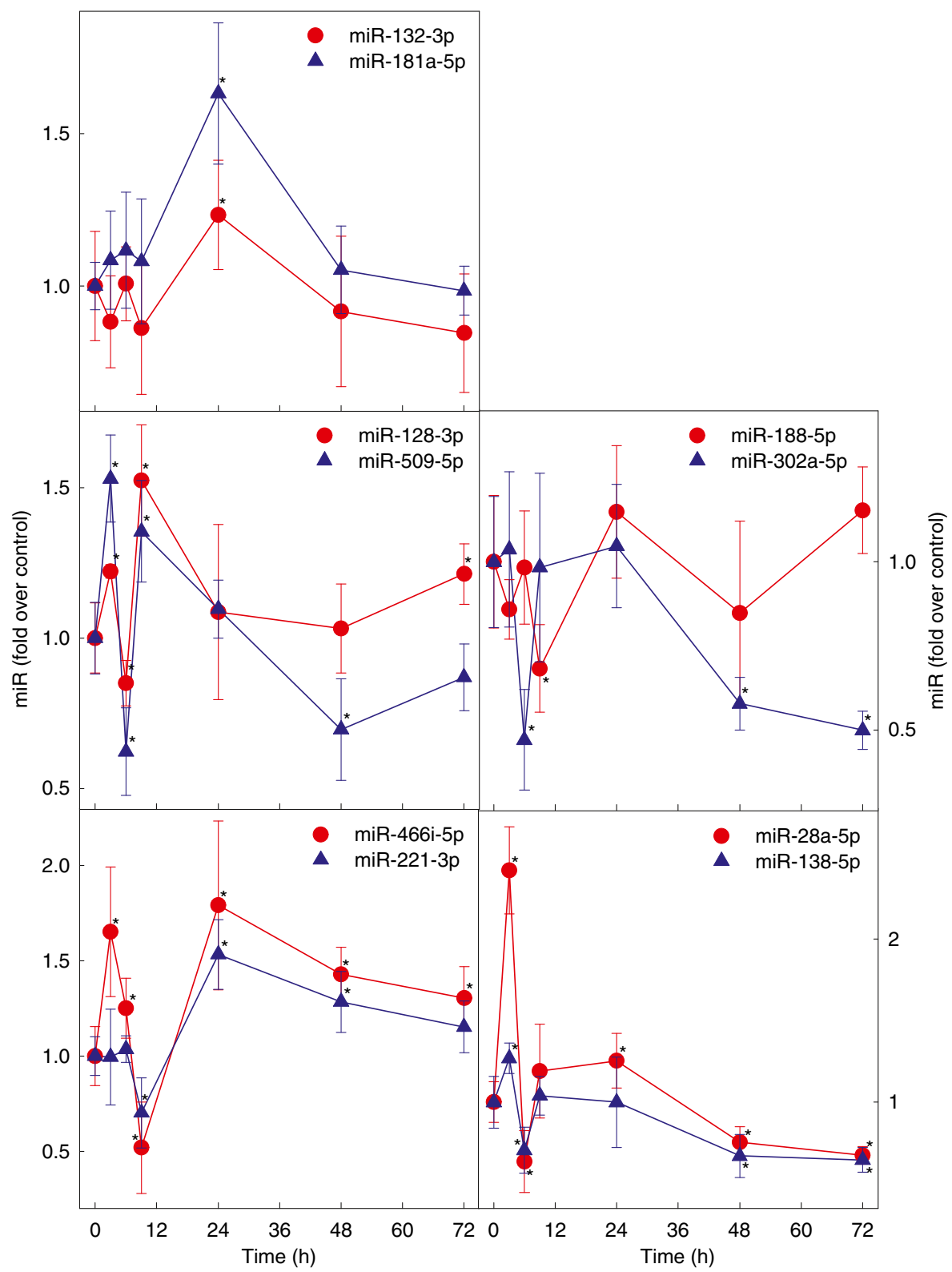

neuroinflammatory response creates an intricate network of autocrine/paracrine and intracellular signaling pathways that may affect neuronal networks. For example, IL-1 $\beta$ and TNF $\alpha$ have an excitatory effect on hippocampal neurons by increasing ceramide synthesis within neurons and by the ensuing NMDA-mediated calcium influx (Viviani et al. 2007; Wheeler et al. 2009). IL-1 $\beta$ also inhibits glutamate reuptake via the downregulation of GLT-1 expression in astrocytes (Prow and Irani 2008), which may further enhance excitability of neuronal circuits. Also, the injection of IL- $1 \beta$ into the hippocampus has been shown to increase the severity of limbic seizures (Vezzani et al. 2002). The protracted upregulation of the Tnfa and $I l 1 b$ genes following PIC challenge (Fig. 4) further strengthens their putative role in the induction and sustenance of seizure hypersusceptibility. Although IL-6 and IFN $\beta$ seem not to directly affect neuronal networks, they amplify the effects of IL- $1 \beta$ and TNF $\alpha$ (McCusker and Kelley 2013). Consistent with this amplifying role, overexpression of IL-6 results in severe neurologic impairment including seizures (Campbell et al. 1993).

A body of evidence also implicates several chemokines upregulated in the hippocampus by PIC challenge (Fig. 5) in the induction of neuronal hyperexcitability. Thus, genes encoding ligands of the CXCR3 chemokine receptor, i.e., CXCL9, CXCL10 and CXCL11, featured the highest upregulation. Neurons are the primary cell types that express CXCR3, and its ligation potently enhances electrical activity of hippocampal neurons (Nelson and Gruol 2004). In addition, CXCR3 ligation alters the expression of several GABA and glutamate receptors (Cho et al. 2009). The genes encoding 
CXCL1 and CXCL2 chemokines also featured robustly upregulated expression following PIC challenge (Fig. 5). Moreover, the gene endcoding their receptor, CXCR2, was also highly upregulated (Fig. 6). Signaling through CXCR2 has been shown to increase neuronal excitability, potentially through the association of CXCR2 with GluR1 AMPA receptors (Lax et al. 2002; Wang et al. 2008). CCl2, CCL4 and CCR 7 are elevated in brain tissue from epilepsy patients, as well as in animal models (Fabene et al. 2010; Lehtimaki et al. 2003; Liimatainen et al. 2013; Vezzani et al. 2008; Vezzani et al. 2002; Hung et al. 2013). In concordance with this, we found the $C c l 2$ and $C c r 7$ genes to feature a prolonged upregulation following PIC challenge (Figs. 5 and 6). Furthermore, CCL2 and CCL4 seem to be crucial for epileptogenesis (Fabene et al. 2010; Kan et al. 2012). Altogether, the above data strongly implicate the role of cytokine and chemokine gene upregulation in PIC-induced seizure hypersusceptibility.

Although some of the genes discussed above displayed sharply transient upregulation, one has to be cognizant that transient expression of the mRNA does not necessarily translate to transient expression of the cognate protein. For example, the $C x c l 1$ and $C x c l 2$ mRNA peaked at $6 \mathrm{~h}$ but returned to the baseline at $9 \mathrm{~h}$ after PIC challenge (Fig. 5). However, the protein synthesized within this 9-h period may persist much longer. This argument also applies to the genes featuring protracted elevation of their mRNA. For example, the $\mathrm{Ccl} 5$ mRNA peaked at $24 \mathrm{~h}$ (Fig. 5), and albeit its levels gradually dropped, the cognate protein, CCL5, may have peaked later and been present at high concentrations during the whole period of hypersusceptibility, i.e., up to $72 \mathrm{~h}$. Finally, it should also be considered that even a short-term upregulation of an inflammatory gene may contribute to the hypersusceptible phenotype through the activation of downstream pathways. These mechanisms will be addressed in future studies.

We have previously shown a quantitative variability in the response of inflammatory genes to PIC challenge among the major subdivisions of the brain, the forebrain, brain stem and cerebellum (Konat et al. 2009; Fil et al. 2011). In general, the cerebellum featured the highest upregulation of these genes. For example, the maximal upregulation of the $I l 1 b, I l 6$ and Cxcll1 genes in the cerebellum was approximately four-fold higher than the respective values for the forebrain. The comparison of the present results from the isolated hippocampus (Figs. 4 and 5) to the whole forebrain (Konat et al. 2009; Fil et al. 2011) reveals further regional heterogeneity. Thus, among the 23 hippocampal genes studied three were significantly less upregulated and four were significantly more upregulated in comparison to the whole forebrain (Table 1). In the most extreme case, the peak upregulation of the Ifnb gene was 50 times lower in the hippocampus than in the whole forebrain. On the other hand, the Cxcl11 gene was nine-fold more robustly upregulated in the hippocampus in comparison with the whole forebrain. Clearly, the hippocampal cells feature a highly
Table 1 Maximal upregulation of selected cytokine and chemokine genes in the forebrain vs. hippocampus in response to PIC challenge

\begin{tabular}{lccl}
\hline Gene & Hippocampus $(\mathrm{H})$ & Forebrain $(\mathrm{F})^{\#}$ & $\mathrm{H} / \mathrm{F}$ \\
\hline Ifnb & $4.05 \pm 1.14$ & $201.55 \pm 37.00^{*}$ & 0.02 \\
Ccl5 & $20.03 \pm 3.88$ & $132.60 \pm 30.01^{*}$ & 0.15 \\
Ccl2 & $107.94 \pm 28.26$ & $215.05 \pm 51.11^{*}$ & 0.50 \\
Cxcl11 & $6547.68 \pm 692.19$ & $720.88 \pm 101.16^{*}$ & 9.1 \\
Ccl12 & $154.19 \pm 13.80$ & $20.50 \pm 7.01 *$ & 7.5 \\
Cxcl10 & $3213.78 \pm 458.29$ & $1112.07 \pm 93.22^{*}$ & 2.9 \\
Cxcl1 & $1192.98 \pm 285.75$ & $718.50 \pm 111.02^{*}$ & 1.7 \\
\hline
\end{tabular}

\# data from Konat et al. (2009) and Fil et al. (2011); * $p \leq 0.05$

specific pattern of genetic response to PIC challenge vs. the average forebrain cell. This finding warrants further experimental inquiry into the responsiveness of other discrete brain structures that may provide a basis for various behavioral traits associated with immune-to-brain communication.

Prevailing theories behind seizure development and epileptogenesis converge upon changes in neuronal excitation and inhibition. These mechanisms strongly hinge on neurotransmitter receptors, where excitatory, glutamatergic neurotransmission is increased and inhibitory, GABAergic transmission is diminished (Casillas-Espinosa et al. 2012; Gonzalez 2013; Werner and Covenas 2011). Consequently, in addition to the effects of the cytokines/chemokines discussed hitherto, peripheral inflammatory signals may alter the balance between excitatory and inhibitory neurotransmission by changing the expression of neurotransmitter receptor genes. In support of this notion, we found altered expression of a number of hippocampal genes encoding neurotransmitter receptors (Fig. 7) in the same time frame as the blood cytokine surge (Fig. 3) and the rapid upregulation of inflammatory genes (Figs. 4, 5, 6). Although the significance of these changes must be verified at the protein level and through functional analysis, tentative correlations can be inferred from the changes in the mRNA levels. For example, the upregulation of the Grik3 gene (Fig. 7) may contribute to the hypersusceptible phenotype, as long-lasting kainate receptormediated events have been associated with sustained, rhythmic firing in a rodent model of temporal lobe epilepsy (Artinian et al. 2011). The $\mathrm{GABA}_{\mathrm{A}}-\varepsilon$ subunit, encoded by the Gabre gene, is associated with increased spontaneous channel activity (Bollan et al. 2008), and therefore, the prolonged downregulation of the Gabre gene following PIC challenge (Fig. 7) may increase hyperexcitability by impeding spontaneous inhibitory currents. Also, the GRM7 receptor negatively regulates GABAergic inhibition (CasillasEspinosa et al. 2012), and knockout of the $\mathrm{Grm} 7$ gene results in increased susceptibility to seizures (Sansig et al. 2001). Thus, the downregulation of the $\mathrm{Grm} 7$ gene induced by PIC challenge (Fig. 7) is consistent with the gene's contribution to 
the hypersusceptible phenotype. However, two metabotropic glutamate receptor genes revealed unpredicted changes. Thus, while the GRM1 receptor tends to be pro-epileptic (Ure et al. 2006), the Grm 1 gene was downregulated following PIC challenge (Fig. 7). Likewise, the upregulation of the Grm6 gene (Fig. 7) is incongruent with the function of GRM6 receptor that negatively regulates glutamate release, and therefore is protective against seizures (Ure et al. 2006).

LPS challenge has been shown to alter expression of the Grik1 and Grik2 genes in the spinal cord (Guo et al. 2002), as well as the genes encoding NMDA receptors in the hippocampus (Harre et al. 2008). We did not observe changes in these genes following PIC challenge suggesting a divergence in the cerebral effects of APR induced by bacterial vs. viral inflammagens. This is consistent with the induction of the inflammatory genes discussed earlier.

In addition to neurotransmitter imbalances, dysfunction in the metabolic coupling between neurons and astrocytes may be causative of hyperexcitation, seizure spread and neurotoxicity (Seifert and Steinhauser 2013). PIC challenge upregulated the $L d h a$ and downregulated the Gldh genes (Fig. 7) that encode two key metabolic enzymes involved in glutamate recycling. Such enzymatic changes are expected to enhance the accumulation of extracelluar glutamate resulting in hyperexcitation. Our results are concordant with previous studies that found the same changes in epilepsy patients and animal kindling models (Erakovic et al. 2001; Malthankar-Phatak et al. 2006). Moreover, another astrocytic gene, the Kcnj10 gene that encodes potassium channel Kir4.1 featured a transient downregulation (Fig. 7). Reduced expression of Kir4.1 has been found in patients with congenital epilepsy (Bockenhauer et al. 2009), and conditional knockout of Kcnj10 in mice results in the development of stress-induced seizures through increased synaptic potentiation (Djukic et al. 2007).

As in the case of inflammatory genes (see above), the expression of mRNAs encoding neurotransmission-related genes does not necessarily reflect their expression at the protein level. miRs are important regulators of mRNA translation, and thus, may further modulate protein production from the upregulated or downregulated mRNAs. In addition, miRs could alter protein production even in the absence of measurable changes in the levels of preexisting cognate mRNAs through translational regulation (Petersen et al. 2006). Consequently, miRs may provide another regulatory layer in the development of hyperexcitability. In support of this notion, we found changes in the expression of several hippocampal miRs instigated by PIC challenge (Fig. 8). Although it is hard to interpret the role of these miRs in the development of hyperexcitability, other studies provide some clues. For example, miR-132 and miR138 are associated with changes in synaptic spine morphology and excitability. Specifically, the upregulation of miR-132-3p and downregulation of miR-138-5p observed in our study has been shown to result in larger, stubby spines and an increase in
mEPSC frequency (Edbauer et al. 2010; Siegel et al. 2009). Alterations in other miRs have been associated with changes in cell migration, proliferation and differentiation, the features involved in the development of hippocampal hyperexcitability (Parent et al. 1997). Thus, the upregulation of miR-128 has been associated with increased cell number and neurite length (Guidi et al. 2010), as well as with enhanced mobility through the downregulation of reelin and doublecortin (Evangelisti et al. 2009). Doublecortin seems to be critical for normal hippocampal excitability, as doublecortin knockout mice exhibit spontaneous seizures that originate in the hippocampus (Kerjan et al. 2009). Furthermore, miR-302a-5p negatively regulates the CXCR4 pathway (Fareh et al. 2012) that is important in cell migration in the hippocampus (Bagri et al. 2002). Therefore, the downregulation of miR-302a in response to PIC challenge might result in the upregulation of CXCR4 leading to hyperexcitability. Finally, a recent microarray study identified several miRs, including miR-132-3p, miR-138-5p, miR-181a and miR-221-3p analyzed in this study, that are differentially expressed following pilocarpine-induced status epilepticus (Risbud and Porter 2013).

In conclusion, we have demonstrated that the APR in the peritoneal cavity alters the expression of a multitude of hippocampal genes encoding inflammatory proteins, neurotransmission-related proteins and miRs. This robust polygenic response of hippocampal cells indicates an extensive genetic reprogramming that is likely to underscore the protracted hypersusceptible phenotype. The differentially expressed genes identified here are likely only a subset of genes that are altered by peripheral APR. For instance, we have previously found that 79 out of 280 genes related to inflammation, signaling and stress/toxicity pathways featured differential expression in the cerebellum following PIC challenge (Konat and Borysiewicz 2009). Altogether, our results warrant a comprehensive investigation of the extent of genomic reprogramming in the hippocampus induced by peripheral APR through whole genome expression analysis.

Acknowledgments This study was partly supported by a Research Funding Development Grant from WVU School of Medicine, and by the National Institutes of Health/National Institute of General Medical Sciences, U54GM104942. The content is solely the responsibility of the authors and does not necessarily represent the official views of the NIH. The authors express their gratitude to Dr. Matsumoto for the use of the PAS-Open field automated monitoring system. The authors also would like to thank Mr. Brent Lally for proofreading this manuscript.

\section{References}

Aronica E, Fluiter K, Iyer A, Zurolo E, Vreijling J, van Vliet EA, Baayen JC, Gorter JA (2010) Expression pattern of miR-146a, an inflammation-associated microRNA, in experimental and human temporal lobe epilepsy. Eur J Neurosci 31:1100-1107 
Artinian J, Peret A, Marti G, Epsztein J, Crepel V (2011) Synaptic kainate receptors in interplay with $\mathrm{INaP}$ shift the sparse firing of dentate granule cells to a sustained rhythmic mode in temporal lobe epilepsy. J Neurosci 31:10811-10818

Bagri A, Gurney T, He X, Zou YR, Littman DR, Tessier-Lavigne M, Pleasure SJ (2002) The chemokine SDF1 regulates migration of dentate granule cells. Development 129:4249-4260

Ben-Ari Y, Cossart R (2000) Kainate, a double agent that generates seizures: two decades of progress. Trends Neurosci 23:580-587

Berke IC, Li Y, Modis Y (2013) Structural basis of innate immune recognition of viral RNA. Cell Microbiol 15:386-394

Bockenhauer D et al (2009) Epilepsy, ataxia, sensorineural deafness, tubulopathy, and KCNJ10 mutations. N Engl J Med 360: 1960-1970

Bollan KA, Baur R, Hales TG, Sigel E, Connolly CN (2008) The promiscuous role of the epsilon subunit in GABAA receptor biogenesis. Mol Cell Neurosci 37:610-621

Campbell IL, Abraham CR, Masliah E, Kemper P, Inglis JD, Oldstone MB, Mucke L (1993) Neurologic disease induced in transgenic mice by cerebral overexpression of interleukin 6. Proc Natl Acad Sci USA 90:10061-10065

Casillas-Espinosa PM, Powell KL, O'Brien TJ (2012) Regulators of synaptic transmission: roles in the pathogenesis and treatment of epilepsy. Epilepsia 53(Suppl 9):41-58

Cho J, Nelson TE, Bajova H, Gruol DL (2009) Chronic CXCL10 alters neuronal properties in rat hippocampal culture. J Neuroimmunol 207:92-100

Cunningham C, Campion S, Teeling J, Felton L, Perry VH (2007) The sickness behaviour and CNS inflammatory mediator profile induced by systemic challenge of mice with synthetic double-stranded RNA (poly I:C). Brain Behav Immun 21:490-502

Djukic B, Casper KB, Philpot BD, Chin LS, McCarthy KD (2007) Conditional knock-out of Kir4.1 leads to glial membrane depolarization, inhibition of potassium and glutamate uptake, and enhanced short-term synaptic potentiation. J Neurosci 27:11354-11365

Edbauer D, Neilson JR, Foster KA, Wang CF, Seeburg DP, Batterton MN, Tada T, Dolan BM, Sharp PA, Sheng M (2010) Regulation of synaptic structure and function by FMRP-associated microRNAs miR-125b and miR-132. Neuron 65:373-384

Erakovic V, Zupan G, Varljen J, Laginja J, Simonic A (2001) Altered activities of rat brain metabolic enzymes caused by pentylenetetrazol kindling and pentylenetetrazol-induced seizures. Epilepsy Res 43: $165-173$

Evangelisti C, Florian MC, Massimi I, Dominici C, Giannini G, Galardi S, Bue MC, Massalini S, McDowell HP, Messi E, Gulino A, Farace MG, Ciafre SA (2009) MiR-128 up-regulation inhibits Reelin and DCX expression and reduces neuroblastoma cell motility and invasiveness. FASEB J 23:4276-4287

Fabene PF, Bramanti P, Constantin G (2010) The emerging role for chemokines in epilepsy. J Neuroimmunol 224:22-27

Fareh M, Turchi L, Virolle V, Debruyne D, Almairac F, de la Forest DS, Paquis P, Preynat-Seauve O, Krause KH, Chneiweiss H, Virolle T (2012) The miR 302-367 cluster drastically affects self-renewal and infiltration properties of glioma-initiating cells through CXCR4 repression and consequent disruption of the SHH-GLI-NANOG network. Cell Death Differ 19:232-244

Fil D, Borysiewicz E, Konat GW (2011) A broad upregulation of cerebral chemokine genes by peripherally-generated inflammatory mediators. Metab Brain Dis 26:49-59

Finney SJ, Leaver SK, Evans TW, Burke-Gaffney A (2012) Differences in lipopolysaccharide- and lipoteichoic acid-induced cytokine/ chemokine expression. Intensive Care Med 38:324-332

Galic MA, Riazi K, Pittman QJ (2012) Cytokines and brain excitability. Front Neuroendocrinol 33:116-125

Gandhi R, Hayley S, Gibb J, Merali Z, Anisman H (2007) Influence of poly I:C on sickness behaviors, plasma cytokines, corticosterone and central monoamine activity: moderation by social stressors. Brain Behav Immun 21:477-489

Gibb J, Hayley S, Gandhi R, Poulter MO, Anisman H (2008) Synergistic and additive actions of a psychosocial stressor and endotoxin challenge: Circulating and brain cytokines, plasma corticosterone and behavioral changes in mice. Brain Behav Immun 22:573-589

Gonzalez MI (2013) The possible role of GABAA receptors and gephyrin in epileptogenesis. Front Cell Neurosci 7:113

Guha-Thakurta N, Majde JA (1997) Early induction of proinflammatory cytokine and type I interferon mRNAs following Newcastle disease virus, poly [rI:rC], or low-dose LPS challenge of the mouse. J Interferon Cytokine Res 17:197-204

Guidi M, Muinos-Gimeno M, Kagerbauer B, Marti E, Estivill X, Espinosa-Parrilla Y (2010) Overexpression of miR-128 specifically inhibits the truncated isoform of NTRK3 and upregulates BCL2 in SH-SY5Y neuroblastoma cells. BMC Mol Biol 11:95

Guo W, Zou S, Tal M, Ren K (2002) Activation of spinal kainate receptors after inflammation: behavioral hyperalgesia and subunit gene expression. Eur J Pharmacol 452:309-318

Harre EM, Galic MA, Mouihate A, Noorbakhsh F, Pittman QJ (2008) Neonatal inflammation produces selective behavioural deficits and alters N-methyl-D-aspartate receptor subunit mRNA in the adult rat brain. Eur J Neurosci 27:644-653

Hu K, Zhang C, Long L, Long X, Feng L, Li Y, Xiao B (2011) Expression profile of microRNAs in rat hippocampus following lithiumpilocarpine-induced status epilepticus. Neurosci Lett 488:252-257

Huckans M, Seelye A, Parcel T, Mull L, Woodhouse J, Bjornson D, Fuller BE, Loftis JM, Morasco BJ, Sasaki AW, Storzbach D, Hauser $P$ (2009) The cognitive effects of hepatitis $C$ in the presence and absence of a history of substance use disorder. J Int Neuropsychol Soc 15:69-82

Hung YW, Lai MT, Tseng YJ, Chou CC, Lin YY (2013) Monocyte chemoattractant protein-1 affects migration of hippocampal neural progenitors following status epilepticus in rats. J Neuroinflammation 10:11

Jacobs BL, Langland JO (1996) When two strands are better than one: the mediators and modulators of the cellular responses to doublestranded RNA. Virology 219:339-349

Jimenez-Mateos EM, Bray I, Sanz-Rodriguez A, Engel T, McKiernan RC, Mouri G, Tanaka K, Sano T, Saugstad JA, Simon RP, Stallings RL, Henshall DC (2011) miRNA Expression profile after status epilepticus and hippocampal neuroprotection by targeting miR132. Am J Pathol 179:2519-2532

Kan AA, van der Hel WS, Kolk SM, Bos IW, Verlinde SA, van Nieuwenhuizen O, de Graan PN (2012) Prolonged increase in rat hippocampal chemokine signalling after status epilepticus. J Neuroimmunol 245:15-22

Kerjan G, Koizumi H, Han EB, Dube CM, Djakovic SN, Patrick GN, Baram TZ, Heinemann SF, Gleeson JG (2009) Mice lacking doublecortin and doublecortin-like kinase 2 display altered hippocampal neuronal maturation and spontaneous seizures. Proc Natl Acad Sci USA 106:6766-6771

Kirschman LT, Borysiewicz E, Fil D, Konat GW (2011) Peripheral immune challenge with dsRNA enhances kainic acid-induced status epilepticus. Metab Brain Dis 26:91-93

Konat GW, Borysiewicz E (2009) Cerebellar expression of inflammatory genes triggered by peripheral challenge with dsRNA. J Neurochem 108 (Suppl. 1) :133

Konat GW, Borysiewicz E, Fil D, James I (2009) Peripheral challenge with double-stranded RNA elicits global up-regulation of cytokine gene expression in the brain. J Neurosci Res 87:1381-1388

Lax P, Limatola C, Fucile S, Trettel F, Di BS, Renzi M, Ragozzino D, Eusebi F (2002) Chemokine receptor CXCR2 regulates the functional properties of AMPA-type glutamate receptor GluR1 in HEK cells. J Neuroimmunol 129:66-73 
Lehtimaki KA, Peltola J, Koskikallio E, Keranen T, Honkaniemi J (2003) Expression of cytokines and cytokine receptors in the rat brain after kainic acid-induced seizures. Brain Res Mol Brain Res 110:253-260

Lenczowski MJ, Van Dam AM, Poole S, Larrick JW, Tilders FJ (1997) Role of circulating endotoxin and interleukin- 6 in the ACTH and corticosterone response to intraperitoneal LPS. Am J Physiol 273: R1870-R1877

Liimatainen S, Kai L, Johanna P, Tiina A, Jukka P (2013) Immunological perspectives of temporal lobe seizures. J Neuroimmunol 263:1-7

Liu DZ, Tian Y, Ander BP, Xu H, Stamova BS, Zhan X, Turner RJ, Jickling G, Sharp FR (2010) Brain and blood microRNA expression profiling of ischemic stroke, intracerebral hemorrhage, and kainate seizures. J Cereb Blood Flow Metab 30:92-101

Loftis JM, Huckans M, Ruimy S, Hinrichs DJ, Hauser P (2008) Depressive symptoms in patients with chronic hepatitis $\mathrm{C}$ are correlated with elevated plasma levels of interleukin-1beta and tumor necrosis factor-alpha. Neurosci Lett 430:264-268

Malthankar-Phatak GH, de Lanerolle N, Eid T, Spencer DD, Behar KL, Spencer SS, Kim JH, Lai JC (2006) Differential glutamate dehydrogenase (GDH) activity profile in patients with temporal lobe epilepsy. Epilepsia 47:1292-1299

Marquette C, Linard C, Galonnier M, Van UA, Mathieu J, Gourmelon P, Clarencon D (2003) IL-1beta, TNFalpha and IL-6 induction in the rat brain after partial-body irradiation: role of vagal afferents. Int $\mathrm{J}$ Radiat Biol 79:777-785

Matsumoto T, Takahashi H, Shiva D, Kawanishi N, Kremenik MJ, Kato Y, Yano H (2008) The reduction of voluntary physical activity after poly I:C injection is independent of the effect of poly I:C-induced interferon-beta in mice. Physiol Behav 93:835-841

McCusker RH, Kelley KW (2013) Immune-neural connections: how the immune system's response to infectious agents influences behavior. J Exp Biol 216:84-98

Muller U, Steinhoff U, Reis LF, Hemmi S, Pavlovic J, Zinkernagel RM, Aguet M (1994) Functional role of type I and type II interferons in antiviral defense. Science 264:1918-1921

Nelligan JA, Loftis JM, Matthews AM, Zucker BL, Linke AM, Hauser P (2008) Depression comorbidity and antidepressant use in veterans with chronic hepatitis C: results from a retrospective chart review. J Clin Psychiatry 69:810-816

Nelson TE, Gruol DL (2004) The chemokine CXCL10 modulates excitatory activity and intracellular calcium signaling in cultured hippocampal neurons. J Neuroimmunol 156:74-87

Parent JM, Yu TW, Leibowitz RT, Geschwind DH, Sloviter RS, Lowenstein DH (1997) Dentate granule cell neurogenesis is increased by seizures and contributes to aberrant network reorganization in the adult rat hippocampus. J Neurosci 17:3727-3738

Petersen CP, Bordeleau ME, Pelletier J, Sharp PA (2006) Short RNAs repress translation after initiation in mammalian cells. Mol Cell 21: 533-542

Prow NA, Irani DN (2008) The inflammatory cytokine, interleukin-1 beta, mediates loss of astroglial glutamate transport and drives excitotoxic motor neuron injury in the spinal cord during acute viral encephalomyelitis. J Neurochem 105:1276-1286

Quan N, Banks WA (2007) Brain-immune communication pathways. Brain Behav Immun 21:727-735
Risbud RM, Porter BE (2013) Changes in microRNA expression in the whole hippocampus and hippocampal synaptoneurosome fraction following pilocarpine induced status epilepticus. PLoS ONE 8: e53464

Romanovsky AA, Ivanov AI, Lenczowski MJ, Kulchitsky VA, Van Dam AM, Poole S, Homer LD, Tilders FJ (2000) Lipopolysaccharide transport from the peritoneal cavity to the blood: is it controlled by the vagus nerve? Auton Neurosci 85:133-140

Sansig G, Bushell TJ, Clarke VR, Rozov A, Burnashev N, Portet C, Gasparini F, Schmutz M, Klebs K, Shigemoto R, Flor PJ, Kuhn R, Knoepfel T, Schroeder M, Hampson DR, Collett VJ, Zhang C, Duvoisin RM, Collingridge GL, van Der PH (2001) Increased seizure susceptibility in mice lacking metabotropic glutamate receptor 7. J Neurosci 21:8734-8745

Sayyah M, Javad-Pour M, Ghazi-Khansari M (2003) The bacterial endotoxin lipopolysaccharide enhances seizure susceptibility in mice: involvement of proinflammatory factors: nitric oxide and prostaglandins. Neuroscience 122:1073-1080

Seifert G, Steinhauser C (2013) Neuron-astrocyte signaling and epilepsy. Exp Neurol 244:4-10

Siegel $\mathrm{G}$ et al (2009) A functional screen implicates microRNA-138dependent regulation of the depalmitoylation enzyme APT1 in dendritic spine morphogenesis. Nat Cell Biol 11:705-716

Soreq H, Wolf Y (2011) NeurimmiRs: microRNAs in the neuroimmune interface. Trends Mol Med.

Tellez-Zenteno JF, Matijevic S, Wiebe S (2005) Somatic comorbidity of epilepsy in the general population in Canada. Epilepsia 46:19551962

Ure J, Baudry M, Perassolo M (2006) Metabotropic glutamate receptors and epilepsy. J Neurol Sci 247:1-9

Vezzani A, Moneta D, Richichi C, Aliprandi M, Burrows SJ, Ravizza T, Perego C, De Simoni MG (2002) Functional role of inflammatory cytokines and antiinflammatory molecules in seizures and epileptogenesis. Epilepsia 43(Suppl 5):30-35

Vezzani A, Balosso S, Ravizza T (2008) The role of cytokines in the pathophysiology of epilepsy. Brain Behav Immun 22: 797-803

Viviani B, Gardoni F, Marinovich M (2007) Cytokines and neuronal ion channels in health and disease. Int Rev Neurobiol 82:247-263

Wang JG, Strong JA, Xie W, Yang RH, Coyle DE, Wick DM, Dorsey ED, Zhang JM (2008) The chemokine CXCL1/growth related oncogene increases sodium currents and neuronal excitability in small diameter sensory neurons. Mol Pain 4:38

Weber F, Wagner V, Rasmussen SB, Hartmann R, Paludan SR (2006) Double-stranded RNA is produced by positive-strand RNA viruses and DNA viruses but not in detectable amounts by negative-strand RNA viruses. J Virol 80:5059-5064

Werner FM, Covenas R (2011) Classical neurotransmitters and neuropeptides involved in generalized epilepsy: a focus on antiepileptic drugs. Curr Med Chem 18:4933-4948

Wheeler D, Knapp E, Bandaru VV, Wang Y, Knorr D, Poirier C, Mattson MP, Geiger JD, Haughey NJ (2009) Tumor necrosis factor-alphainduced neutral sphingomyelinase- 2 modulates synaptic plasticity by controlling the membrane insertion of NMDA receptors. J Neurochem 109:1237-1249 


\section{Lindsay T. Michalovicz \\ (Other Surname: Kirschman)}

West Virginia University Health Sciences

Department of Neurobiology \& Anatomy

PO Box 9128

Morgantown, WV 26506

Itkirschman@mix.wvu.edu

\section{EDUCATION}

2006-2014 Ph. D., Neuroscience, West Virginia University, Morgantown, West Virginia.

2002-2006 B.A., Biochemistry, Washington \& Jefferson College, Washington, Pennsylvania.

1998-2002 High School Diploma, Keystone Oaks School District, Pittsburgh, Pennsylvania.

\section{RESEARCH INTERESTS}

Immune-to-brain signaling. I am interested in the mechanism and pathway by which peripheral immune signaling modulates neural function, with specific relationship to severe neurological diseases such as epilepsy, multiple sclerosis, etc. My work has investigated how an acute antiviral response initiated in the periphery (peritoneum) can elicit a robust brain inflammatory response that predisposes the individual to severe epileptic episodes.

Signal transduction. I have a particular interest in how disease-states regulate/interfere with proper molecular signaling.

Neurodegeneration. My specific interest is understanding the molecular mechanisms involved in inducing and/or protecting from cell death.

\section{PUBLICATIONS}

Michalovicz LT, Lally B, Konat GW. Peripheral challenge with a viral mimic upregulates expression of the complement genes in the hippocampus. (In prep).

Michalovicz LT and Konat GW. Peripherally restricted acute phase response to a viral mimic alters hippocampal gene expression. Metab. Brain Dis. 2014; 29(1): 75-86.

Borysiewicz E, Doppalapudi S, Kirschman LT, Konat GW. TLR3 ligation protects human astrocytes against oxidative stress. J. Neuroimmunol. 2013; 255(1-2): 54-59. (Cited by 4) 
Kirschman LT, Borysiewicz E, Fil D, Konat GW. Peripheral immune challenge with dsRNA enhances kainic acid-induced status epilepticus. Metab. Brain Dis. 2011; 26(1): 91-93. PMID: 21305346. (Cited by 3 )

Kirschman LT, Kolandaivelu S, Frederick JM, Dang L, Goldberg AFX, Baehr W, Ramamurthy V. The Leber congenital amaurosis protein, AIPL1, is needed for the viability and functioning of cone photoreceptor cells. Hum. Mol. Genet. 2010; 19(6): 1076-1087. PMID: 20042464. (Cited by 24)

\section{PRESENTATIONS}

Konat G.W. and Michalovicz, L. (2014) Peripheral inflammation induces genomic reprogramming in the hippocampus. $45^{\text {th }}$ Annual Meeting of the American Society of Neurochemistry.

Michalovicz, L. and Konat G.W. (2014) Peripheral inflammation induces genomic reprogramming in the hippocampus. West Virginia University Health Sciences Center Research Day and Van Liere Convocation.

Konat, G.W., Fakhimi, A., Borysiewicz, E. and Michalovicz, L. (2013) MicroRNA approach to control IFNb production in the CNS. 24th Biennial International Society for Neurochemistry and American Society For Neurochemistry Meeting.

Michalovicz, L. and Konat, G.W. (2013) Genomic reprogramming of hippocampus following peripherally restricted inflammation. West Virginia University Health Sciences Center Research Day and Van Liere Convocation.

Konat, G. W., Kirschman, L.T., Borysiewicz, E., Agmon, A. (2012) Peripheral inflammation induces protracted hyperexcitability of hippocampal neurons. $43^{\text {rd }}$ Annual Meeting of the American Society of Neurochemistry.

Kirschman, L.T., Borysiewicz, E., Fil, D., Konat, G.W. (2011) Peripheral immune challenge with dsRNA enhances kainic-acid induced status epilepticus. West Virginia University Health Sciences Center Research Day and Van Liere Convocation. [Poster and Oral Presentation]

Michalovicz, L.T., Kolandaivelu, S., Ramamurthy, V. (2009) The Leber Congenital Amaurosis (LCA) Protein, AIPL1, is Essential for Cone Photoreceptor Cells. ARVO 2009 Annual Meeting.

Michalovicz, L.T., Kolandaivelu, S., Ramamurthy, V. (2008) The Leber Congenital Amaurosis Protein, AIPL1, is Indispensable for Cones. NISBRE Meeting.

Michalovicz, L.T., Kolandaivelu, S., Ramamurthy, V. (2008) The Leber Congenital Amaurosis Protein, AIPL1, is Indispensable for Cone Photoreceptors. 46th ISCEV Meeting.

Michalovicz, L.T., Kolandaivelu, S., Ramamurthy, V. (2008) The Leber Congenital Amaurosis Protein, AIPL1, is Indispensable for Cone Photoreceptors. West Virginia University Health Sciences Center Research Day and Van Liere Convocation. [Poster and Oral Presentation]

\section{EDITORIAL POSITIONS}

Ad hoc reviewer: 
Behavioural Brain Research

Brain, Behavior, and Immunity

Drug Design, Development and Therapy

Glia

Journal of Neurochemistry

Journal of Neuroinflammation

Metabolic Brain Disease

Neurochemistry International

Pharmacology, Biochemistry and Behavior

\section{TEACHING EXPERIENCE}

Mentoring of Visiting Scholar in Graduate Lab, West Virginia University, Morgantown, WV. We had a visiting scholar from Iran working in the research lab. I mentored him in RNA isolation, cDNA synthesis, and Real-time PCR techniques, as well as reviewed his in prep publications.

Mentoring of Undergraduate and High School Students in Graduate Lab, West Virginia University, Morgantown, WV. Throughout my graduate education I have mentored four students from the local high schools and four undergraduates in the research lab for independent studies and summer internships. This involved hands-on training in lab techniques as well as teaching basic biochemistry, molecular biology and neuroscience. These students have gone on to achieve great things including: winning $1^{\text {st }}$ place in the $49^{\text {th }}$ Annual National Junior Science and Humanities Symposium in San Diego, an exclusive summer internship at the Massachusetts Institute of Technology, and the US Presidential Scholars award.

Freshman Cell Biology Workshop, Washington \& Jefferson College, Washington, Pennsylvania. As a mentor for this freshman workshop, I aided students with cell biology techniques, poster development and presentation, lab notebook maintenance and general Biology/Biochemistry major advice. I also edited posters and developed and graded exams.

Laboratory Assistant, Departments of Biology and Chemistry, Washington \& Jefferson College, Washington, Pennsylvania. As lab assistant, I was responsible for making solutions, cleaning glassware, modifying/creating protocols for experiments/equipment.

Labs assisted:

BIO 149 Freshman Cell Biology Workshop (January 2005)

BIO 412 Experimental Biology: Tick Research (Spring 2004)

BCH 212 Cellular Biology (Fall 2005)

BCH 333 Biochemistry (Spring 2006)

CHM 100N Nutrition (Summer 2004)

CHM 100B Chemistry of Beer (Summer 2004)

CHM 105 General Chemistry I (Summer 2004, Fall 2004) 
Teaching Assistant, Departments of Biology and Chemistry, Washington \& Jefferson College, Washington, Pennsylvania. As teaching assistant, I aided students with understanding concepts related to the course, problem solving, laboratory report writing, writing and participating in scientific poster sessions, graded homework and exams.

Courses assisted:

BIO 101 General Biology I (Fall 2003)

BIO 102 General Biology II (Spring 2004)

CHM 105 General Chemistry I (Summer 2004, Fall 2004)

CHM 106 General Chemistry II (Summer 2004)

CHM 100N Nutrition (Summer 2004)

CHM 100B Chemistry of Beer (Summer 2004)

BIO 149 Freshman Cell Biology Workshop (January 2005)

\section{WORK EXPERIENCE}

Office Assistant to Biology Department Chair, Department of Biology, Washington \& Jefferson College, Washington, Pennsylvania, January 2005-May 2006.

Biochemistry Assistant, Biochemistry Major Advisory Committee, Washington \& Jefferson College, Washington, Pennsylvania, August 2005-May 2006.

\section{HONORS AND AWARDS}

$3^{\text {rd }}$ Place, Oral Presentation, West Virginia University Van Liere Research Convocation, March 2011, West Virginia University, Morgantown, West Virginia.

ARVO Foundation for Eye Research/Richard Newton Lolley Travel Grant, to attend the 2009 Association for Research in Vision and Ophthalmology conference. 1 of 15,000 applicants to receive award.

2nd Place, Oral Presentation, West Virginia University Van Liere Research Convocation, April 2008, West Virginia University, Morgantown, West Virginia.

Phi Sigma Biological Sciences Honorary Society, inducted April 2005.

President of Phi Sigma, Fall 2005-Spring 2005.

Alpha Lambda Delta Freshman Honorary Society, inducted Spring 2004.

Alpha Scholar, Washington \& Jefferson College, Washington, Pennsylvania, Fall 2003.

Beta Scholar, Washington \& Jefferson College, Washington, Pennsylvania, Fall 2004.

Dean's List, Washington \& Jefferson College, Washington, Pennsylvania, 2002-present. 
Presidential Scholarship, Washington \& Jefferson College, Washington, Pennsylvania.

Salutatorian, Keystone Oaks School District, Pittsburgh, Pennsylvania, 2002.

Rachel Carson Book Award and Scholarship, Chatam College, Pittsburgh, Pennsylvania, 2001.

\section{INTERNSHIP}

Department of Pulmonary Medicine, University of Texas M.D. Anderson Cancer Center, Houston, Texas, May - August 2005. I created a targeting construct of platelet factor 4 (PF4) to be introduced into mouse embryonic stem cells. The overall purpose was to create a mouse knock-in model to determine the role of PF4 in mast cell exocytosis. This internship was conducted under the guidance of Shakeel Thakurdas, Ph.D. and Roberto Adachi, M.D., Ph.D.

\section{SERVICE WORK}

Washington Area Humane Society, July 2012 - August 2012, Petco Washington, PA. As a volunteer at the WAHS, I visited the shelter cats available for adoption at the Washington, PA Petco satellite location. My main duty has been to care for the animals by cleaning cages, replacing bedding and litter, feeding and watering. I also help to socialize the cats and serve as an intermediary between potential adopters and the shelter.

Graduate Research Education Panel, Spring 2009, Washington \& Jefferson College. As an alumus of Washington \& Jefferson College in a scientific research graduate program, I was invited to speak as part of a panel on the graduate application process and life as a graduate student in a research program.

Biologically-related Internships Panel, November 3, 2005, Washington \& Jefferson College, Washington, Pennsylvania. As a member of the panel, I discussed my research internship experience and general internship suggestions to members of the Washington \& Jefferson College community.

Science Symposium, April 8-9, 2005, Washington \& Jefferson College, Washington, Pennsylvania. Washington \& Jefferson College held this symposium in order to stimulate alumni to donate to a science initiative that will help fund a new campus science building, among other things. As part of the symposium, I presented research that I was doing in the Biology Department in the spring.

Alpha Phi Omega Service Fraternity, inducted Spring 2004, Mu Upsilon chapter, Washington \& Jefferson College. As a member of Alpha Phi Omega, I have participated in such service activities as Habitat for Humanity, the American Cancer Society's Daffodil Days, and clothing drives.

Student Activities Board, member from Fall 2002 to Spring 2005, Washington \& Jefferson College. As a member of the Student Activities Board, I helped to plan non-profit events for the college campus and local community such as, Bingo nights, campus movie series, and comedy and musical performances. 